\title{
Dynamics of freshwater plumes: observations and numerical modeling of the wind-forced response and alongshore freshwater transport
}

\author{
by \\ Derek Allen Fong \\ B.S. Stanford University \\ (1991) \\ M.S. Stanford University \\ (1992) \\ Submitted in partial fulfillment of the \\ requirements for the degree of \\ DOCTOR OF PHILOSOPHY \\ MANNE \\ at the \\ BIOLOGEM MASSACHUSETTS INSTITUTE OF TECHNOLOGY \\ LABORATOPY \\ and the \\ LIPARYWOODS HOLE OCEANOGRAPHIC INSTITUTION \\ WOONS HOLE, MASS. \\ June 1998 \\ W. 4.0 .1 . \\ (C) Derek Allen Fong \\ The alithor hereby grants to MIT and to WHOI permission to reproduce \\ and to distribute copies of this thesis dncument in whole or in part.
}

Signature of Author

Joint Progran in Physical Oceanography

Massachusetts Institute of Technology

Woods Hole Oceanographic Institution

June 15,1998

Certified by .....

W. Rockwell Geyer

Associate Scientist

Certified by ...........

Thesis Supervisor

David C. Chapman

Senior Scientist

Thesis Supervisor

Accepted by .........

Karl R. Helfrich

Acting Chairman, Joint Committee for Physical Oceanography Massachusetts Institute of Technology

Woods Hole Oceanographic Institution 


\title{
Dynamics of freshwater plumes: observations and numerical modeling of the wind-forced response and alongshore freshwater transport by
}

\author{
DEREK A. FONG \\ MIT/WHOI Joint Program in Oceanography
}

\begin{abstract}
Submitted to the Massachusetts Institute of Technology/Woods Hole Oceanographic Institution Joint Program in Oceanography in May, 1998 in partial fulfillment of the requirements for the Degree of Doctor of Philosophy
\end{abstract}

\begin{abstract}
A freshwater plume often forms when a river or an estuary discharges water onto the continental shelf. Freshwater plumes are ubiquitous features of the coastal ocean and usually leave a striking signature in the coastal hydrography. The present study combines both hydrographic data and idealized numerical simulations to examine how ambient currents and winds influence the transport and mixing of plume waters.

The first portion of the thesis considers the alongshore transport of freshwater using idealized numerical simulations. In the absence of any ambient current, the downstream coastal current only carries a fraction of the discharged fresh water; the remaining fraction recirculates in a continually growing "bulge" of fresh water in the vicinity of the river mouth. The fraction of fresh water transported in the coastal current is dependent on the source conditions at the river mouth. The presence of an ambient current augments the transport in the plume so that its freshwater transport matches the freshwater source. For any ambient current in the same direction as the geostrophic coastal current, the plume will evolve to a steady-state width. A key result is that an external forcing agent is required in order for the entire freshwater volume discharged by a river to be transported as a coastal current.

The next section of the thesis addresses the wind-induced advection of a river plume, using hydrographic data collected in the western Gulf of Maine. The observations suggest that the plume's cross-shore structure varies markedly as a function of fluctuations in alongshore wind forcing. Consistent with Ekman dynamics, upwelling favorable winds spread the plume offshore, at times widening it to over 50 $\mathrm{km}$ in offshore extent, while downwelling favorable winds narrow the plume width to a few Rossby radii. Near-surface current meters show significant correlations be-
\end{abstract}


tween cross-shore currents and alongshore wind stress, consistent with Ekman theory. Estimates of the terms in the alongshore momentum equation calculated from moored current meter arrays also indicate an approximate Ekman balance within the plume. A significant correlation between alongshore currents and alongshore wind stress suggests that interfacial drag may be important.

The final section of the thesis is an investigation of the advection and mixing of a surface-trapped river plume in the presence of an upwelling favorable wind stress, using a three-dimensional model in a simple, rectangular domain. Model simulations demonstrate that the plume thins and is advected offshore by the crossshore Ekman transport. The thinned plume is susceptible to significant mixing due to the vertically sheared horizontal currents. The first order plume response is explained by Ekman dynamics and a Richardson number mixing criterion. Under a sustained wind event, the plume evolves to a quasi-steady, uniform thickness. The rate of mixing slowly decreases for longer times as the stratification in the plume weakens, but mixing persists under a sustained upwelling wind until the plume is destroyed. Mixing is most intense at the seaward plume front due to an Ekman straining mechanism in which the advection of cross-shore salinity gradients balances vertical mixing. The mean mixing rate observed in the plume is consistent with the mixing power law suggested by previous studies of $1-\mathrm{D}$ mixing, in spite of the two-dimensional dynamics driving the mixing in the plume.

Thesis co-supervisor: Dr. W. Rockwell Geyer

Title: Associate Scientist, Woods Hole Oceanographic Institution

Thesis co-supervisor: Dr. David C. Chapman

Title: Senior Scientist, Woods Hole Oceanographic Institution 


\section{Acknowledgments}

During my tenure as a Joint Program student, I have had the help, encouragement and friendship of so many people, that it is difficult to know where to begin and end this list. Even after one of the longest acknowledgment lists ever written in a Joint Program thesis is done, I am sure I will have forgotten some important people; to you I offer my apologies and implicit thanks.

This thesis was a long road to becoming a better scientist. My growth as a scientist is attributable to many teachers and colleagues at both MIT and WHOI. First and foremost, I owe a great deal of thanks to my advisors Rocky Geyer and Dave Chapman. I thank them for their excellent advice, their ability to point out important aspects in a particular problem, and above all, their efforts to help me hone my skills of scientific inquiry while respecting my own opinions and interests. I think I learned as much about how to approach my science as I did about river plumes. For both these experiences, I will be forever grateful. I would also like to thank the other members of my thesis committee-Glenn Flierl, Glen Gawarkiewicz, and Steve Lentz, who in spite of their own busy schedules, took the time to read my manuscripts and the thesis, attend meetings, and share their wisdom. I would like to especially thank Steve Lentz for his unlimited availability; because he was only a couple steps down the hall, he was often the guinea pig for the latest of my frequent fits of insight or dillusion. Bruce Warren, thank you for chairing my defense and providing a broader perspective on my thesis. Many thanks to a couple leaders in the field of plumes, Rich Garvine and Bill Boicourt for both their enthusiasm and encouragement, and comradery at the conferences. Special thanks to Michele Connor for her friendship and never-ending assistance in making sure I was able to reach my always busy advisor.

Many thanks to the members of the Red Tide team: Rocky, Rich Signell, Don Anderson, Peter Franks, Bruce Keafer, and Ted Loder. I cannot thank Rich enough for his assistance with a myriad of computer-related questions and his invaluable mentorship with the Blumberg-Mellor model. Thanks, of course, are owed to Alan Blumberg who kindly allowed me to use his model. Thanks to Albert Fischer, I was able to use a scanner to incorporate figures from previous studies into the thesis. I would also like to acknowledge my insightful proofreader, Melissa Bowen.

Finally, I come to the people who made this whole experience more than just a chance to get piled higher and deeper. I first would like to thank the members of the original talented ten from 1992: Jay Austin, Natalia Beliakova, Lyn Harris, Stefan Lewellyn-Smith, François Primeau, Jamie Pringle, Brian Racine, Miles Sundermeyer, and Bill Williams. Your friendship and sharing of the experiences were helpful innumerable ways. I would also like to thank other members of the P.O. legacy for their friendship: Juli Atherton, Melissa Bowen, Chris Edwards, Ari Epstein, Albert Fischer, Dan Goldner, Steph Harrington, Steven Jayne, Paula Fratantoni, Paul Robbins, and Sandra Werner. Thank you also to the many other 
Joint Program students like Deb Hassler, Ann Pearson, and Sheri White who reminded me that P.O. was not the center of the universe. To Julia Westwater in the Education Office, thanks for the amazing key lime pie recipe, your friendship, and always assisting me in those moments of crisis. Thank you to my friend and Stanford officemate Chris Rehmann whose scientific advice, friendship, and sense of humor have been of great value for so many years.

Some special thank yous are owed to some friends who helped me remember to partake in things like good food and recess. Brian and Kate Racine, thanks for sharing in the adjustment to life in New England. It was nice to be part of a second family. Craig Lee and Joanna Muench, thank you for sharing in my indulgences of exquisite food and music. Jay, you'll never be Minnesota Fats in either billiards ability or stature, but thanks for blowing aways some insolent spheres with me. Jessica Baker, Shannon McDaniel, Ellen Mecray, Greg Winston, the rest USGS/SEA gang, and members of the Falmouth Track Club: thanks for sharing what it's like to not be a student. Jess, a special thank you for rounding out what would have been an otherwise humdrum final few months with your good humor, friendship, and inspiration. Sandra, Steve, Ellyn Montgomery, Payal Parekh, and Bob Pickartthanks for sharing the whole first marathon experience: it is one I'll never forget. Lyn and François, you were terrific schoolmates, but more importantly, wonderful housemates and playmates.

I owe many thanks to some special housemates who made life much more bearable through their friendship and support over the past five and a half years. Thank you Peter (and Michelle!) Unrau for your wit, interest in bridge, the sailing adventures, and a shared passion for salt and vinegar. François, you're a crazy Canadian, but you taught me so much (some good, some bad, some ugly); I know I would not have made it though generals without your mutual bickering, studying, and suffering. Lyn, thank you for your friendship, warm home (even sans coal!), and teaching me so many things about living life to its fullest. Thanks for the bike rides (someday we'll take that long tour) and getting me into running. Finally, Liz Kujawinski and Steve: thank you for putting up with an aging (but, aging well) grump of an old man. I'm so glad that our friendship and household were more resilient than either our road or washing machines.

My parents, Lincoln and Moria Fong, and friends from a far, Janet Anderson, John Beckman, Pat Broun, Hugo and Marie Burgemeestre, Calendula Chang, Morris and Doris Close, Rachel Collin, Allen and Alice Cuenca, Wayne and Liz Fischer, Jackie Holen, Tony and Louise Huen, Erin Jones, Lisa Kimura, Anu Krishnaswamy, Johnny Lin, Caroline Park, David Ross, Kerri Winters, Jennifer Yamashita, have all lent me encouragement, prayers, and the timely phone call or email to keep me in touch with things that are really important.

And finally, the fundamental and important thanks: this research was funded by a National Science Foundation graduate fellowship, and Gulf of Maine Regional Marine Research Program grants UM-S227 and UM-S276. 


\section{Contents}

$\begin{array}{ll}\text { Abstract } & 3\end{array}$

Acknowledgments $\quad 5$

1 Introduction $\quad 13$

1.1 The bulge region and coastal current . . . . . . . . . . 16

1.2 Plume response to alongshore wind forcing . . . . . . . . . . . 18

1.3 Thesis outline . . . . . . . . . . . . . . . 21

2 The alongshore transport of fresh water in a surface-trapped river plume $\quad 23$

2.1 Introduction . . . . . . . . . . . . . . 25

2.2 The numerical model . . . . . . . . . . . . . . . . . . . . . . . 28

2.3 The unforced river plume . . . . . . . . . . . . . . . 32

2.3 .1 Base case ................... . . . . 34

2.3.2 Coastal current freshwater transport . . . . . . . . . . 40

2.3.3 Plume response for different inflow parameters . . . . . . . . 43

2.3.4 Temporal variations in freshwater transport ........ . 53

2.4 The influence of an ambient flow field . . . . . . . . . . . . . 55

2.5 Summary ................................ 67

3 The wind-forced response of a buoyant coastal current:

Observations of the western Gulf of Maine $\quad 71$

3.1 Introduction . . . . . . . . . . . . . . . 73

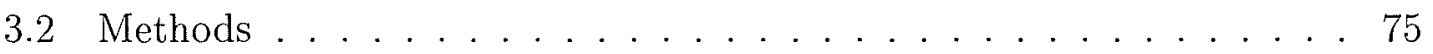


3.3 Hydrographic surveys . . . . . . . . . . . . . . . 76

3.4 Moored Current Meter records . . . . . . . . . . . . . . . . . 83

3.4 .1 Ekman balance . . . . . . . . . . . . . . . 87

3.4.2 Other contributors to the alongshore momentum balance . . 89

3.5 Discussion and Summary . . . . . . . . . . . . . . 90

4 The response of a river plume during an upwelling favorable $\begin{array}{ll}\text { wind event } & 95\end{array}$

4.1 Introduction . . . . . . . . . . . . . 97

4.2 Theory . . . . . . . . . . . . . . . . 100

4.2.1 Parameterizing vertical mixing in the plume . . . . . . 100

4.2 .2 A simple conceptual model . . . . . . . . . . . . . . . 102

4.3 3-D Model description . . . . . . . . . . . . . . . . 107

4.3 .1 Boundary conditions . . . . . . . . . . . . . . 109

4.3 .2 Initializing a freshwater plume . . . . . . . . . . . . 110

4.4 Plume response to a moderate amplitude wind . . . . . . . . . . 113

4.4 .1 Basic plume response . . . . . . . . . . . . . . . . 113

4.4.2 Plume mixing dynamics for a moderate amplitude wind . . . 119

4.5 Sensitivity to forcing conditions . . . . . . . . . 128

4.5.1 Quasi-steady plume thickness . . . . . . . . . . 130

4.5 .2 Plume mixing rates . . . . . . . . . . . . . 136

4.5.3 Comparison of plume mixing with 1-D mixing studies . . . 138

4.6 Comparison with downwelling winds . . . . . . . . . . . 142

4.7 Discussion and summary . . . . . . . . . . . . . . 146

5 Summary and discussion $\quad 151$

5.1 Summary . . . . . . . . . . . . . . . . . . 152

5.2 Unresolved issues . . . . . . . . . . . . . . 156

Appendix: The unsteady Ekman problem 159

$\begin{array}{ll}\text { Bibliography } & 163\end{array}$ 


\section{List of Figures}

2.1 Surface salinity distribution in an idealized numerical model . . . . . 26

2.2 Surface salinity distribution for the Chesapeake Plume, July/August $1972 \ldots \ldots \ldots \ldots . \ldots \ldots \ldots$

2.3 Model Configuration . . . . . . . . . . . . . . 30

2.4 Schematic of river mouth forcing conditions . . . . . . . . . . 31

2.5 Model surface salinity and velocity fields . . . . . . . . . . . 36

2.6 Cross-shore momentum balance in coastal current . . . . . . . . . . 38

2.7 Cartoon of circulation within bulge and coastal current . . . . . . . 39

2.8 Idealized Margules front representation of the coastal current . . . . . 41

2.9 Model freshwater transport $Q_{f c c}$ in coastal current . . . . . . . . . . 44

2.10 Bulge behavior for different input conditions . . . . . . . . . . . . 46

2.11 Freshwater transport as a function of discharge Rossby number . . . . 48

2.12 Bulge shapes as a function of Rossby number . . . . . . . . . . 50

2.13 Eddy/bulge leakage cartoon . . . . . . . . . . . . . . 52

2.14 Temporal variations in the coastal current . . . . . . . . . . . . . 54

2.15 Bulge width as a function of time . . . . . . . . . . . . 56

2.16 Surface salinity for base model run plus $10 \mathrm{~cm} / \mathrm{s}$ ambient current . . . 58

2.17 Freshwater transport for same parameters as Base case plus an ambient flow field of $10 \mathrm{~cm} / \mathrm{s} \ldots \ldots . \ldots . \ldots 59$

2.18 Steady state plume width . . . . . . . . . . . . 61

2.19 Traces of 31 psu isohaline at plume surface for Base case with different ambient flow fields . . . . . . . . . . . . . . 62

2.20 Freshwater transport as a function of time for different ambient flows 63

2.21 Freshwater transport as a function of ambient flow field strength . . . 65 
3.1 The study region: the western Gulf of Maine . . . . . . . . . 74

3.21993 observations in the western Gulf of Maine . . . . . . . . . 77

3.31994 observations in the western Gulf of Maine . . . . . . . . 78

3.4 Surface salinity for downwelling and upwelling wind conditions . . . 80

3.5 Time series of alongshore wind stress, salinity and cross-shore velocities measured at Cape Porpoise in 1994 . . . . . . . . . . . 84

3.6 Time series of terms in the shear alongshore momentum equation . . 88

3.7 Balancing the shear alongshore momentum . . . . . . . . . . 91

4.1 Velocity and density profiles in simple theory . . . . . . . . . . . 101

4.2 Cartoon of conceptual model plume response . . . . . . . . . . 104

4.3 Numerical model configuration . . . . . . . . . . . . . . 108

4.4 Surface salinity for river plume forced by a moderate upwelling wind . 112

4.5 Stress and salinity sections . . . . . . . . . . . . . 115

4.6 Profiles of Coriolis and stress divergence terms . . . . . . . . . . 116

4.7 Salinity and alongshore momentum balance terms . . . . . . 118

4.8 Cross-shore momentum balance . . . . . . . . . . . . 120

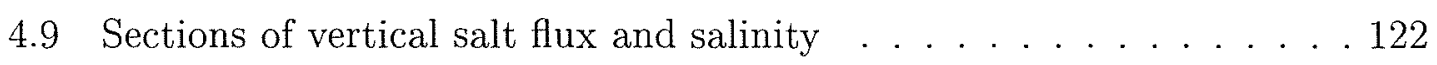

4.10 Profiles of velocity shears, salt flux, and salinity . . . . . . . . 124

4.11 Profiles of stress, stratification, and vertical salt flux . . . . . . 125

4.12 Circulation pattern in reference frame of the advected plume . . . . 127

4.13 Sections of salinity and vertical salt flux $\ldots \ldots \ldots \ldots \ldots$

4.14 Numerical model plume thickness $h_{s}$ versus theoretical thickness $h_{c} .134$

4.15 Bulk Richardson number as a function of wind stress . . . . . . 135

4.16 Integrated salt flux as a function of time for different wind stresses . . 137

$4.17 \mathrm{Log}$-log plot of $R i_{*}$ versus non-dimensional entrainment rate $w_{\text {e* }} \ldots 141$

4.18 Plume response to downwelling . . . . . . . . . . . . . 143

4.19 Comparison of mixing during upwelling and downwelling . . . . 145 


\section{List of Tables}

2.1 Parameters of numerical calculations. . . . . . . . . . . . 32

2.2 Summary of freshwater transport. . . . . . . . . . . . . 4 47

3.1 Observed change in plume width at Cape Porpoise vs. simple model theory . . . . . . . . . . . . . . . . 82

3.2 Low-passed correlation coefficients for observed winds and velocities . 83

3.3 Low passed correlation coefficients for alongshore momentum terms . 87

4.1 Parameters of numerical calculations presented in Section 4.4. . . . 128

4.2 Comparison of numerical simulations with conceptual model. . . . . . 132 
The ocean has been good to me.

-Jack Rudloe 


\title{
Chapter 1
}

\section{Introduction}

Hobbes: "Do you have an idea for your story yet?"

Calvin: "No, I'm waiting for inspiration."

\author{
Bill Watterson
}


A large fraction of the terrestrial material delivered to the ocean is accomplished via river discharge. River discharge carries freshwater and is often a source of nutrients, biological species, sediment, and unwanted toxic contaminants [Franks et al., 1992; Masse and Murthy, 1992; Nittrouer et al., 1991]. The discharge can play an important role in coastal ocean dynamics in the vicinity of the river mouth because it acts as a source of momentum and buoyancy. Typically, the river discharge first mixes with oceanic water in an estuary such that water entering the coastal ocean is not completely fresh and is often only slightly less saline than the ambient coastal waters. The studies presented here will focus on interactions of the brackish riverine discharge after it has left an estuary mouth.

The less dense water of a river discharge and its associated flow field are called a river plume. River plumes occur over a variety of spatial scales. Garvine [1995] provides a simple framework in which to study different plume systems. His classification scheme is based on the Kelvin number $(K)$, the ratio of the plume width to the baroclinic Rossby radius. A description of the dynamics of small-scale (low $K)$ plumes in which inertial effects are more important than rotation can be found in O'Donnell [1990], Garvine [1974,1981,1984], and Garvine and Monk [1974]. The dynamics are usually nonlinear, and rotation is typically unimportant. For plumes of $K \approx 0(1)$ or greater, earth's rotation becomes important and tends to turn the buoyant discharge to the right (in the Northern Hemisphere) as it exits the estuary mouth. This thesis focuses on large-scale (large $K$ ) river plumes where earth's rotation is important to the plume dynamics.

Large-scale plumes have traditionally been viewed as coastal currents driven by their own baroclinicity $[K a o, 1981]$. The alongshore transport of fresh water and flow within the plume, however, can be strongly influenced by external forcing conditions 
such as winds [Münchow and Garvine, 1993b] and remotely forced ambient flow fields. It is likely that these two forcing agents may play important roles in the alongshore flow of plume water.

Chapman and Lentz [1994] classify plumes as either surface-trapped or bottomattached. The former plume is one where the fresh water forms a shallow, surfacetrapped layer that spreads over the ambient shelf water and exhibits strong vertical stratification. Examples of surface-trapped plumes are the Columbia River and Chesapeake Bay plumes [Boicourt, 1973; Hickey et al., 1998]. A plume is bottomattached if a significant portion of the plume spans the water column from surfaceto-bottom. These plumes have been observed in the South Atlantic Bight [Blanton and Atkinson, 1983].

Yankovsky and Chapman [1997] provide a framework for determining whether a freshwater discharge will be surface-trapped or bottom-trapped and describe some of the dynamical differences in the source region. It is worth noting that the presence of wind forcing can alter a plume's structure, and hence classification. For example, a sustained downwelling wind event can advect a surface-trapped plume against the coast such that its structure temporarily becomes bottom-attached. While this thesis will focus primarily on the surface-trapped class of plumes, it is hoped that many of dynamics discussed will be relevant to both surface-trapped and bottomattached plumes. The literature review which follows will discuss previous work involving both plume types and only distinguish between the two when necessary. 


\subsection{The bulge region and coastal current}

A surface-trapped plume consists of two distinct dynamical regions: a bulge region near the estuary mouth and a geostrophic current in the direction of Kelvin wave propagation downstream of the bulge (Figure 1.1). Most laboratory studies of plumes have focused on the establishment of the geostrophically-balanced downcoast buoyancy current flowing in the direction of Kelvin wave propagation [Griffiths and Hopfinger, 1983; Stern et al., 1982]. These studies have shown that the leading edge or nose of the plume propagates at the rate comparable to the phase speed of the first mode baroclinic wave. Whitehead and Chapman [1986] note that the nose propagation decays in time, caused by shelf wave radiation. The deceleration of the density-driven current suggests that, in the absence of winds or external forcing, the plume water will only be transported a finite distance downstream. While the photographs contained in these studies hint at the presence of a bulge upstream of the coastal current, no mention is made of its existence.

The buoyancy-driven plume flow has been studied extensively with numerical models. Like the aforementioned lab studies, early studies by Kao [1981] and Garvine [1987] focus on the rightward veering of the river discharge (in the North-

ern Hemisphere) and its subsequent steady-state geostrophic current. Garvine [1987] does, however, acknowledge that there exists a transition region between the river mouth and the downstream coastal current.

One of the first studies to identify the bulge region of the plume is the modeling study of Chao and Boicourt [1986]. They model a freshwater plume in the absence of any external forcing (e.g., tides, winds, ambient flow field). Their base model run shows that, at least at depth, the bulge region near the estuary mouth consists 


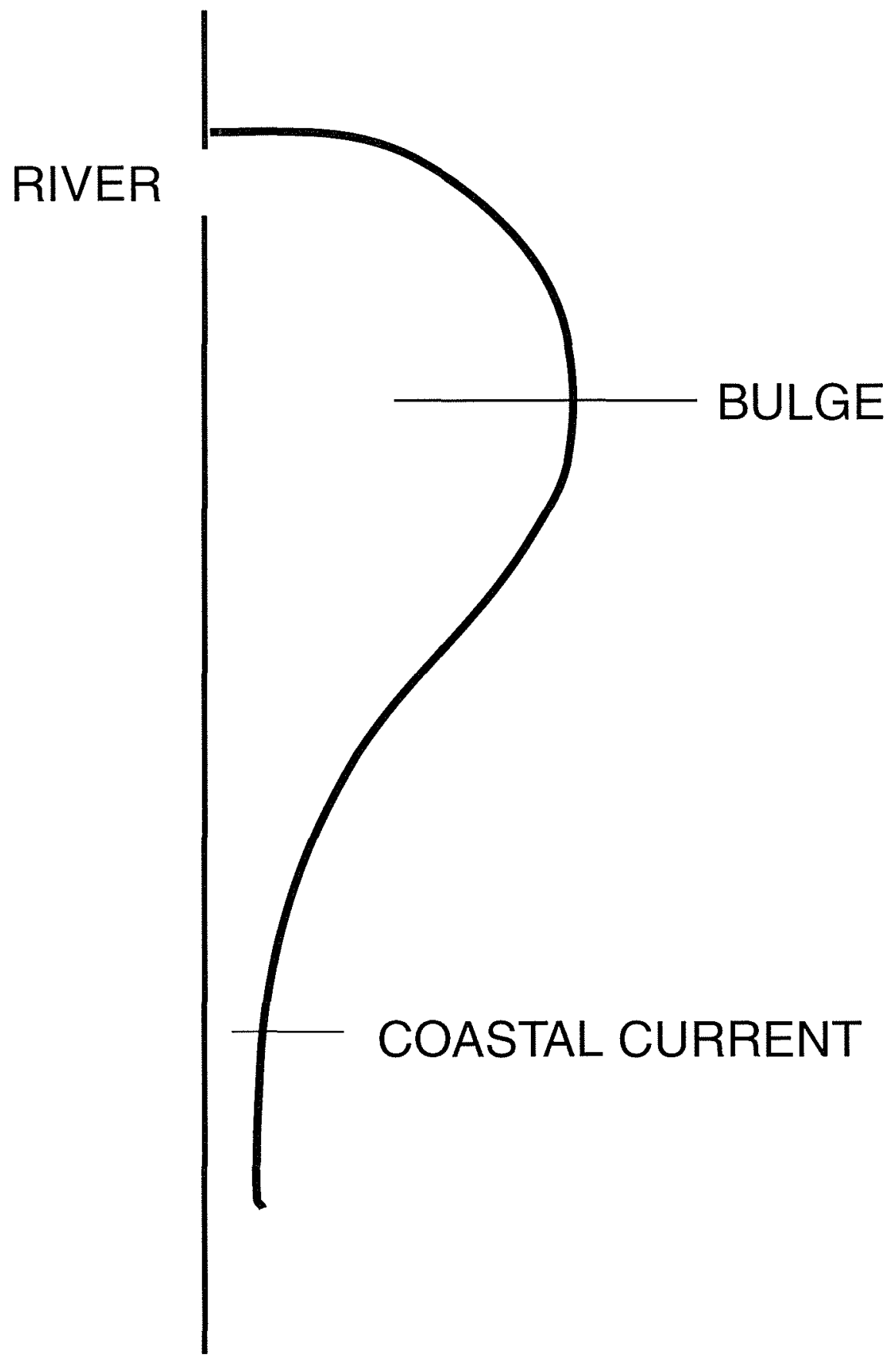

Figure 1.1: Cartoon of surface-trapped plume. 
of an anti-cyclonic, recirculating cell of brackish water. Between $t=5$ and 10 days of buoyancy forcing, the bulge widens and expands offshore. The growth of the bulge implies that the downstream geostrophic current does not transport the entire freshwater volume supplied by the river discharge downstream, and the plume is not in steady-state. This behavior is also observed in a recent study by Oey and Mellor [1993] where their bulge region continually grows in time and periodically sheds eddies, apparently due to a baroclinic instability mechanism. Based on the observed continual growth of the bulge in these studies, it is likely that a plume cannot be treated as a steady-state phenomenon.

Modeling studies by Kourafalou et al. [1996b], McCreary et al. [1997], and Chapman and Lentz [1994] also note significant recirculation near the river mouth and that some of the freshwater is transported upcoast, opposite the direction of Kelvin wave propagation, in the absence of any external forcing. If the fate of a freshwater plume is to be understood, it is necessary to investigate how much buoyancy the geostrophic current in the plume can transport, and the role external forcing plays in enhancing or arresting the downcoast transport of freshwater. One of the goals of this thesis is to identify the role an ambient current plays in alongshore plume advection and transport of fresh water. It will consider ambient currents oriented in the direction of Kelvin wave propagation, similar to those found on many continental shelves.

\subsection{Plume response to alongshore wind forcing}

Most plume systems are exposed to additional external forcing mechanisms that can affect the advection and fate of the fresh water: e.g., winds and tides. The former 
has been the subject of several studies. Münchow and Garvine [1993a] show how alongshore winds could significantly alter the cross-shore structure of the Delaware River plume. Upwelling winds tend to spread the plume significant distances offshore while downwelling winds tend to confine the plume against the coast. The observed behavior is consistent with Ekman dynamics. The offshore spreading of the Delaware plume is large under upwelling winds such that the hydrographic surveys show a plume over $30 \mathrm{~km}$ wide, and not completely resolved by the surveys.

Modeling studies also demonstrate the plume's Ekman-like response to alongshore wind forcing [Chao, 1988b; Kourafalou et al., 1996a]. Chao [1987] shows how upwelling winds tend to spread the plume offshore and also arrest downstream propagation of fresh water because of the downwind barotropic response. In contrast, downwelling winds strengthen the downcoast transport of fresh water by enhancing cross-shore density gradients, and hence, the geostrophic current. While the basic Ekman response has been described in previous studies, the wind-induced advection has not been quantified.

Wind forcing not only advects the plume; it also can lead to the mixing of plume waters. While some of the previous modeling studies have looked into the sensitivity of plume mixing to bottom friction, stratification, and magnitude of the background diffusivity [Chao, 1988a; Kourafalou et al., 1996b], there has been little work done to address the underlying physics driving the mixing in a freshwater plume.

The role of tidal mixing is investigated by Blanton and co-workers using observations in the South Atlantic Bight (SAB) [Blanton et al., 1994; Blanton and Atkinson, 1983]. They find that river discharge in the SAB, where the plume is often bottom-trapped, is vigorously mixed by tidal currents. They suggest that in the 
absence of strong prevailing winds, tidal mixing should be the dominant mechanism by which plume waters are mixed and dispersed.

It seems likely, however, that in a surface-trapped plume, tidal mixing should play a less important role. Wind stress may be the dominant mixing agent because the significant stresses within the plume may lead to turbulent mixing. If the plume is not in contact with the bottom topography, it is likely that the tidally generated turbulence near the bottom will have little effect on mixing in the plume.

While the basic plume response to winds has been discussed in several previous studies, almost no attention has been focused on addressing the role of winds in mixing the plume and ambient coastal waters. Based on their observations of the Niagara River plume, Masse and Murthy [1992] suggest that enhanced mixing is expected during upwelling due to weakened vertical density gradients; they also suggest that mixing should be inhibited during downwelling due to enhanced gradients. It seems reasonable, however, to expect that mixing would be enhanced during either type of alongshore wind stress because of the energy source provided by the winds. In addition, it is likely that upwelling winds would actually increase vertical salinity gradients while at the same time enhancing velocity shears.

The one-dimensional mixing problem of a stratified fluid forced by a surface stress has been studied extensively in the laboratory (e.g., Fernando [1991], Kato and Phillips [1969], Kantha et al. [1977]). Trowbridge [1992] shows that mixing is a gradient transport process where turbulent mixing is maintained at a constant Richardson number. Although the river plume problem is clearly two- if not threedimensional, the mixing processes in a plume may bear some relation to the mixing observed in these studies. One of the goals of this thesis is to identify the mixing 
mechanisms that occur in a plume during a wind event.

\subsection{Thesis outline}

The goal of this study is to elucidate the basic physical processes associated with a large-scale, surface-trapped river plume. In particular, the study focuses on understanding the role of wind-forcing and the ambient coastal circulation in determining the structure and evolution of a plume. The thesis includes observations of the wind-forced plume dynamics in the western Gulf of Maine and some processoriented numerical modeling experiments of wind-induced mixing during upwelling

winds and plume dynamics in the absence of winds. One of the key contributions of this work is the quantification of both the along and cross-shore motions of plume waters.

The thesis is organized as follows. In Chapter 2, an idealized series of numerical modeling experiments is conducted to study the evolution of a surface-trapped plume neglecting the influence of winds, but considering the effects of an along-shore barotropic flow. In this section of the thesis, the importance of the bulge region is identified. One key result is that much of the fresh water volume discharged by a river is not transported downstream by the plume's baroclinicity; external forcing may play an important role in augmenting the freshwater transport in the plume. In Chapter 3, cross-shore motions of a plume are studied using observations collected from the western Gulf of Maine. Using some simple ideas, it is found that the cross-shore motion of the plume is approximated by an Ekman balance. The windinduced mixing of the plume during an upwelling favorable wind event is described and quantified in Chapter 4. In this chapter, the mechanism by which mixing is 
maintained during a sustained upwelling wind event is described. In Chapter 5, the thesis results are summarized and future work is suggested. These chapters employ a range of methods to probe the fundamental dynamics governing a freshwater plume. Each of them shows evidence that the winds and ambient currents can dominate the buoyancy-forcing in determining the transport and fate of a plume. 


\section{Chapter 2}

\section{The alongshore transport of fresh water in a surface-trapped river plume}

Hobbes: "OK...um, first let's make a list of what we know." Calvin: "Yeah, that's a good way to start!"

Bill Watterson 


\begin{abstract}
The alongshore transport of a surface-trapped river plume is studied using a three-dimensional model. Model simulations exhibit the previously observed rightward veering (in the Northern Hemisphere) of the fresh water and establishment of a downstream geostrophically-balanced coastal current. In the absence of any ambient current, the plume does not reach a steady-state. The downstream coastal current only carries a fraction of the discharged fresh water; the remaining fraction recirculates in a continually growing "bulge" of fresh water in the vicinity of the river mouth.

The river mouth conditions influence the amount of fresh water transported in the coastal current relative to the growing bulge. For high Rossby number $(O(1))$ discharge conditions, the bulge shape is circular and the coastal current transport is smaller than for the model runs of low Rossby number discharges. For all model runs conducted without an ambient current, the freshwater transport in the coastal current is less than the freshwater discharged at the river mouth.

The presence of an ambient current (in the same direction as the geostrophic coastal current) augments the transport in the plume such that its downstream freshwater transport matches the freshwater source, and the plume evolves to a steady-state width. The steady-state transport accounted for by the ambient current is independent of the strength of the ambient current. The amplitude of the ambient current only determines the time required to reach a steady-state plume width. The key result of this study is that an external forcing agent (e.g., wind or ambient current) is required in order for the entire freshwater volume discharged by a river to be transported downstream.
\end{abstract}




\section{$2.1 \quad$ Introduction}

The rightward turning (for an observer looking towards the sea from the river mouth) of large-scale river inflow [Garvine, 1995] in the northern hemisphere has been well documented in previous studies. The fresh water discharged from the Chesapeake and Delaware Bays, and Androscoggin/Kennebec Rivers have all been found to leave a significant freshwater signature towards the right and downstream of the river mouth (where downstream is defined to refer hereafter to the direction a Kelvin wave propagates) [Boicourt, 1973; Münchow and Garvine, 1993b, Chapter 3]. Similar behavior has also been observed in the laboratory [Griffiths and Hopfinger, 1983; Stern et al., 1982; Whitehead and Chapman, 1986] and in numerical models [Chao and Boicourt, 1986; Kourafalou et al., 1996; Oey and Mellor, 1993].

The plume can be separated into two dynamically distinct regions: a bulge region near the river mouth and a downstream coastal current [Chao and Boicourt, 1986]. Many of the previous studies (e.g., Garvine [1987], Kao [1981]) have focused primarily on the downstream coastal current; these studies have found that the coastal current is largely in geostrophic balance. This cross-shore momentum balance is consistent with field observations [Münchow and Garvine, 1993a].

A few studies have looked at the dynamics at the river mouth [Chao and Boicourt, 1986; Valle-Levinsion et al., 1996; Zhang et al., 1987]. These papers investigate the exchange flows near the estuary/river mouth and the lateral variations in the estuarine circulation for a wide estuary/river mouth. Less attention has been paid to the bulge region itself, which appears to be a prominent feature in previous investigations (e.g., Figure 2.1). One would expect that the bulge could contain a significant fraction of the fresh water discharged by the river. 

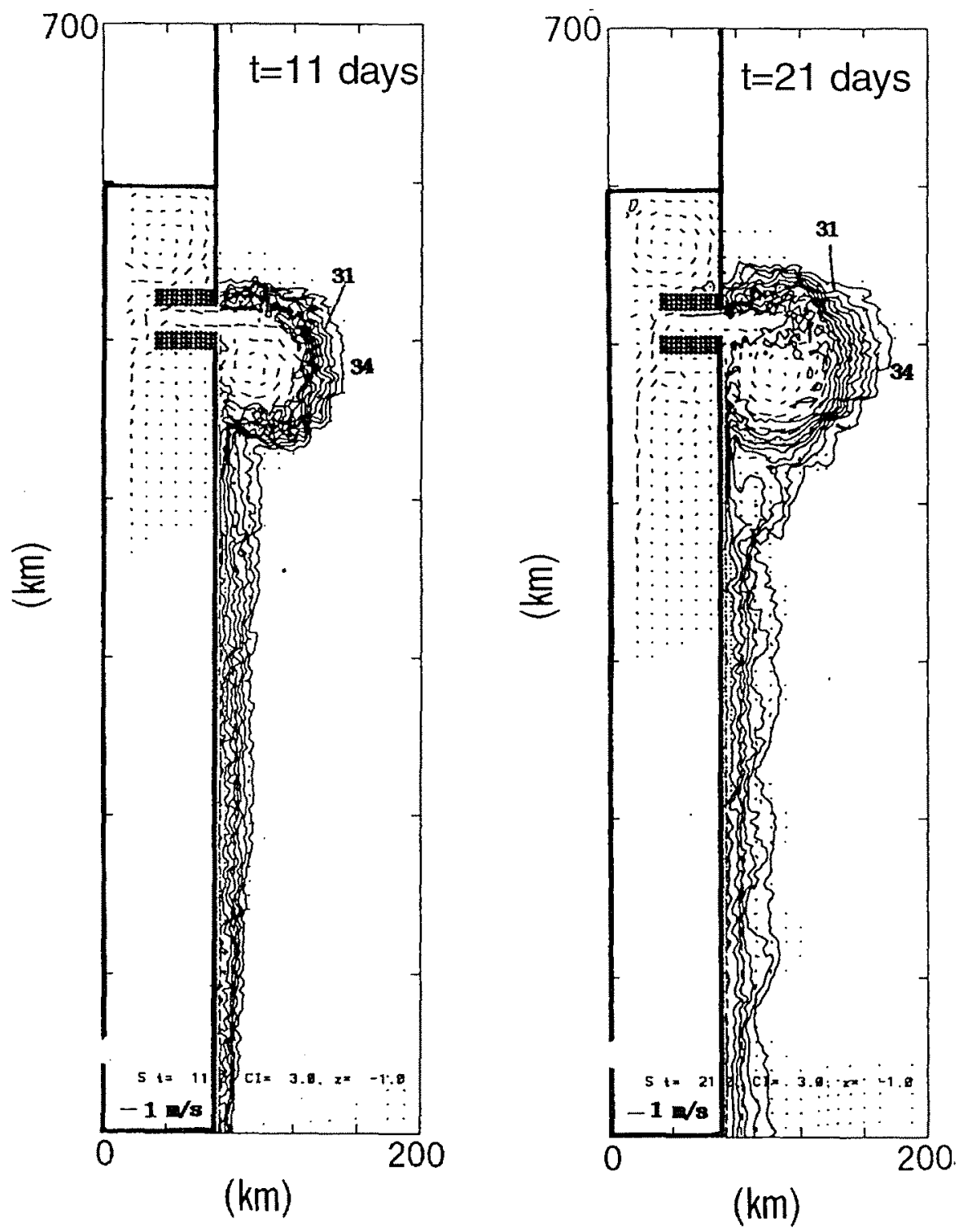

Figure 2.1: Surface salinity distribution at $\mathrm{t}=11$ and 21 days in an idealized numerical modeling study of an estuarine-forced plume without winds, tides, or ambient flow field (adapted from Oey and Mellor [1993]). 


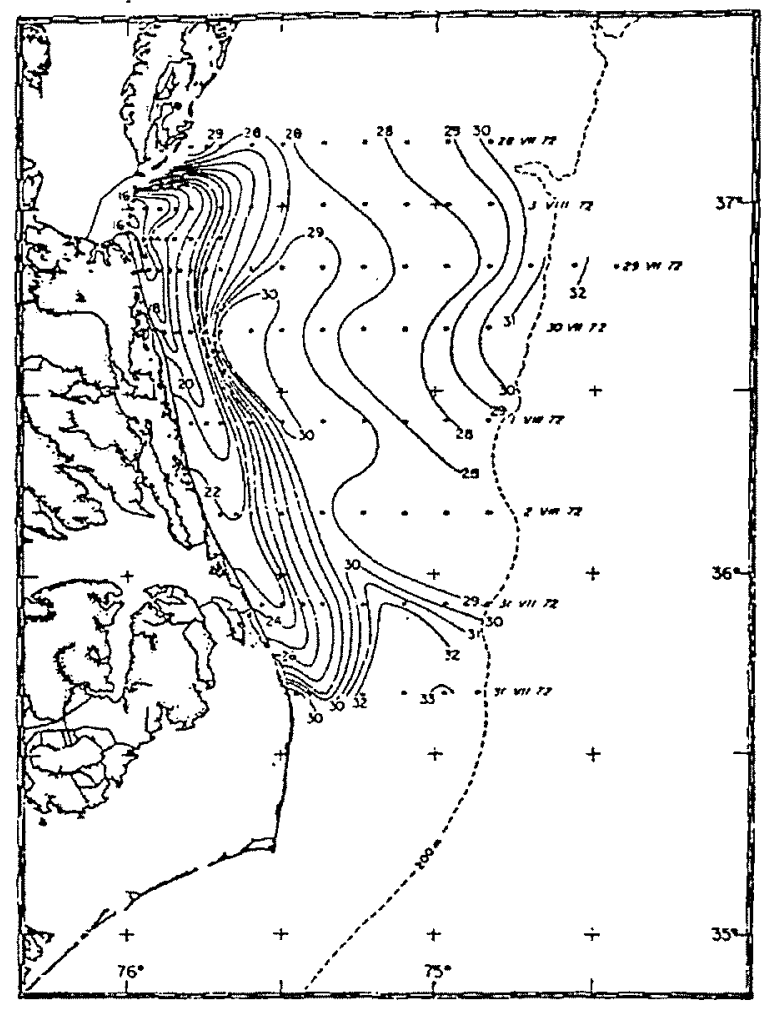

Figure 2.2: Surface salinity distribution for the Chesapeake Plume, July/August 1972 (from Boicourt [1973]).

Chao and Boicourt [1986] note that the bulge consists primarily of an anticyclonic flow field that induces upwelling within it. Oey and Mellor [1993] show the bulge may shed eddies downstream. Yankovsky and Chapman [1997] suggest that the dynamics within the bulge are primarily cyclostrophic in nature, i.e., the momentum balance is dominated by the pressure gradient, the Coriolis force, and the centrifugal force associated with the azimuthal velocity around the bulge.

Although the previous modeling studies have identified the bulge region in the vicinity of the river mouth and the much narrower downstream coastal current (Fig- 
ure 2.1), the actual dynamics of the bulge need to be addressed. Furthermore, the plume bulges observed in models are usually more pronounced than those in nature. For example, the surface salinity structure of the Chesapeake plume [Boicourt, 1973] suggests a slight bulge near the river mouth; however, the downstream coastal current is nearly the same width as the bulge (Figure 2.2), in contrast to Chao and Boicourt's [1986] simulation (their Figure 6).

It is understandable that plumes in previous modeling studies may differ from those observed in the field: typically, numerical models have sought to isolate the buoyancy forcing of the river from the other complex physical processes influencing plume behavior. Thus, the numerical studies have often neglected external forcing agents such as ambient coastal circulation. Understanding the differences between the unforced and forced model plumes is a necessary step to furthering the understanding of plume dynamics.

The idealized numerical experiments presented in this chapter explain some of the differences between previous field observations and idealized numerical simulations of surface-trapped river plumes. The numerical model is presented in Section 2.2. The dynamics of the unforced river plume are investigated in Section 2.3, concentrating on the implications for the alongshore transport of fresh water. The influence of an ambient alongshore flow is considered in Section 2.4. The results are summarized in Section 2.5 .

\subsection{The numerical model}

A three-dimensional, primitive equation model [Blumberg and Mellor, 1987] is used, with the model domain consisting of a rectangular basin with a flat bottom of $50 \mathrm{~m}$ 
depth (Figure 2.3). Fresh water is discharged uniformly (in $y$ and $z$ ) at the coastline $(x=0)$, via a river centered at $y=277 \mathrm{~km}$ into a $65 \mathrm{~km} \times 340 \mathrm{~km}$ model basin. In order to resolve the spatial structure of the plume, a variable resolution grid with $50 \times 100 \times 23$ grid cells is employed (shown as dots in Figure 2.3). The horizontal grid resolution is $1.5-3 \mathrm{~km}$ in the cross-shore direction and $3-6 \mathrm{~km}$ in the alongshore direction; vertical grid resolution is better than $1 \mathrm{~m}$ within the surface-trapped plume.

The model solves the hydrostatic, Boussinesq primitive equations. Sub-grid scale processes are parameterized by eddy coefficients for both momentum and scalar diffusion using the Mellor-Yamada level 2.5 closure scheme [Mellor and Yamada, 1982] for vertical mixing. Horizontal diffusivities are held constant at $10 \mathrm{~m}^{2} / \mathrm{s}$. The influence of rotation is implemented with a constant Coriolis parameter $f$ set to $10^{-4} \mathrm{~s}^{-1}$, a reasonable value for a mid-latitude plume. The model uses a split time step for internal and external modes. The external mode is two-dimensional and stepped in 10 second steps to satisfy the CFL condition associated with surfacegravity waves. The internal mode time step, based on the internal wave speed, is 7 minutes. A recursive Smolarkiewicz [Smolarkiewicz and Grabowski, 1990] scheme is used to advect scalar fields. General model properties and details of the numerical algorithms can be found in Blumberg and Mellor [1987].

The model is forced with a river inflow centered at $y=287.5 \mathrm{~km}$. The river inflow is of uniform density and discharged with uniform velocity from a river mouth of width $L_{r}$ and depth $h_{r}$ (Figures 2.3 and 2.4). This buoyancy forcing is steady and occurs for a period of up to 30 days. For the model runs investigating the role of ambient flows, a uniform, barotropic alongshore ambient flow field is imposed at the upstream $(\mathrm{y}=340 \mathrm{~km})$ boundary of the model domain. All model runs presented 


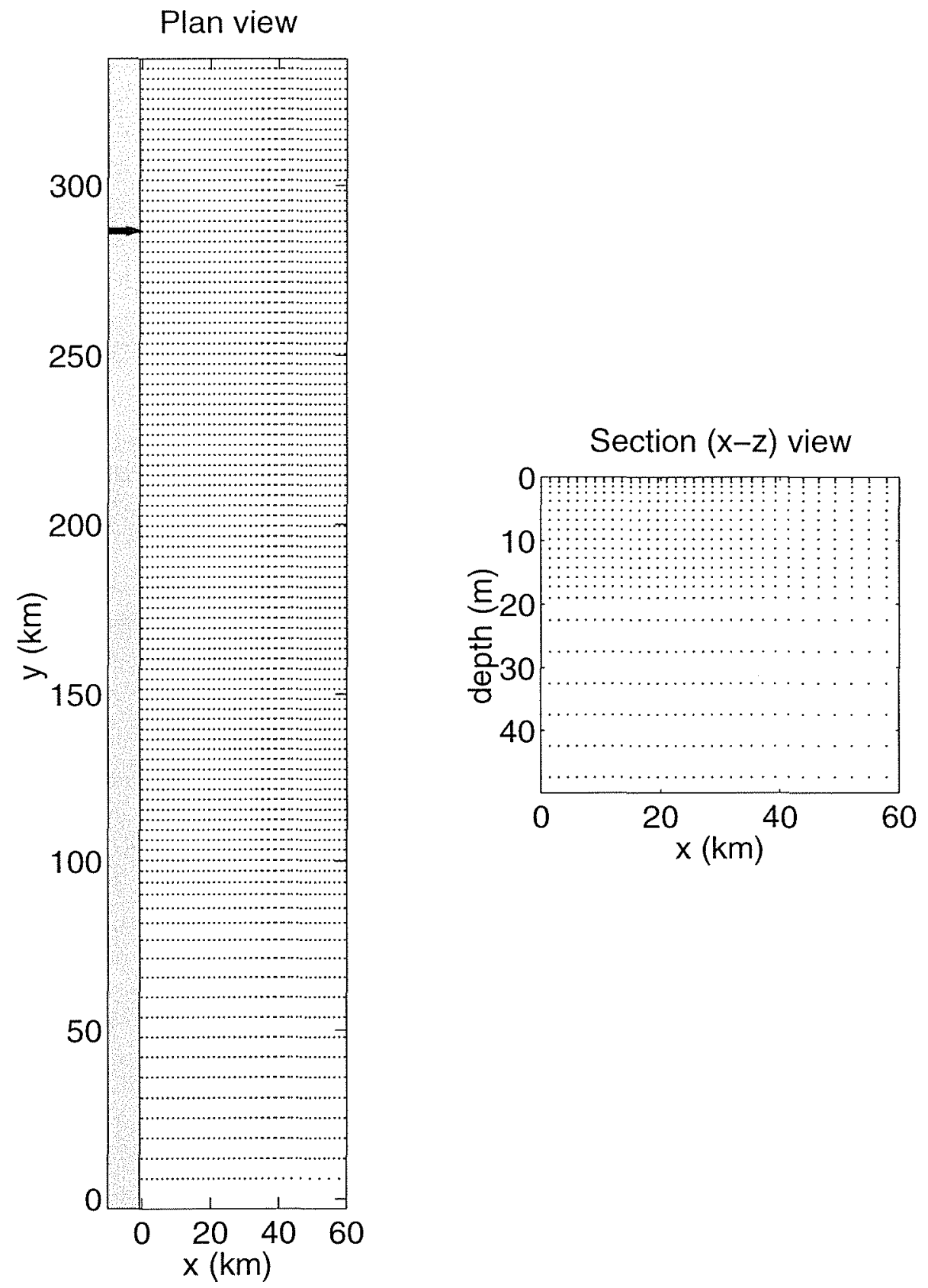

Figure 2.3: Model configuration. Blumberg and Mellor's Estuarine Coastal Ocean Model-3D (ECOM-3D) is run on a $65 \mathrm{~km} \mathrm{x} 340 \mathrm{~km} \mathrm{x} 50 \mathrm{~m}$ grid. Grid resolution is indicated by small dots in both plan and section views. Vertical sigma levels are closely spaced at the surface to resolve the near surface plume behavior. Freshwater is discharged from a river at $x=0$ centered about the alongshore position $y=287.5$ $\mathrm{km}$ (indicated by arrow). The river width is varied from $3-15 \mathrm{~km}$ (in vicinity of river mouth, grid cells (dots) are spaced $3 \mathrm{~km}$ apart in the alongshore (y) direction). The coastline (and land) is shaded in light gray. 


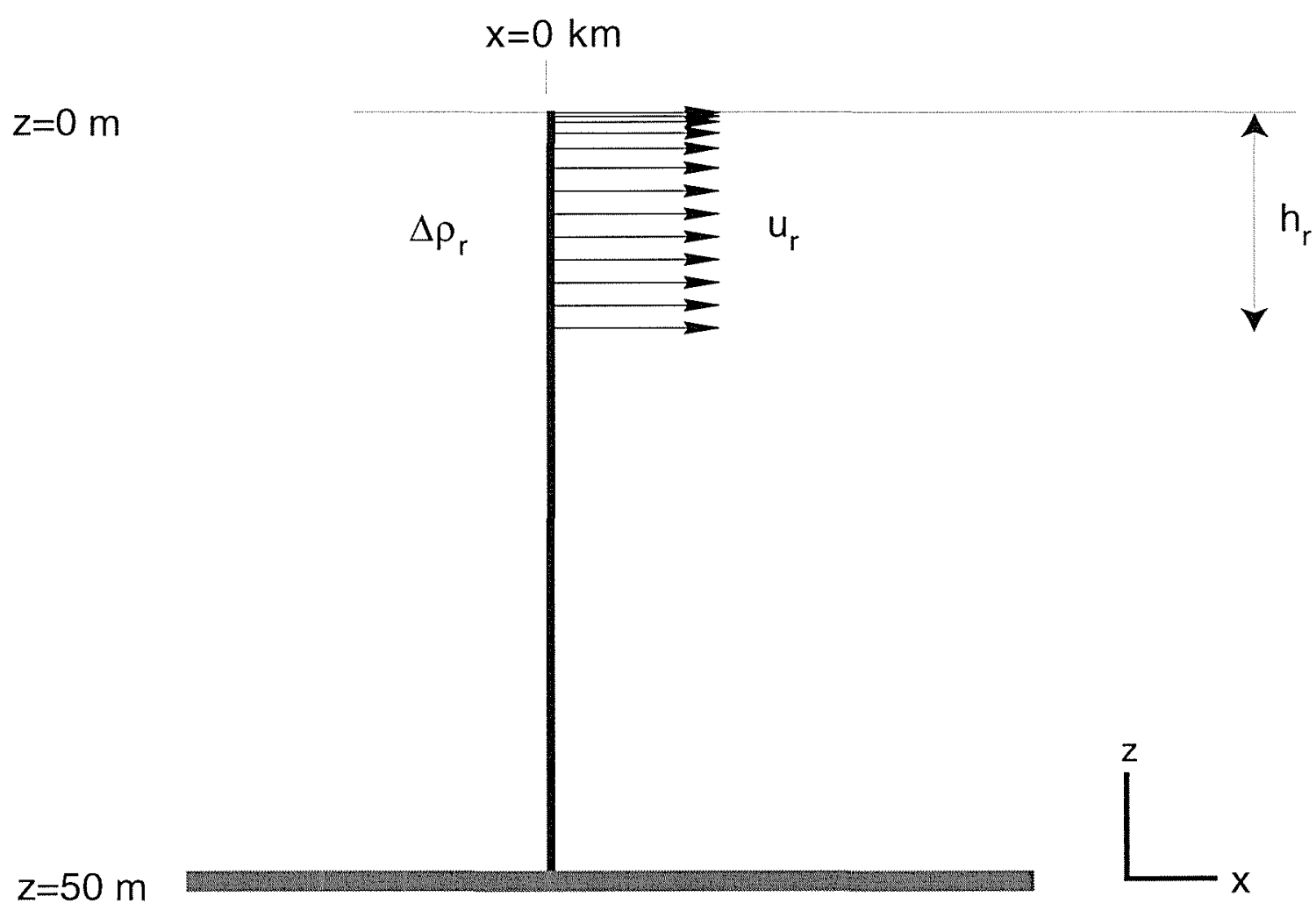

Figure 2.4: Schematic of river mouth forcing conditions. River discharge is accomplished through a uniform river discharge of water which differs in density from the ambient fluid by $\Delta \rho_{r}$. Discharge is accomplished through a river mouth of width $L_{r}$ and depth $h_{r}$ with velocity $u_{r}$. 
neglect the influence of tides and winds. The only variable scalar property considered in this study is salinity. The temperature of both the river discharge and the ambient coastal water is held fixed at $4{ }^{\circ} \mathrm{C}$. The ambient coastal salinity is 32 psu while the salinity of the river inflow ranges from $16-28 \mathrm{psu}$.

It is worth noting that rarely in nature does a river plume develop in the absence of either winds or an ambient flow field for more than a few days, so these simulations are not intended to represent actual river outflows. The goal of this study is, however, to compare previous idealized studies with the complicated plume structures observed in nature. In order to facilitate such a comparison, this study replicates previous idealized investigations and infers the limitations of making such simplifications to the plume system. In short, the objectives are to understand the underlying physics involved with the buoyancy flux of the river itself, and how these physics are modified by the presence of an ambient flow field.

\subsection{The unforced river plume}

Four model parameters are varied within the following ranges: the volume flux of water discharged by the river, $2,500<Q_{r}<10,000 \mathrm{~m}^{3} / \mathrm{s}$; the density anomaly of the river discharge $3.1<(\Delta \rho)_{r}<12.4 \mathrm{~kg} / \mathrm{m}^{3}$ which is equivalent to a salinity anomaly of the river discharge $4<(\Delta S)_{r}<16$; the width of the river inflow, $3<L_{r}<30$ $\mathrm{km}$; and the thickness of the river inflow, $3<h_{r}<30 \mathrm{~m}$. For all cases presented, the equivalent fresh water discharged by the river is $Q_{f r}=1250 \mathrm{~m}^{3} / \mathrm{s}$. Table 2.1 summarizes the inflow parameters for all the model runs.

For the narrowest river mouth cases considered $\left(L_{r}=3 \mathrm{~km}\right)$, the river mouth is only one model grid cell wide. To insure the results presented were not dependent 
Table 2.1. Parameters of numerical calculations presented in Section 2.6. $Q_{r}$ is the total volumetric transport of the river discharge, $Q_{f r}$ is the fresh water river discharge, and $(\Delta S)_{r}$ is the salinity anomaly associated with the river discharge. All other variables are defined in the text.

\begin{tabular}{ccccccc}
\hline $\begin{array}{c}\text { Run } \\
\text { No. }\end{array}$ & $\begin{array}{c}Q_{r} \\
(\mathrm{~m} 3 / \mathrm{s})\end{array}$ & $\begin{array}{c}Q_{f r} \\
\left(\mathrm{~m}^{3} / \mathrm{s}\right)\end{array}$ & $\begin{array}{c}(\Delta S)_{r} \\
(\mathrm{psu})\end{array}$ & $\begin{array}{c}(\Delta \rho)_{r} \\
\left(\mathrm{~kg} / \mathrm{m}^{3}\right)\end{array}$ & $\begin{array}{c}h_{r} \\
(\mathrm{~m})\end{array}$ & $\begin{array}{c}L_{r} \\
(\mathrm{~km})\end{array}$ \\
\hline 1 & 10,000 & 1,250 & 4 & 3.1 & 15 & 3 \\
2 & 10,000 & 1,250 & 4 & 3.1 & 15 & 6 \\
3 & 10,000 & 1,250 & 4 & 3.1 & 15 & 9 \\
4 & 10,000 & 1,250 & 4 & 3.1 & 15 & 12 \\
5 & 10,000 & 1,250 & 4 & 3.1 & 3 & 3 \\
6 & 10,000 & 1,250 & 4 & 3.1 & 3 & 6 \\
7 & 10,000 & 1,250 & 4 & 3.1 & 3 & 9 \\
8 & 10,000 & 1,250 & 4 & 3.1 & 3 & 12 \\
9 & 10,000 & 1,250 & 4 & 3.1 & 3 & 15 \\
10 & 10,000 & 1,250 & 4 & 3.1 & 30 & 3 \\
11 & 10,000 & 1,250 & 4 & 3.1 & 30 & 9 \\
12 & 10,000 & 1,250 & 4 & 3.1 & 30 & 15 \\
13 & 5,000 & 1,250 & 8 & 6.2 & 15 & 3 \\
14 & 2,500 & 1,250 & 16 & 12.4 & 15 & 3 \\
\hline
\end{tabular}


on the under-resolution of the river mouth, sensitivity tests were conducted using a limited model domain at four times the horizontal resolution (for both $x$ and $y$ directions) of the standard runs reported. The basic properties of bulge width and position, coastal current width, and freshwater transport agree to within $2 \%$. However, there was a noticeable change in the plume structure at the bulge circumference between the low and high resolution simulations. The wave-like meanders surrounding the bulge in Figure 2.5 disappeared in the high resolution simulation. This discrepancy suggests that in order to model the detailed dynamics of the bulge region, and the potential eddy fluxes associated with it (e.g., Oey and Mellor [1993]), one must be careful in choosing the grid resolution of the model.

\subsubsection{Base case}

As a base case (Run 1 in Table 2.1), a freshwater river inflow of $1,250 \mathrm{~m}^{3} / \mathrm{s}$ (accomplished through a $10,000 \mathrm{~m}^{3} / \mathrm{s}$ discharge of $28 \mathrm{psu}$ salinity $\left.\left(\Delta \rho=3.1 \mathrm{~kg} / \mathrm{m}^{3}\right)\right)$ is imposed entering a coastal ocean initially at $32 \mathrm{psu}$ salinity. The fresh water enters through a river mouth of $3 \mathrm{~km}$ width and $15 \mathrm{~m}$ depth. The size of the freshwater inflow is representative of a moderately strong discharge during the spring freshet

for several North American rivers such as the Kennebec/Androscoggin, Delaware, and the South Atlantic Bight River systems [Blanton and Atkinson, 1983; Geyer et al., 1998; Münchow and Garvine, 1993a].

The development of the unforced plume closely resembles the behavior found in previous modeling studies (e.g., Figure 2.1, Chao [1998]) of surface-trapped plumes. Most of the river water turns to the right upon entering the model domain (Figure 2.5). After only a few days, the plume has developed into two distinct regions: a near source bulge and a downstream coastal current. The coastal current is only 
a few kilometers wide, in contrast to the continually expanding bulge region which extends over $30 \mathrm{~km}$ offshore after seven days of river discharge. In addition, there is a small leakage of water upstream, i.e., in the direction opposite of Kelvin wave propagation, similar to that found in previous modeling studies such as McCreary et al. [1997] and Chapman and Lentz [1994].

Chapman and Lentz [1994] suggest the upstream flowd is related to the initial geostrophic adjustment of the river discharge. They argue that this produces a buoyancy flux which subsequently feeds a self-sustaining upstream propagation of the upstream intrusion. The simulations presented here are consistent with their hypothesis. The northward intrusion is present at the onset of river discharge, and is sustained for all time (Figure 2.5). In addition, the model runs conducted in this study exhibit stronger upstream propagation for larger density anomaly inflows, consistent with Chapman and Lentz [1994].

A recent study by McCreary et al. [1997] found that an upstream intrusion of the plume is consistent with a layered analytical model; however, the mechanism by which this upstream intrusion is achieved requires ambient stratification in the coastal waters. The northward intrusion observed here and in other studies (e.g., Chapman and Lentz [1994], Kourafalou et al. [1996]) takes place in spite of an initially unstratified coastal ocean. The upstream transport of fresh water is the topic of current research and beyond the scope of this study. It is only important to note that the upstream leakage can account for up to $10 \%$ of the total freshwater discharge.

The coastal current is unidirectional with velocities up to $40 \mathrm{~cm} / \mathrm{s}$ in the downstream direction. The cross-shore momentum balance is primarily geostrophic in the 


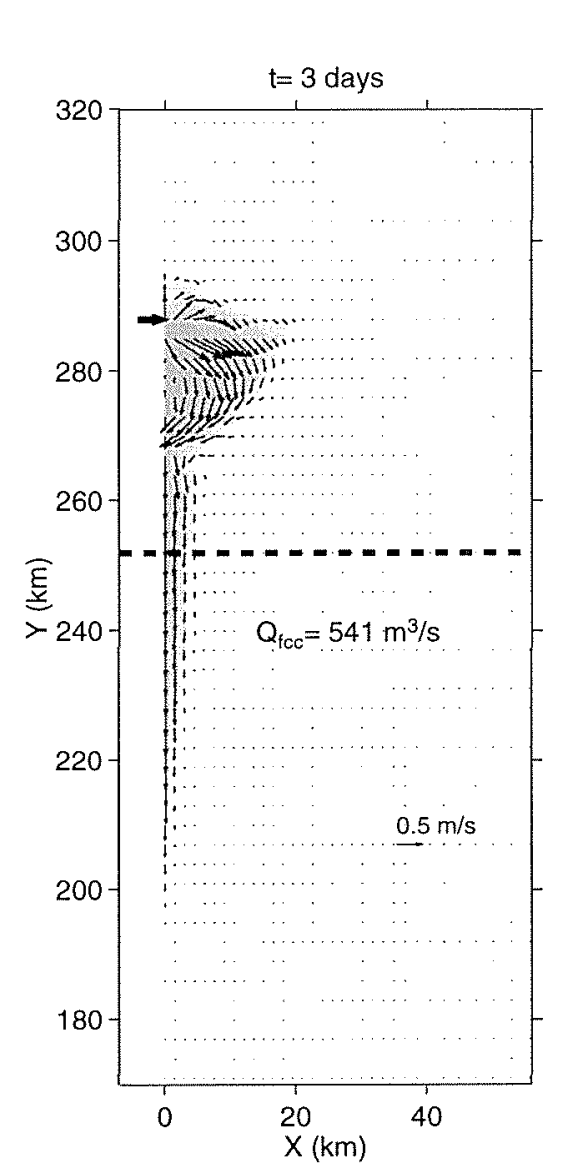

\section{Surface Salinity (psu)}
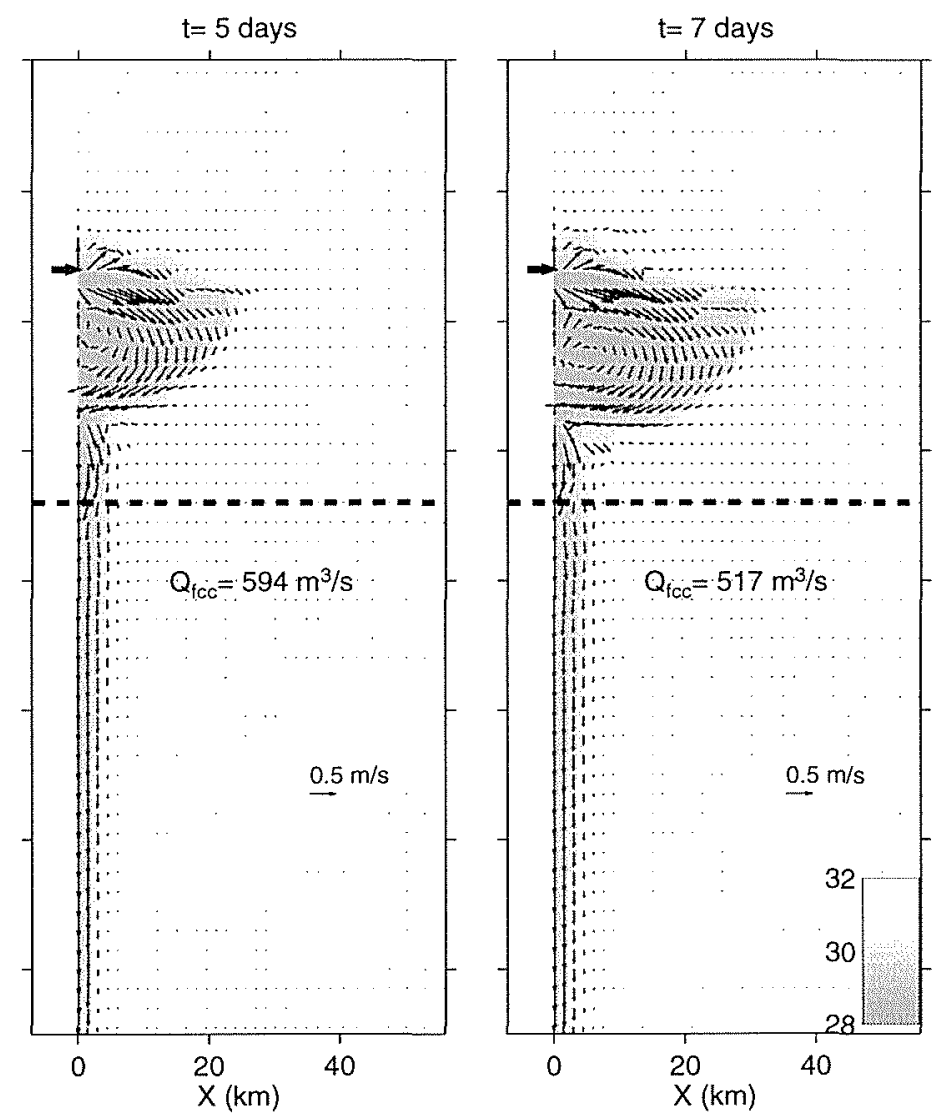

Figure 2.5: Surface salinity (psu), indicated by gray shading, for Base Case model run (Run 1) at $\mathrm{t}=3,5$, and 7 days. Velocity vectors are superimposed to indicate the flow field. Freshwater transport in coastal current is measure at $y=252 \mathrm{~km}$ (indicated by dashed line). River mouth location is indicated by bold arrow. 
coastal current with the Coriolis and pressure gradient terms being over a magnitude larger than all other terms (Figure 2.6).

The bulge region is similar in appearance to an anticyclonic gyre or eddy, with velocities approaching $50 \mathrm{~cm} / \mathrm{s}$ at its circumference and slower velocities near the center. The transport around the bulge is not axially symmetric. The seaward side of the bulge has a stronger flow field than near the coast. The asymmetry can be explained by a simple cartoon (Figure 2.7). The perimeter flow on the seaward side of the bulge contains both recently discharged river water and "older" recirculating water. The water that does not get transported in the coastal current is then recirculated in the near coast portion of the bulge. The freshwater transport in the coastal current $Q_{f c c}$ is defined as

$$
Q_{f c c} \equiv \iint v \frac{\Delta S}{S_{0}} d A
$$

where $v$ is the alongshore velocity, $\Delta S$ is the salinity difference between the plume and ambient water, $S_{0}$ is the ambient salinity, $32 \mathrm{psu}$, and the area integral is computed over the depth/cross-shore section of the coastal current. For the base case, the freshwater transport in the coastal current (measured at $\mathrm{y}=252 \mathrm{~km}$ ) is between $500-600 \mathrm{~m}^{3} / \mathrm{s}$ (Figure 2.5), less than half of the $1250 \mathrm{~m}^{3} / \mathrm{s}$ fresh water input by the river. Since the coastal current does not transport all of the freshwater input at the river mouth, the excess recirculates in the bulge region. It should be emphasized that it is unclear a priori whether the bulge recirculation is a consequence of the strength of the coastal current or visa-versa. The influence of the source conditions on the bulge behavior and freshwater transport in the coastal current will be discussed in Section 2.3.3. 

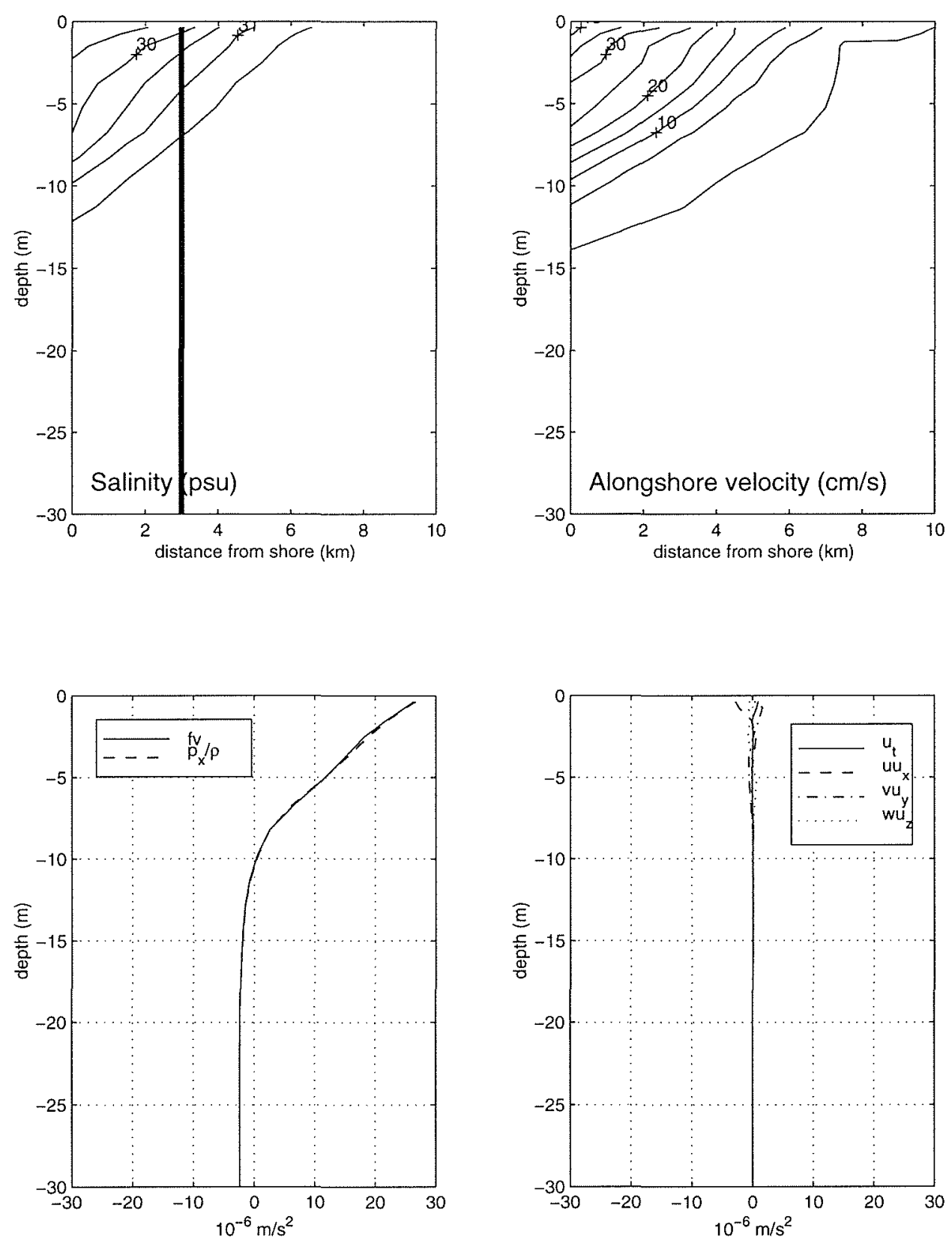

Figure 2.6: Sections of salinity (psu) and alongshore velocity are shown in the upper two panels. Profiles of terms in the cross-shore momentum balance are shown in the lower panels at the location given by the heavy vertical line overlying the salinity contours. 


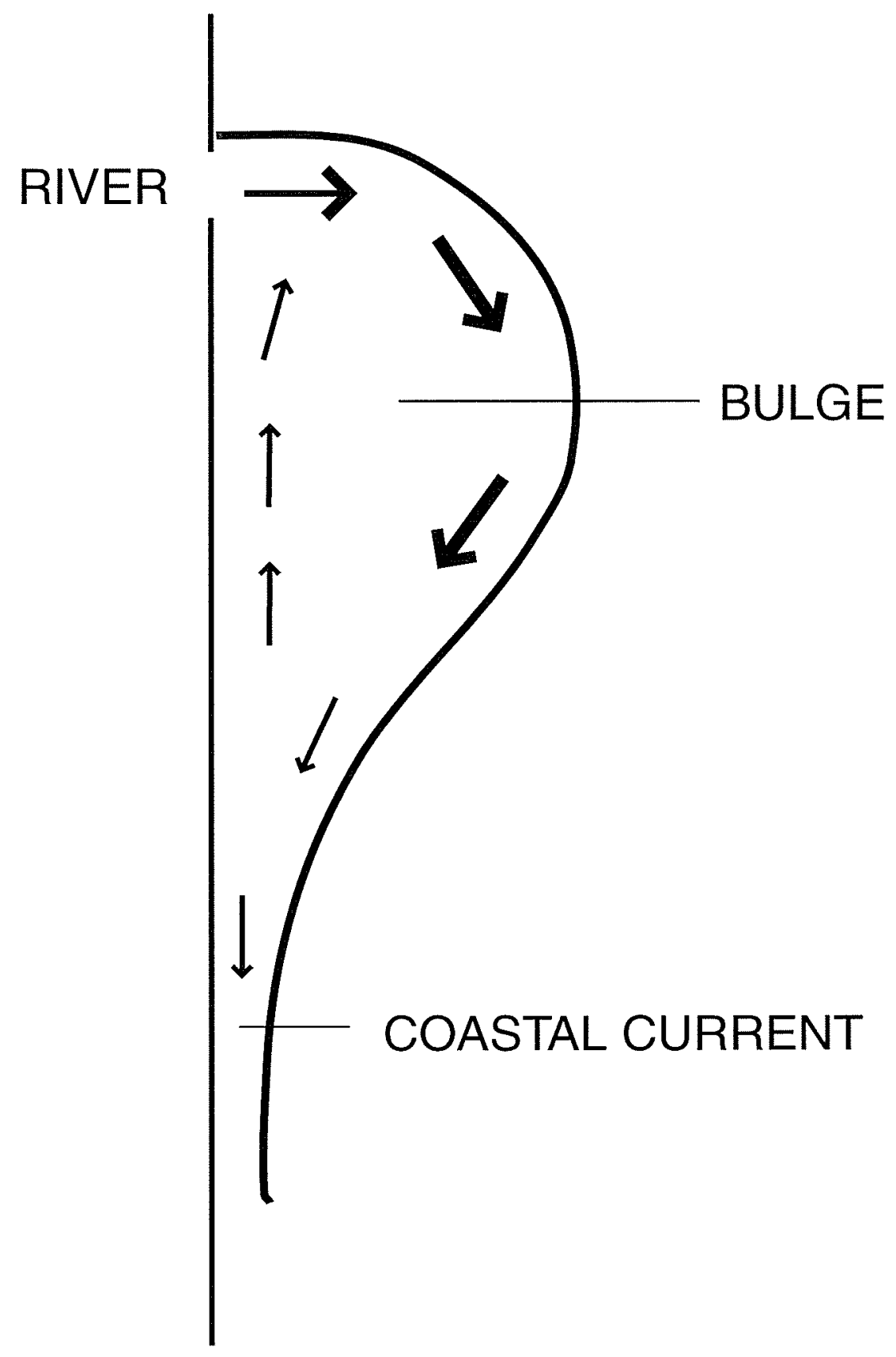

Figure 2.7: Cartoon of circulation within bulge and coastal current. The flow along the seaward side of the bulge transports water which supplies water to both the coastal current and the continually growing recirculation within the bulge. 
The discrepancy between coastal current transport and fresh water river input persists through the model run, and this necessitates a growing bulge. The mismatch between the river discharge and coastal current transport does vary somewhat in time; however the freshwater transport of the coastal current is found to be significantly less than the river discharge for the entire model simulation. The temporal variability of the freshwater transport is discussed in Section 2.3.4.

In spite of the observed meanders on the circumference of the bulge region, the bulge remains stable for all 21 days of simulation. In fact, none of the conducted model runs exhibits eddy shedding as predicted by Oey and Mellor [1993]. As discussed earlier, it is plausible that the observed instabilities in their modeling study are due to their coarse grid resolution.

The continuous growth of the bulge implies that the unforced river plume is an unsteady phenomenon. This behavior contrasts the assumption of steadiness used in several previous studies of freshwater plumes [Garvine, 1996; Yankovsky and Chapman, 1997; Zhang et al., 1987].

\subsubsection{Coastal current freshwater transport}

Qualitatively, the freshwater transport in the coastal current can be understood by considering a simple representation shown in Figure 2.8. Consider a 2-layer, Margules front system which has a quiescent lower layer and a geostrophic crossshore momentum, i.e.,

$$
v=g \frac{\Delta \rho}{\rho_{0} f} \frac{\partial h}{\partial x}
$$




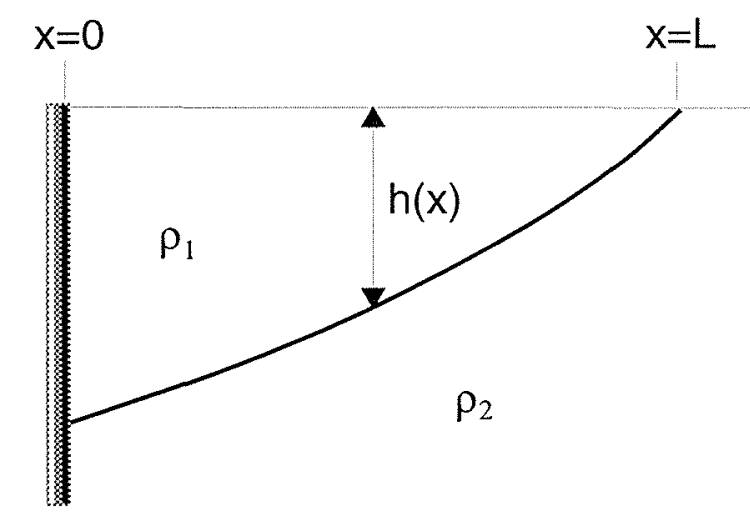

Figure 2.8: Idealized Margules front representation of the coastal current.

where $\Delta \rho=\left(\rho_{2}-\rho_{1}\right)$ is the density difference between the plume and the ambient water, $h$ is the plume thickness, $v$ is the alongshore velocity, $f$ is the Coriolis parameter, $\rho_{0}$ is a ambient density equal to $1025 \mathrm{~kg} / \mathrm{m}^{3}$, and $g$ is the gravitational acceleration.

The transport in the coastal current is,

$$
Q_{c c} \equiv \iint v d A=\int_{0}^{L} v h d x
$$

where $A$ is the cross-sectional area of the plume and $L$ is the plume width. Substitution of (2.1) into (2.2) and integration gives an expression for the geostrophic transport in the coastal current,

$$
Q_{c c}=\frac{g^{\prime}}{2 f}\left(h_{L}^{2}-h_{0}^{2}\right)
$$

where $g^{\prime}$ is the reduced gravity $\left(g \frac{\Delta \rho}{\rho}\right)$ and $h_{0}$ and $h_{L}$ are the plume thickness at the coast and its offshore edge, respectively. If one assumes $h_{L} \ll h_{0}$, then the transport can be estimated by,

$$
Q_{c c}=\frac{g^{\prime}}{2 f}\left(h_{0}^{2}\right)
$$


where the minus sign associated with transport being in the negative $y$ direction has been dropped for convenience. It should be noted that since the density of the plume is only a function of salinity in the numerical experiments, the salinity anomaly is approximately proportional to the density anomaly and hence, $g^{\prime}$ (assuming a linear equation of state, $\Delta \rho=\beta \Delta S$, where $\beta=0.79 \mathrm{~m}^{3} \mathrm{~kg}^{-1} \mathrm{psu}^{-1}$ ).

Similarly, one can derive an expression for the freshwater transport for the Margules front,

$$
Q_{f c c} \equiv \iint v \frac{\Delta S}{S_{0}} d A \approx \frac{\rho_{0}}{g \beta S_{0}} \frac{\left(g^{\prime} h_{0}\right)^{2}}{2 f}
$$

where $\Delta \rho_{0}$ is the ambient water density and again, it has been assumed $h_{L} \ll h_{0}$. Equation (2.5) predicts that for the Margules front the freshwater transport is a function of only $g^{\prime} h_{0}$, the buoyancy of the plume at the coast. This quantity is proportional to the potential energy of the coastal current.

For more complicated salinity structures than a Margules front, the relationship between the plume buoyancy and the freshwater transport remains the same. Namely, for a continuously stratified plume, the freshwater transport in the coastal current depends on $\left(g^{\prime} h_{0}\right)^{2}$, and only the coefficient in front of expression (2.5) is modified and $g^{\prime}$ is based on the depth-averaged density anomaly. For example, for salinity profile that varies linearly with $x$ and $z$ within the plume, $(\Delta S=$ $\Delta S_{0}\left(1-x / L+z / h_{0}\right)$, where $\Delta S_{0}$ is the maximum salinity anomaly within the plume), the factor of one-half in (2.5) is replaced by $1 / 3$. 


\subsubsection{Plume response for different inflow parameters}

In this subsection, the behavior and physics of the base case are tested for a variety of forcing conditions (see Table 2.1).

\section{Potential energy and freshwater transport in the coastal current}

For all the model runs conducted, the freshwater transport in the coastal current shows a consistent dependence on the plume's potential energy at the coast. A linear fit of the observed model freshwater transport as a function of the squared potential energy at the coast $\left(g^{\prime} h_{0}\right)^{2}$ at $\mathrm{t}=5$ days is shown in Figure 2.9. The least squares regression of the model's coastal current freshwater transport

$$
Q_{f c c}=\gamma\left(\frac{\rho_{0}}{g \beta S_{0}}\right) \frac{\left(g^{\prime} h_{0}\right)^{2}}{f}+\sigma
$$

results in $\gamma=0.377$ and $\sigma=61 \mathrm{~m}^{3} / \mathrm{s}$. The fit is excellent $\left(r^{2}=0.94\right)$, consistent with a cross-shore momentum balance that is primarily geostrophic in nature. It should be noted that the conputed y-intercept $\sigma$, does not make sense for small $g^{\prime} h_{0}$. Without any buoyancy, $Q_{f c c}$ should equal zero. The regression is similar for the entire duration of the model runs considered. For a regression which includes all the model runs for $\mathrm{t}=1$ day through $\mathrm{t}=14$ days, the fit is also excellent with $\gamma=0.383$ and $r^{2}=0.98$. As was previously noted, the coefficient $\gamma$ can be interpreted as a "shape factor" related to the details of the salinity distribution within the coastal current. Figure 2.6 shows a typical section within the coastal current. The structure is roughly linear in both the depth and cross-shore directions, consistent with the value of $\gamma=1 / 3$ for linearly varying salinity in $x$ and $z$. 


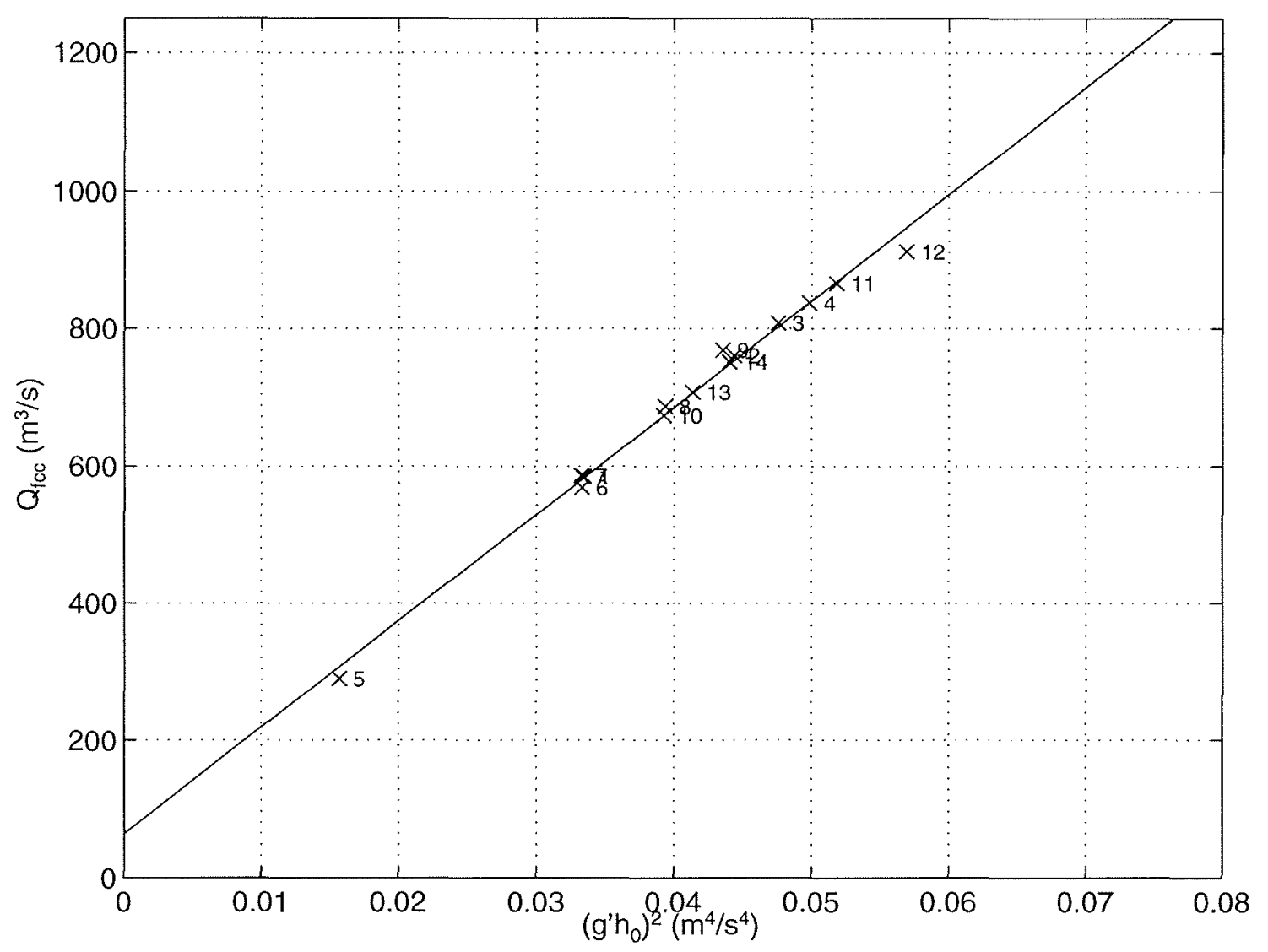

Figure 2.9: Model freshwater transport $Q_{f c c}$ in coastal current at $\mathrm{t}=5$ days, $\mathrm{y}=252$ $\mathrm{km}$, as a function squared potential energy in coastal current. Run numbers are indicated for each data point (see Table 2.2). 


\section{Source conditions and freshwater transport in the coastal current}

For all the model runs conducted, the freshwater transport in the coastal current is less than the fresh water supplied by the river. The amount of this mismatch varies according to the forcing conditions at the river mouth. The variability and dependence of the freshwater transport on the river mouth conditions are discussed below.

It has been previously shown that the coastal current transport is a function of the potential energy in the coastal current. Using the regression computed from equation (2.6), the value of $g^{\prime} h_{0}$ necessary for $Q_{f c c}=Q_{f r}$ is $0.279 \mathrm{~m}^{2} / \mathrm{s}^{2}$. In other words, if the

potential energy in the coastal current (at $x=0$ ) were to equal $0.279 \mathrm{~m}^{2} / \mathrm{s}^{2}$, there would be no mismatch between the coastal current transport of freshwater and the river discharge.

The potential energy for three different model runs $(5,1$, and 11) in which there is a significant variation in the coastal current transport is contoured in Figure 2.10. Also shown in Figure 2.10 are contours of the Bernoulli function which quantifies the total plume energy

$$
B=g^{\prime} h+\frac{\bar{u}^{2}+\bar{v}^{2}}{2}
$$

where $\bar{u}$ and $\bar{v}$ are the depth-averaged plume velocities.

All three model cases shown in Figure 2.10 exhibit similar potential and total energy levels within the bulge. The potential energy $\left(g^{\prime} h\right)$ of some plume water exceeds $0.279 \mathrm{~m}^{2} / \mathrm{s}^{2}$, and significant portions of the plume have total energies $(B)$ larger $0.279 \mathrm{~m}^{2} / \mathrm{s}^{2}$. The distribution of the potential energy $\left(g^{\prime} h\right)$, however, differs substantially for the runs. The highest potential energy water in Run 5 is contained 

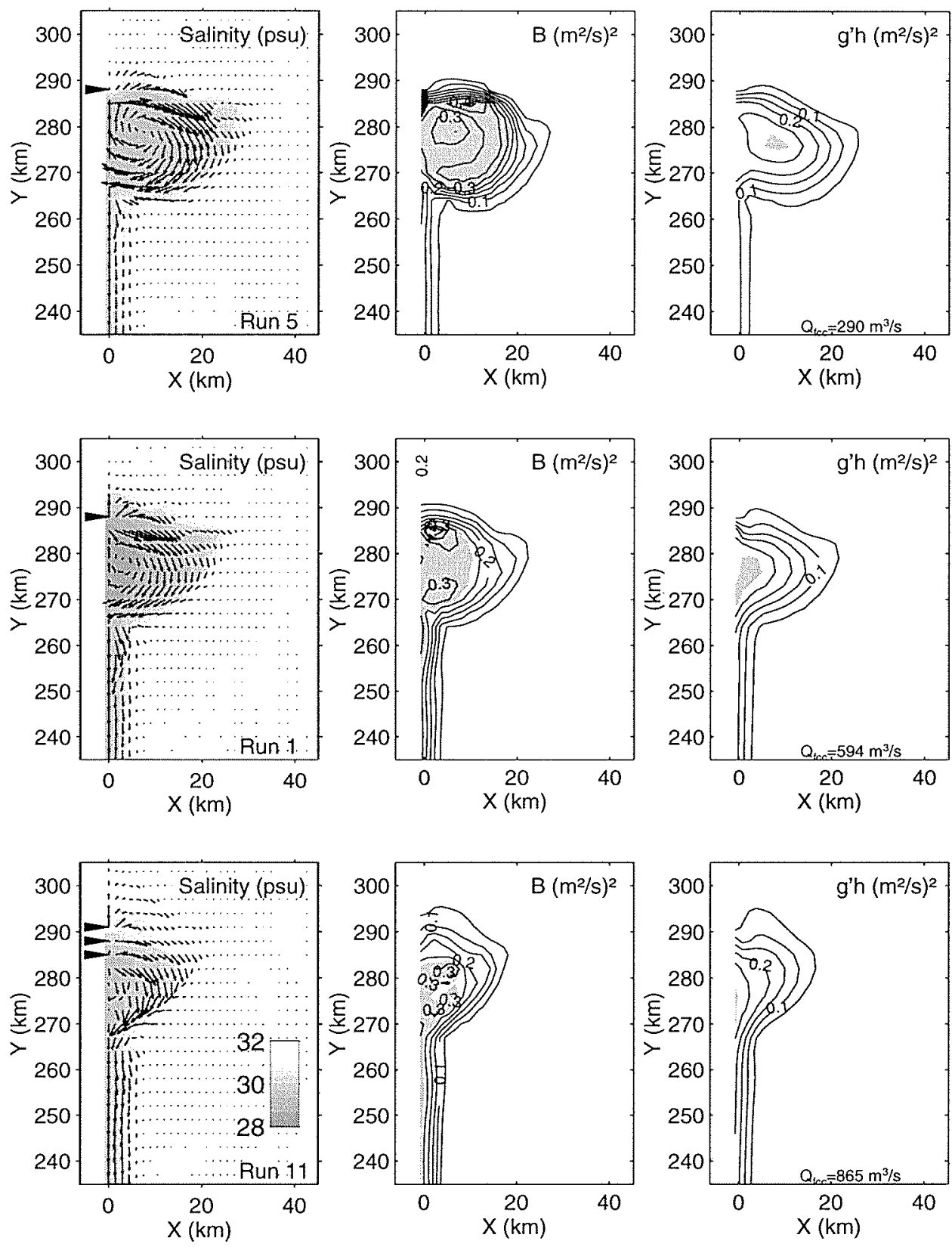

Figure 2.10: Bulge behavior for different Froude number conditions. The surface salinity and velocity; Bernoulli function $B$; and potential energy $g^{\prime} h$ are plotted for Runs 5,1 , and 11. Shaded regions in the panels plotting $B$ and $g^{\prime} h$ indicate regions of $B$ and $g^{\prime} h>0.279 \mathrm{~m}^{2} / \mathrm{s}^{2}$. Contours of $B$ and $g^{\prime} h$ are in intervals of $0.05 \mathrm{~m}^{2} / \mathrm{s}^{2}$. The coastal current transport at $\mathrm{y}=252 \mathrm{~km}$ is shown in the lower-right of the $g^{\prime} h$ contours. 
in the center of the recirculating bulge. Only weaker potential energy fluid $\left(g^{\prime} h<\right.$ $0.15 \mathrm{~m}^{2} / \mathrm{s}^{2}$ ) makes its way into the coastal current. The $g^{\prime} h$ distribution for Run 11 , which has a wide river mouth and weaker inflow velocities, is very different. The maximum potential energy water is adjacent to the coast and the coastal current contains water of $g^{\prime} h>0.2 \mathrm{~m}^{2} / \mathrm{s}^{2}$.

The Bernoulli function distributions shown in Figure 2.10 indicate that for all three model runs, a large fraction of the plume water is of sufficient energy for $Q_{f c c}$ to match $Q_{f r}$ (assuming all or most of the kinetic energy $\left(\frac{\bar{u}^{2}+\bar{v}^{2}}{2}\right)$ could be converted into potential energy $\left(g^{\prime} h\right)$ ). The variability in $Q_{f c c}$ observed between the different runs is not due to a lack of energy in the river discharge. Instead, $Q_{f c c}$ is determined by the distribution of energy in the bulge and subsequently, the energy of the water entering the coastal current.

Corresponding with the variability in coastal current potential energy are distinct changes in bulge shape between the different model runs. When the coastal current is weak, the bulge is circular in shape, resembling the flow field observed for an anticyclonic eddy (Run 5, Figure 2.10). In contrast, the bulge for the higher transport cases exhibits a semi-circular shape (Figure 2.10, Run 11).

The shape of the bulge and the freshwater transport in the coastal current are found to depend mainly on the velocity of the inflow and the width of the river mouth (Table 2.2). High velocity and narrow river mouth discharges have weaker coastal currents. The Rossby number, $R o=\frac{u_{r}}{f L_{r}}$ characterizes the shape of the bulge and the magnitude of the coastal current transport. The dependence of the coastal current transport on Ro is shown in Figure 2.11. Two runs (Runs 15 and 16) in addition to those listed in Tables 2.1 and 2.2 are included in Figure 2.11. Runs 15 


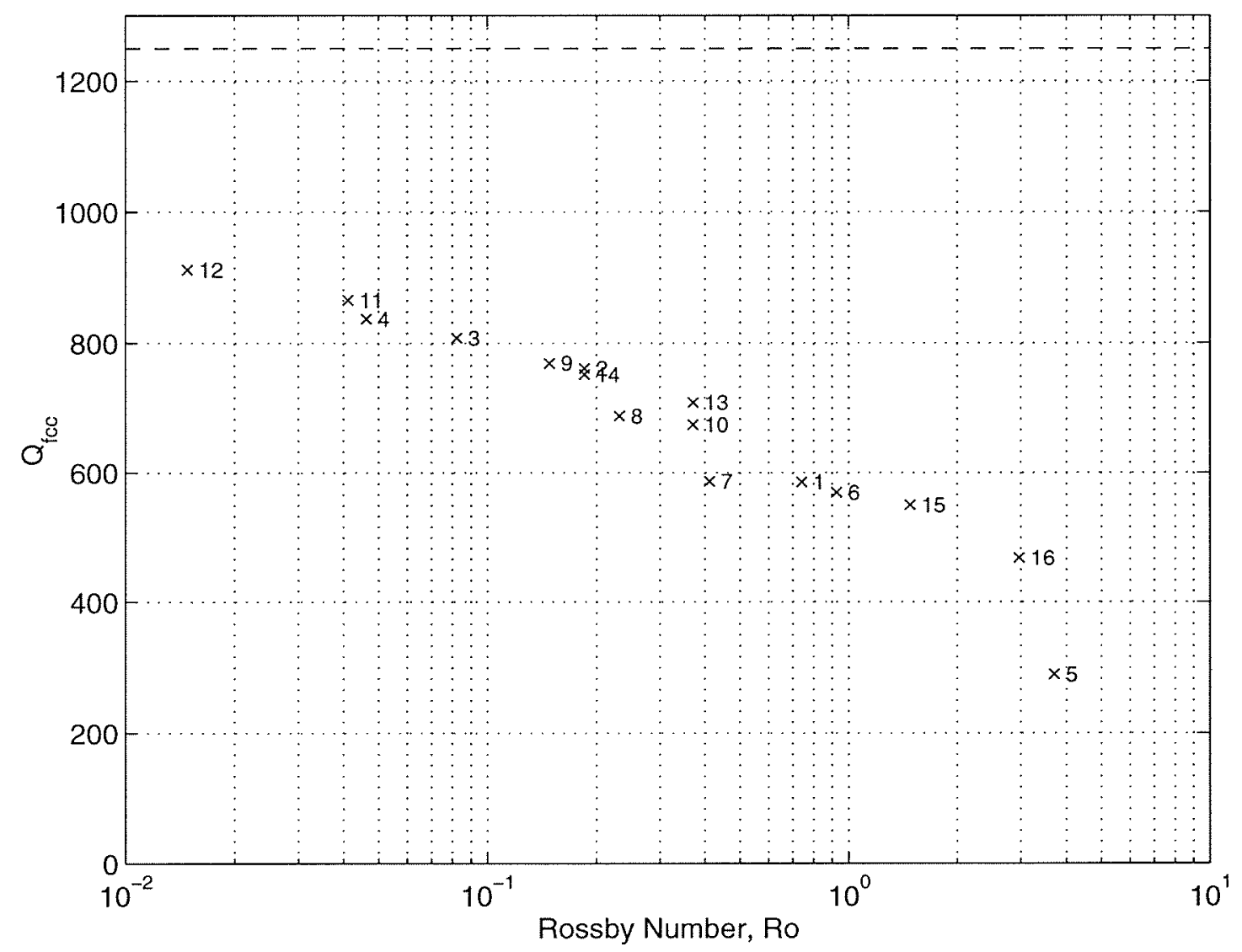

Figure 2.11: Freshwater transport $\left(\mathrm{m}^{3} / \mathrm{s}\right)$ as a function of Rossby number at $\mathrm{t}=5$ days, $\mathrm{y}=252 \mathrm{~km}$. For Runs 15 and 16 , the transport is calculated at $\mathrm{y}=232$, an alongshore position outside of the bulge. The dashed line indicates the freshwater discharge rate at the river mouth. 
Table 2.2. Summary of freshwater transport at $\mathrm{t}=5$ days, $\mathrm{y}=252 \mathrm{~km}$ for different model runs presented in Section 2.3. The Rossby number, $R o=\frac{u_{r}}{f L_{r}}$ is shown.

\begin{tabular}{ccccc}
\hline $\begin{array}{c}\text { Run } \\
\text { No. }\end{array}$ & $\begin{array}{c}L_{r} \\
(\mathrm{~km})\end{array}$ & $\begin{array}{c}u_{r} \\
(\mathrm{~m} / \mathrm{s})\end{array}$ & Ro & $\begin{array}{c}Q_{f c c} \\
\left(\mathrm{~m}^{3} / \mathrm{s}\right)\end{array}$ \\
\hline 1 & 3 & 0.22 & 0.74 & 594 \\
2 & 6 & 0.11 & 0.19 & 761 \\
3 & 9 & 0.07 & 0.08 & 808 \\
4 & 12 & 0.06 & 0.04 & 838 \\
5 & 3 & 1.11 & 3.70 & 290 \\
6 & 6 & 0.56 & 0.93 & 570 \\
7 & 9 & 0.37 & 0.41 & 587 \\
8 & 12 & 0.28 & 0.23 & 687 \\
9 & 15 & 0.22 & 0.15 & 769 \\
10 & 3 & 0.11 & 0.37 & 675 \\
11 & 9 & 0.04 & 0.04 & 865 \\
12 & 15 & 0.02 & 0.01 & 913 \\
13 & 3 & 0.11 & 0.37 & 708 \\
14 & 3 & 0.06 & 0.19 & 752 \\
\hline
\end{tabular}

and 16 have the same river mouth conditions as the base case (Run 1). The Coriolis parameter $f$ is, however, reduced to $0.5 \times 10^{-4} \mathrm{~s}^{-1}$ and $0.25 \times 10^{-4} \mathrm{~s}^{-1}$, respectively. The freshwater transport for these two runs is computed further downstream $(y=232$ $\mathrm{km})$ than for Runs 1-14 $(y=252 \mathrm{~km})$, since the alongshore bulge extent is greater. Both alongshore positions used for the calculation are chosen such that they are downstream of the bulge and there is negligible alongshore variability in freshwater transport $\left(<10 \mathrm{~m}^{3} /(\mathrm{km} \mathrm{s})\right)$.

The linear regression of Ro with $Q_{f c c}$ is statistically significant to the $99 \%$ confidence interval $\left(r^{2}=0.79\right)$. The low $R o$ model runs have larger coastal current transports than the high $R o$ cases. Furthermore, the bulge shape is qualitatively correlated with the Rossby number (Figure 2.12). The bulge is more circular for high Rossby number discharges (i.e., the center of the bulge is further offshore) and 

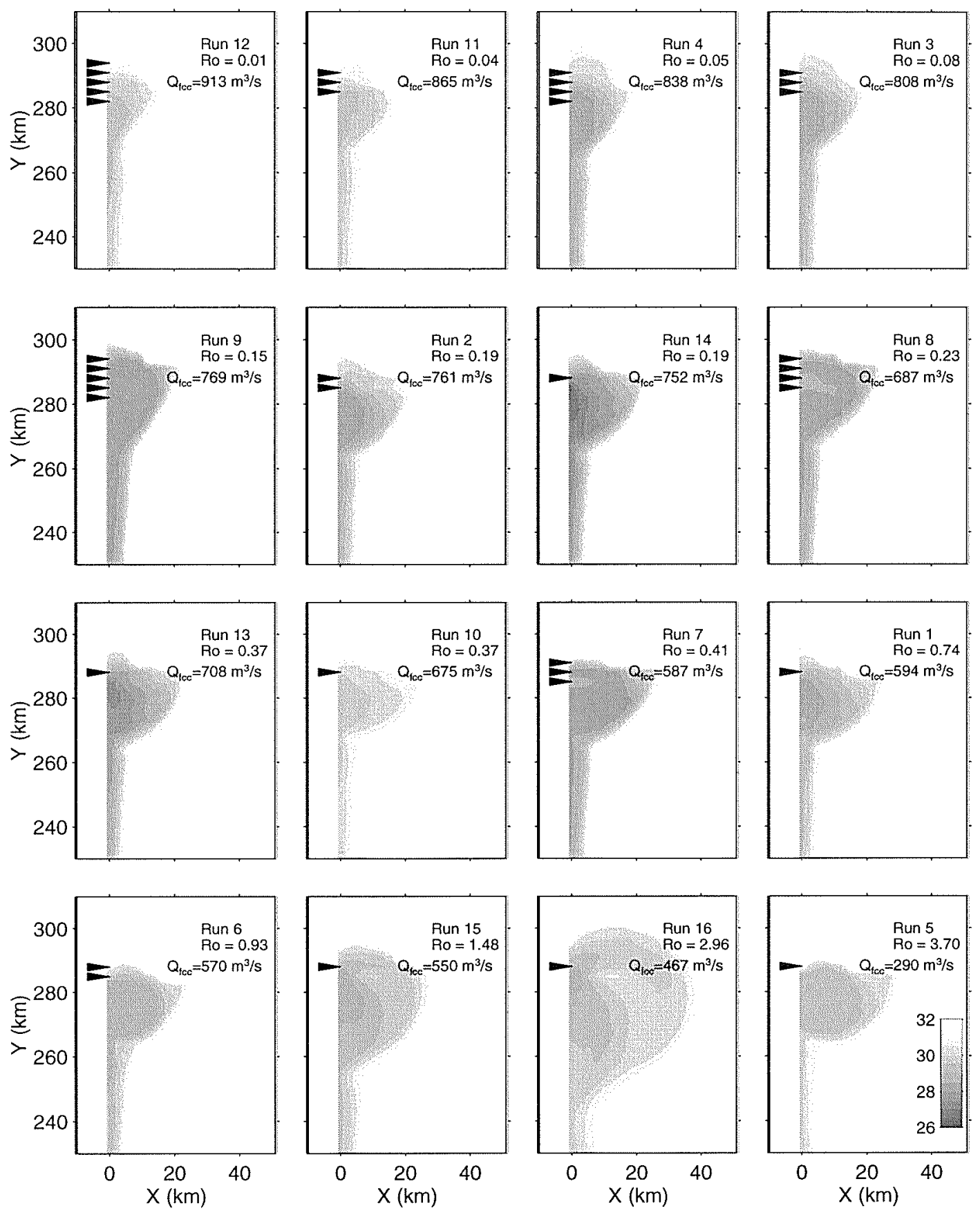

Figure 2.12: Surface salinity at $t=5$ days for different Rossby number conditions are shown in gray. The location of the river mouth (and river mouth widths) are indicated by the arrows. The width of the river mouth is the number of arrows times $3 \mathrm{~km}$ (e.g., the River mouth is $15 \mathrm{~km}$ wide for Run 12) The Rossby number and the freshwater transport in the coastal current (at $y=252 \mathrm{~km}$ for Runs 1-14 and $y=232 \mathrm{~km}$ for Runs 15 and 16) is shown in each panel. 
semi-circular in shape for low Ro discharges (i.e., the center of the bulge is closer to shore). It should be noted that the width of the plume bulge is much larger for Runs 15 and 16 where the Coriolis parameter has been reduced. The total fresh water volume in Runs 15 and 16, is however, comparable to the other runs; the plume is just thinnger for the cases of weaker rotation.

The dependence of the bulge shape on the Rossby number suggests that the ratio of inertial length scale $\left(u_{r} / f\right)$ and the river mouth width $\left(L_{r}\right)$ sets the trajectory of the river discharge and the shape of the bulge. The offshore bulge extent appears to scale with the inertial length scale, but its alongshore bulge extent is related to the width of the river mouth. The larger the Rossby number, the larger the offshore dimension relative to the alongshore scale. The further offshore the center of the bulge is, the smaller coastal pressure anomaly, and the smaller the quantity of fluid intercepted by the coastal current (Figure 2.10).

The correlation between the shape of the bulge and mismatch between the freshwater transport of the coastal current and the discharge at the river mouth is related to a study by Nof [1988] of a baroclinic eddy colliding with a wall. He uses a nonlinear, layered, analytic model to determine how an eddy interacts with a wall. In the case where only the outer edge of the eddy interacts with the wall, Nof [1988] finds there is a weak flow leakage from the eddy. When the eddy is closer to the wall, the flow leakage is larger. The leaked fluid is analogous to the coastal current in the plume, and the baroclinic eddy is similar to the plume bulge (Figure 2.13). When the bulge is semi-circular, the freshwater transport in the coastal current is fairly large. This is similar to the case of large wall penetration into the eddy, which results in significant fluid leakage. In comparison, a circular bulge (small wall penetration) coincides with a weak coastal current transport (little fluid leakage). 


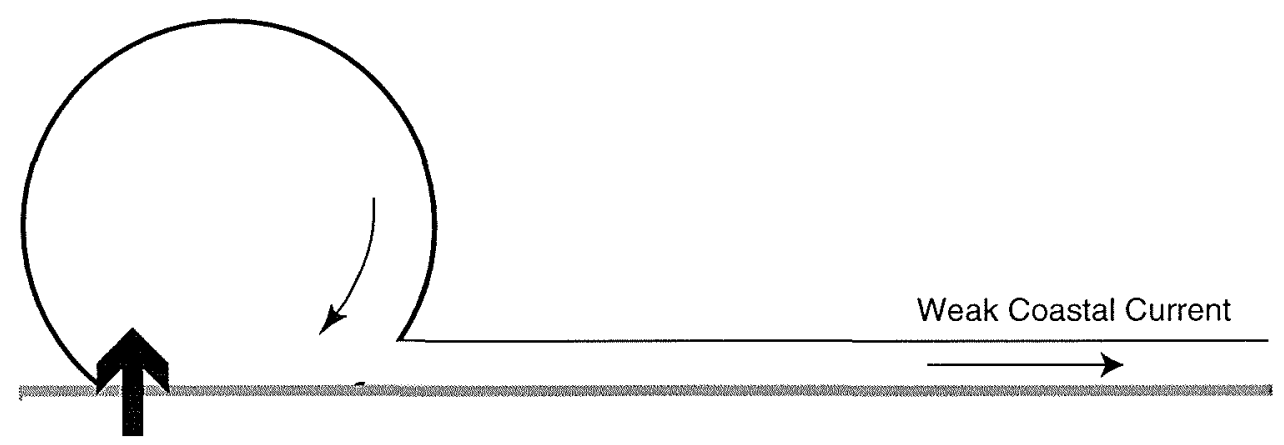

\section{High Ro discharge conditions}

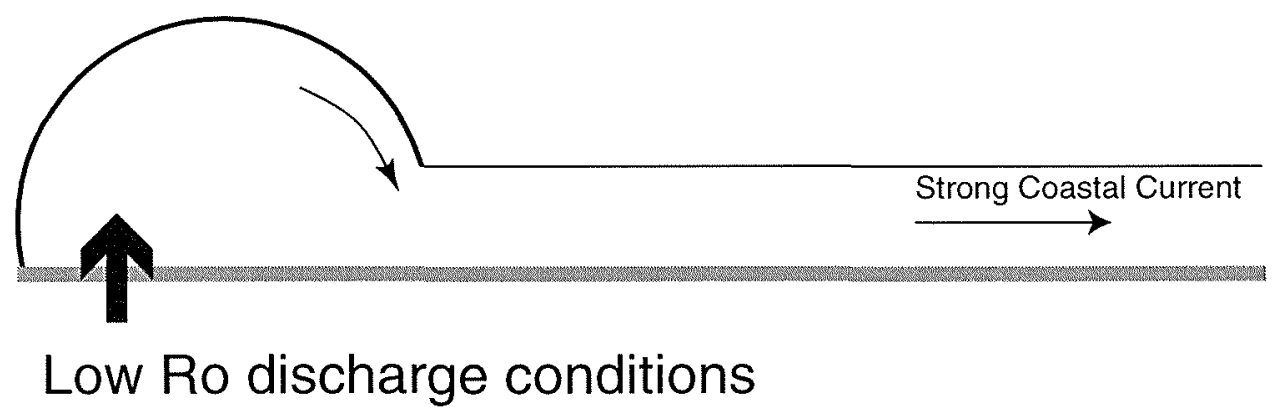

Figure 2.13: Eddy/bulge leakage cartoon. For high $F r$ and high Ro discharges, the bulge is nearly circular and the freshwater transport in the coastal current is weak. For low $\mathrm{Fr}$ and low Ro discharges, the bulge is semi-circular and the freshwater transport in the coastal current is stronger. 
For the plume problem, the Ro, based on the outflow conditions at the river mouth, sets the amount of the eddy "sliced off" by the coastal wall. For high Ro, most of the eddy remains intact and the bulge is nearly circular in shape; for low Ro, the eddy is nearly sliced in half (Figure 2.10, Run 11) and the bulge is semi-circular.

As a consequence, for high Ro conditions, the high potential energy water from the river discharge is trapped in the center of bulge as opposed to the low Ro runs where the higher potential energy water is adjacent to the coast. For the latter cases, some of the higher potential energy fluid enters the coastal current and the freshwater transports are higher.

Garvine [1995] suggests the Kelvin number, the ratio of the river mouth width and the baroclinic Rossby radius, as the important parameter for dynamical classification of plumes. While there appears to be some suggestion of larger freshwater transport for larger Kelvin number discharges, the correlation is not statistically significant.

\subsubsection{Temporal variations in freshwater transport}

As mentioned earlier, the difference in coastal current transport and source discharge varies in time. These fluctuations are coincident with temporal variations in both the plume thickness and density anomaly in the coastal current. Time series of the plume thickness $h_{0}$ and mean reduced gravity $g^{\prime}$ in the coastal current at $x=0$ $\mathrm{km}$ (the coastal wall) and $y=230 \mathrm{~km}$ are plotted in Figure 2.14. (The alongshore position $y=230 \mathrm{~km}$ is chosen so that it is downstream of the bulge for all 30 days of the model simulations.) It also should be noted that after $\mathrm{t}=20$ days, the bulge width approaches the cross-shore width of the basin; hence, there may be some interactions between the offshore boundary and the bulge. 

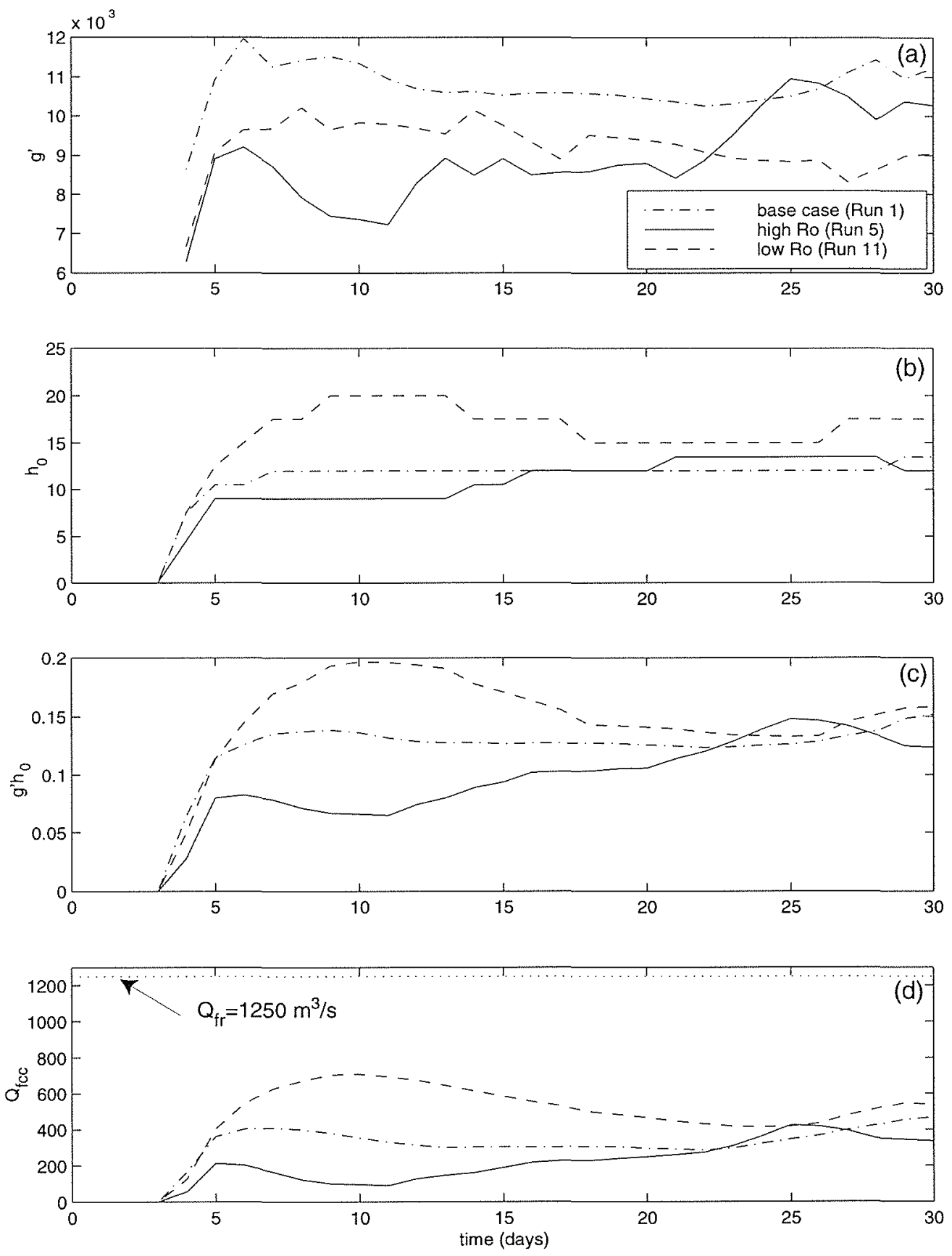

Figure 2.14: Temporal variations in the coastal current at $\mathrm{y}=230 \mathrm{~km}$. (a) $g^{\prime}$, (b) $h_{0}$ (c) $g^{\prime} h_{0}(\mathrm{~d}) Q_{f c c}$. 
Temporal variations in plume thickness and density anomaly are observed for each of the model runs. These variations result in changes in the potential energy in the coastal current, and hence, temporal variations in freshwater transport in the coastal current (Figure 2.14). It is worth mentioning that since the freshwater transport is dependent on the square of the potential energy in the coastal current, small fluctuations in either the density anomaly or plume thickness in the coastal current can result in appreciable changes in coastal current transport. For the model runs conducted, the freshwater transport in the coastal current does not necessarily attain a steady-state value. One potential source of the variability in the coastal current properties may be the unsteady flow field observed at the circumference of the bulge. It is unclear what exact dynamics control the unsteadiness of the bulge flow field. This problem is beyond the scope of this study.

Nevertheless, in spite of the temporal fluctuations in $Q_{f c c}$, for all the durations over which the different model runs are conducted, the freshwater transport in the coastal current is observed to be in significant deficit with the freshwater supplied by the river. Corresponding with this mismatch is a bulge that grows in time for all the model simulations (Figure 2.15). If the mismatch in transports were constant, and the bulge circular with constant thickness, then one would expect the bulge width to be proportional to the square root of time $t$. The bulge widths for the different runs shown in Figure 2.15 are roughly proportional to $t^{1 / 2}$.

\subsection{The influence of an ambient flow field}

In this section, the influence of an ambient flow on the freshwater transport and salinity distribution is considered. Based on the observation that most ambient 


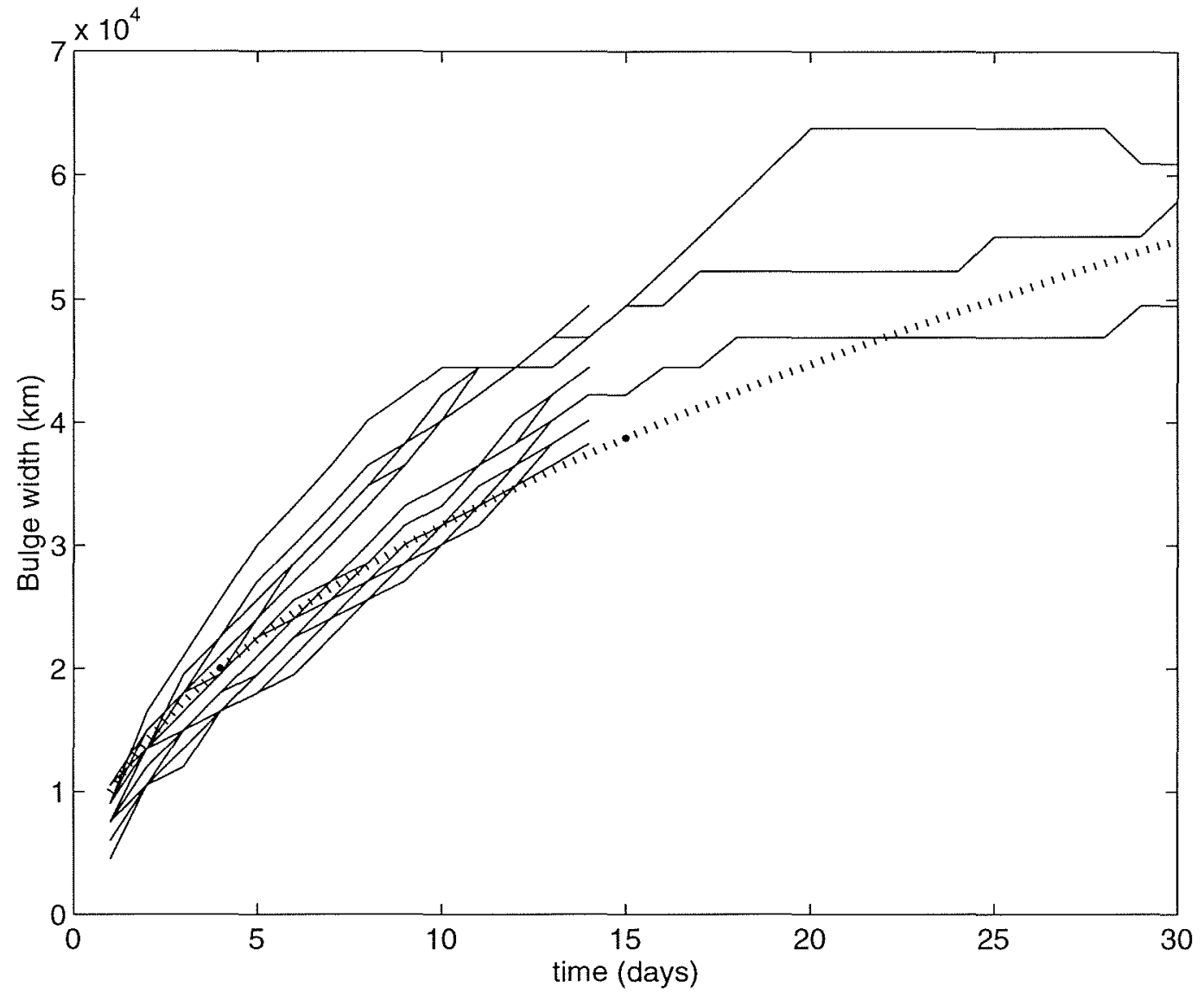

Figure 2.15: Bulge width (defined by the position of the 31.5 psu isohaline) as a function of time for different model runs. The bulge width is approximately proportional to the square root of time for the different model runs (the dotted line denotes a $t^{1 / 2}$ dependence). Note: Bulge widths for $\mathrm{t}>20$ days may not be accurate due to interactions of the bulge with the offshore boundary of the model domain. 
(barotropic) currents in nature are alongshore, in the direction of Kelvin wave propagation [Chapman and Lentz, 1997; Loder et al., 1998], this section only considers ambient flows of this orientation.

The addition of a moderate amplitude ambient flow field dramatically alters plume behavior. For a $10 \mathrm{~cm} / \mathrm{s}$ ambient current in the same direction as Kelvin wave propagation (all other parameters identical to the base run), the bulge is distorted (Figure 2.16) from the structure observed in the unforced case (Figure 2.5). In the presence of an ambient flow, the bulge does not grow offshore indefinitely. For the $10 \mathrm{~cm} / \mathrm{s}$ ambient flow field, the bulge reaches a maximum offshore width after approximately four days and stops growing offshore. For later time, the bulge expands only in the downstream direction.

The finite offshore growth of the bulge is a consequence of the ambient flow field augmenting the freshwater transport within the bulge. As the bulge grows larger (i.e., greater area in the cross-shore/vertical plane), the effect of the ambient current increases. The offshore bulge growth shuts down when the bulge is sufficiently large that the advection of the bulge by the ambient current can augment the freshwater transport where it equals the fresh water discharged at the river mouth (Figure 2.17).

After the bulge stops growing offshore, it is advected downstream by the ambient current. For any alongshore location within the bulge, the freshwater transport equals the freshwater discharged by the river. For the model run shown in Figure 2.16 , the bulge is advected past $\mathrm{y}=252 \mathrm{~km}$ after approximately seven days. For times greater than seven days, the alongshore freshwater transport matches the river discharge (Figures 2.16 and 2.17). 
Surface Salinity (psu)
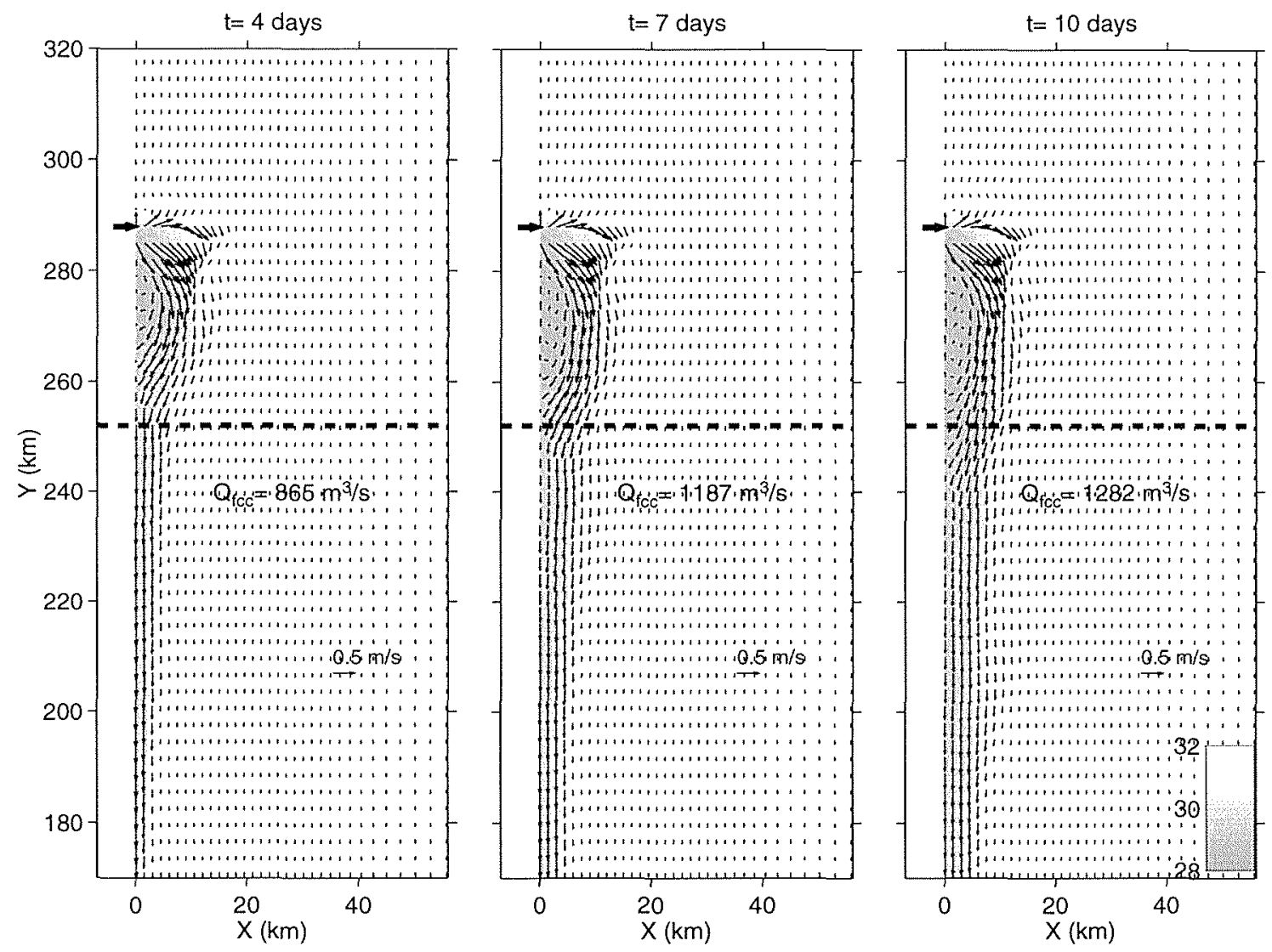

Figure 2.16: Surface salinity (psu) indicated by gray shading for Base Case model run (Run 1) with an ambient current of $10 \mathrm{~cm} / \mathrm{s}(\mathrm{t}=4,7,10$ days). Velocity vectors are superimposed to indicate the flow field. Freshwater transport is measure at $\mathrm{y}=252 \mathrm{~km}$ (indicated by dashed line). River mouth location is indicated by bold arrow. 


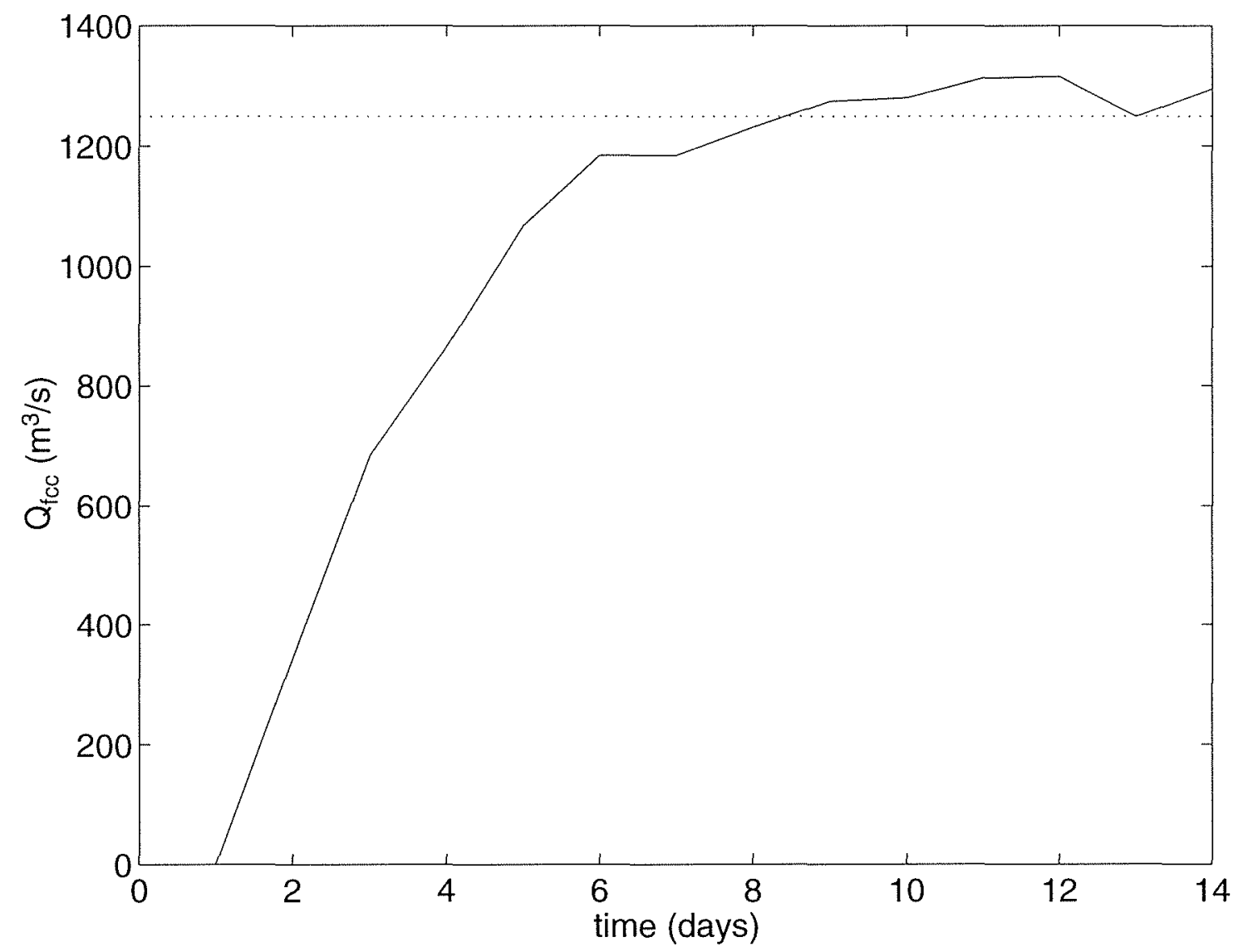

Figure 2.17: Freshwater transport $\left(\mathrm{m}^{3} / \mathrm{s}\right)$ as a function of time at $\mathrm{y}=252 \mathrm{~km}$ for same parameters as Base Case plus an ambient flow field of $10 \mathrm{~cm} / \mathrm{s}$ southward. The dotted line indicates the freshwater discharged by the river: $1250 \mathrm{~m}^{3} / \mathrm{s}$. 
The steady-state width of the plume is a feature for any nonzero ambient flow field (in the same direction as Kelvin wave propagation) (Figure 2.18a). The plume width is roughly proportional to $1 / v_{a m b}$ (shown with the dotted line in Figure 2.18). This propotionality is consistent with the ultimate bulge width being set by the crosssectional plume area necessary to offset mismatch between $Q_{f c c}$ (for the $v_{a} m b=0$ case) and $Q_{f r}$ (i.e., $v_{a m b} h L=$ constant, where $h$ is the depth scale of the plume and $L$ is the plume width).

For weaker ambient flows, the time to reach steady-state width is longer and the maximum plume width is larger than for stronger ambient currents. Even for an ambient current as small as $1 \mathrm{~cm} / \mathrm{s}$, the plume eventually reaches a steady state width (after about 17 days). For large ambient flows $(>20 \mathrm{~cm} / \mathrm{s})$, the steadystate plume width is reached in less than 2 days (Figure 2.19). The subsequent downstream bulge growth occurs at a rate approximately equal to the velocity of the ambient current. For example, the bulge expands downstream at approximately $10 \mathrm{~cm} / \mathrm{s}$ for $\mathrm{t} \geq 4$ days for the model run with a $10 \mathrm{~cm} / \mathrm{s}$ ambient flow (Figure 2.19). The plume behavior demonstrated here explains Yankovsky and Chapman's [1997] surface-trapped plume simulation (their Figure 10) which is not precisely circular, as is assumed in their theory. The distorted nature of their bulge is a consequence of the ambient flow field of $4 \mathrm{~cm} / \mathrm{s}$ that was imposed.

The freshwater transport in the bulge approximately matches the river discharge for all ambient flows considered. The freshwater transport at $\mathrm{y}=252 \mathrm{~km}$ for a wide range of ambient flow strengths is shown in Figure 2.20. The observed freshwater transport for all ambient currents is comparable to the zero ambient current case until the bulge is advected past $\mathrm{y}=252 \mathrm{~km}$. After the bulge has grown past this alongshore location, the measured freshwater transport matches the freshwater 
(a) Steady-state plume width

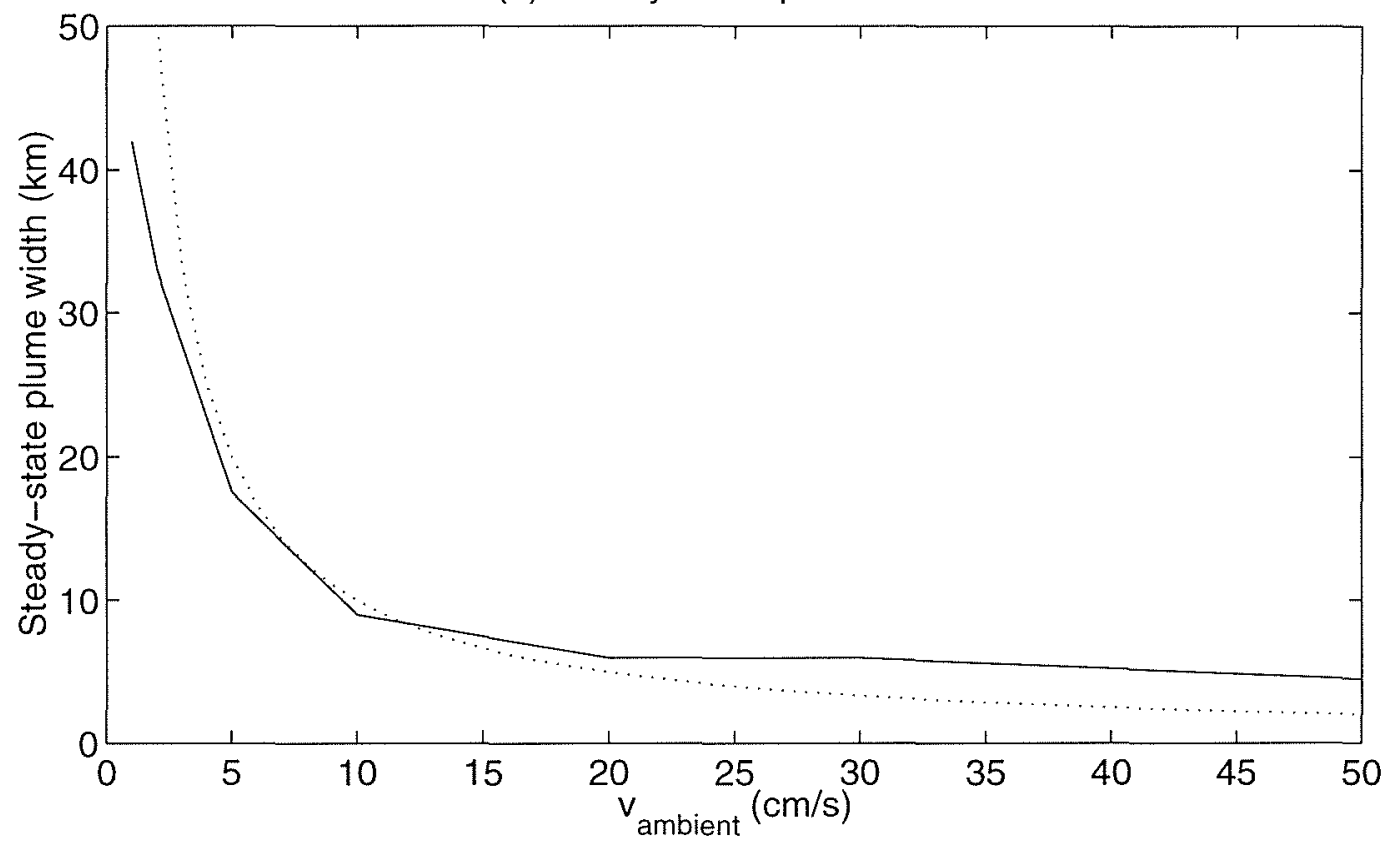

(b) Time to steady-state plume width

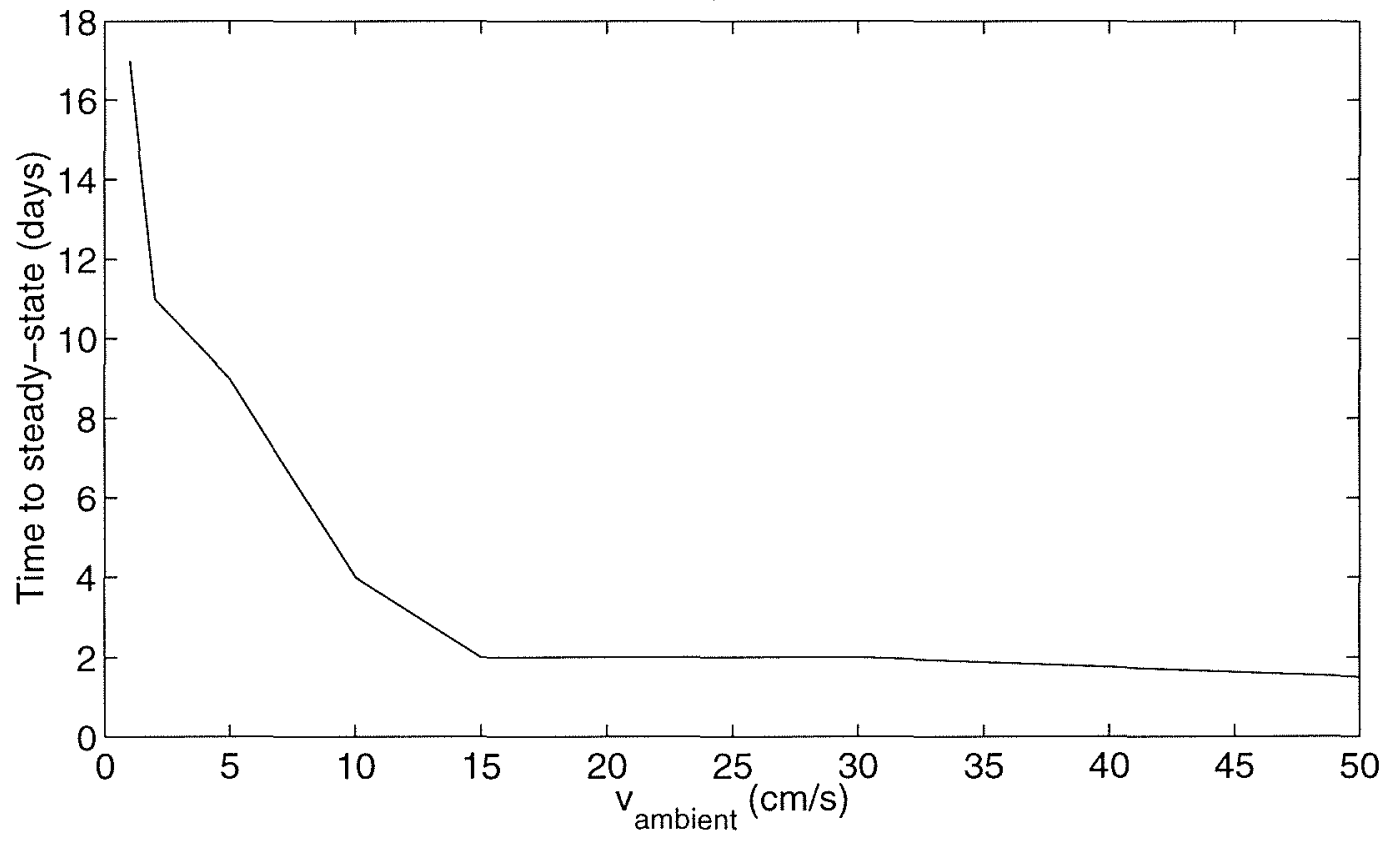

Figure 2.18: Steady state plume width for Base model run with a range of $v_{a} m b$.(a) Steady state plume width (the dotted line indicates a $1 / v_{a m b}$ dependence), and (b) Time to reach steady-state plume width as a function of ambient flow strength. 

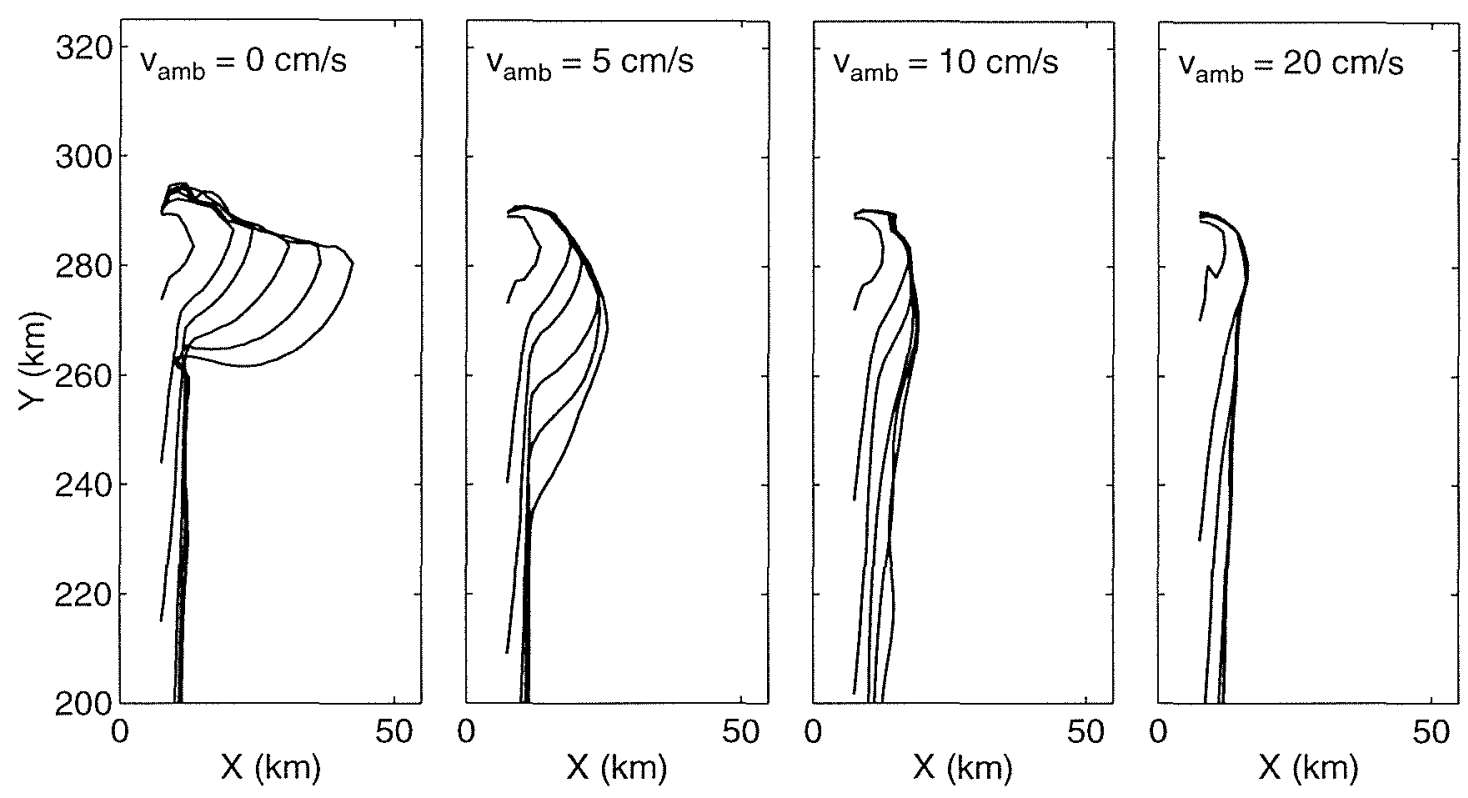

Figure 2.19: Traces of 31 psu isohaline at plume surface $(z=0)$ for Base case with different ambient flow fields. Traces are for $t=1,3,5,7$, and 9 days.

discharge at the river mouth.

The influence of an ambient current on the freshwater transport in the plume can be interpreted as a nearly linear superposition of a barotropic current and the baroclinically-induced current associated with the buoyancy of the plume. If the flow field is assumed to be geostrophic, the freshwater transport can be decomposed into its barotropic and baroclinic components,

$$
Q_{f c c}=\underbrace{\iint v_{b t} \frac{\Delta S}{S_{0}} d A}_{\text {barotropic transport }}+\underbrace{\iint v_{b c} \frac{\Delta S}{S_{0}} d A}_{\text {baroclinic transport }}
$$

where $v_{b c}$ is the baroclinic velocity and $v_{b t}$ is the barotropic velocity. The barotropic velocity is defined as the mean velocity beneath the plume and is similar in amplitude to the imposed ambient flow strength. The baroclinic velocity (equivalent to $v$ in equation (2.2)) is the flow field induced by the cross-shore salinity gradients within the plume; $v_{b c}$ is assumed to vanish beneath the plume. 


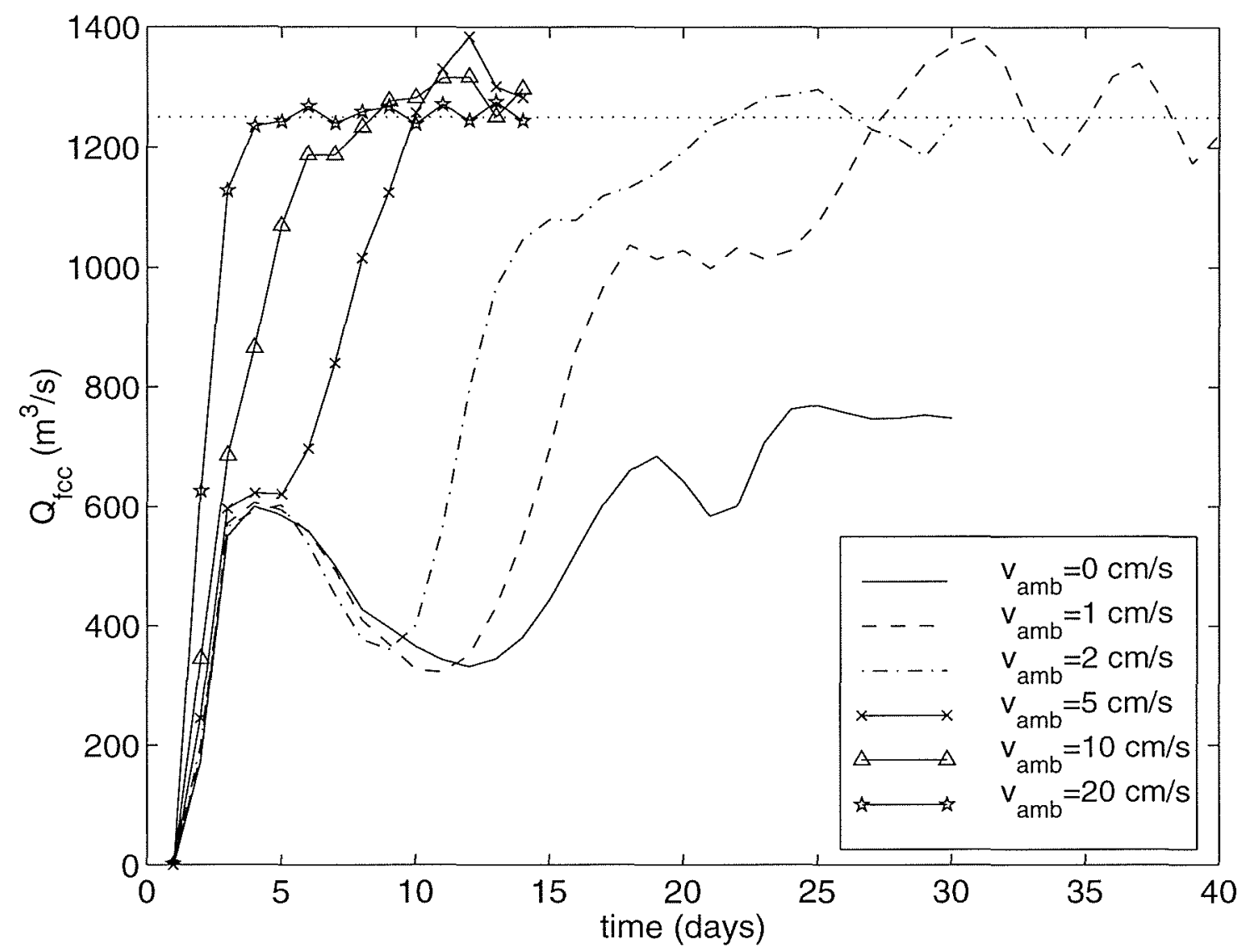

Figure 2.20: Freshwater transport as a function of time for different ambient flows at $\mathrm{y}=252 \mathrm{~km}$. The dotted line indicates the freshwater discharged by the river: 1250 $\mathrm{m}^{3} / \mathrm{s}$. 
Decomposition of the transport between its barotropic and baroclinic components shows that the baroclinic transport is largely independent of the amplitude of the ambient flow field (Figure 2.21). The barotropic transport approaches its "steadystate contribution" in a much shorter time period for stronger ambient flows. After five days, all model runs greater than $15 \mathrm{~cm} / \mathrm{s}$ have reached a steady-state freshwater transport which matches the river discharge at $\mathrm{y}=252 \mathrm{~km}$. The barotropic transport (at $\mathrm{y}=252 \mathrm{~km}$ ) associated with the ambient flow accounts for over half the fresh water transported by the coastal current for all the ambient flows considered.

The model runs suggest that the discrepancy between the observed plumes and those simulated in previous modeling studies may largely be accounted for by an ambient current in the direction of Kelvin wave propagation that advects the bulge along the coast. Although the model runs presented here do not include the influence of winds or tidal forcing, it is expected that the ambient flow will have an order one effect on the geometry of the salinity distribution associated with the plume. For the Chesapeake plume's surface salinity distribution shown in Figure 2.2 , there is a corresponding southwestward ambient flow field of $0(10-15) \mathrm{cm} / \mathrm{s}$ (inferred from Boicourt [1973]). It is likely that the nearly uniform plume width observed just downcoast of the Chesapeake is explained by the prevailing ambient currents distorting and advecting the bulge in the alongshore direction.

Notwithstanding the Chesapeake hydrography, there are very few large-scale surveys of surface-trapped plumes. Nevertheless, those that exist are consistent with the paradigm of an ambient flow field distorting the bulge so that it exhibits a large region of uniform width. For example, Sanders [University of Delaware, pers. comm.] has observed a roughly uniform plume width up to $100 \mathrm{~km}$ downstream of the Delaware River mouth. Typical ambient currents for this coastal region are 


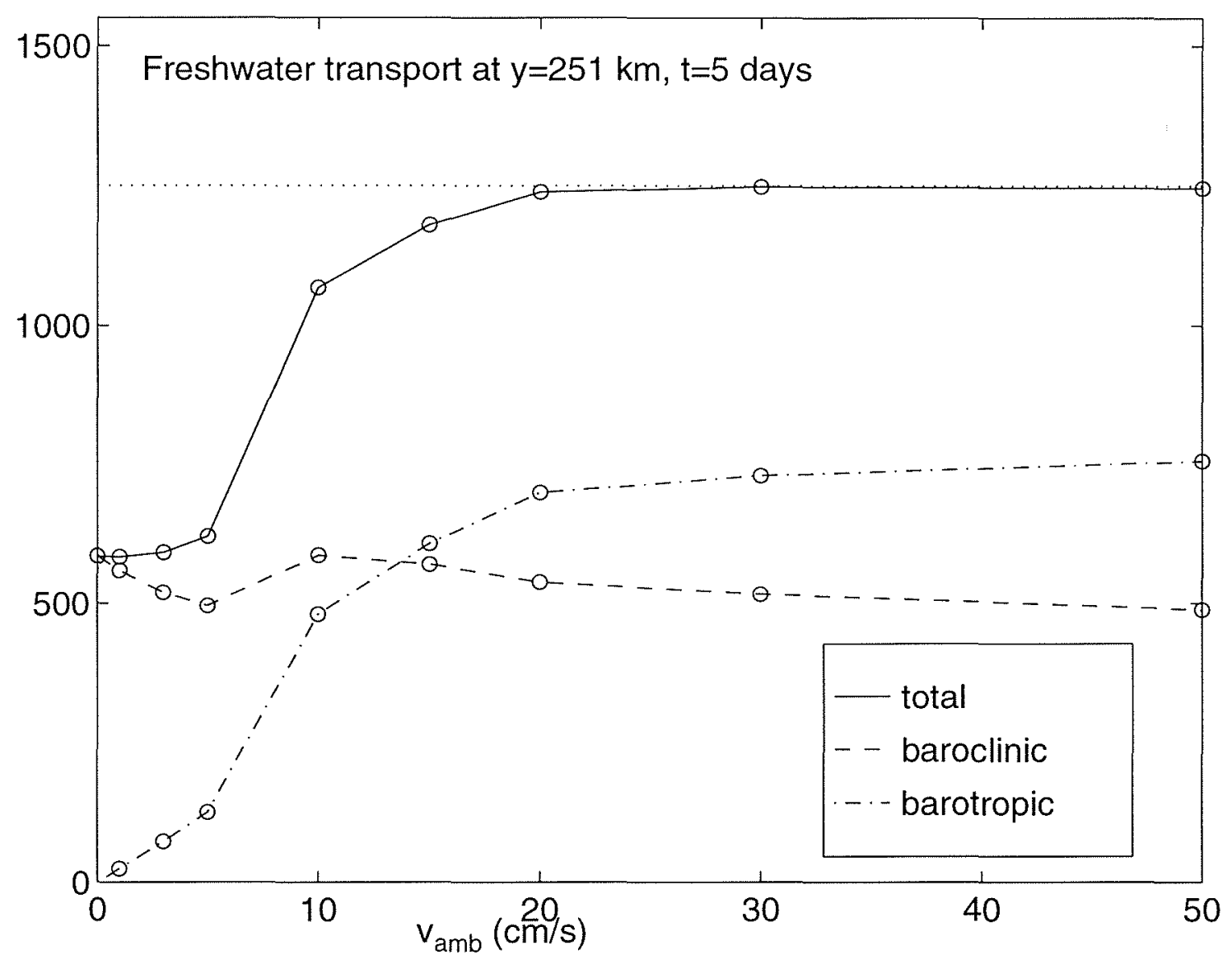

Figure 2.21: Freshwater transport as a function of ambient flow field strength at $\mathrm{y}=252 \mathrm{~km}$ at $\mathrm{t}=5$ days. The baroclinic transport is plotted with a dashed line; the barotropic transport is plotted with a dash-dot line; and the sum is plotted with a solid line. The dotted line indicates the rate of freshwater discharge by the river, $1250 \mathrm{~m}^{3} / \mathrm{s}$. 
$\mathrm{O}(10) \mathrm{cm} / \mathrm{s}$ in the downstream direction [Münchow and Garvine, 1993a]. Likewise, recent observations by Geyer et al. [1998] of the Gulf of Maine plume also show a uniformly wide plume during several hydrographic surveys. For this plume system, the ambient currents range from $5-15 \mathrm{~cm} / \mathrm{s}$ in the downstream direction. Ambient currents in the direction of Kelvin wave propagation are ubiquitous features of continental shelves [Beardsley and Boicourt, 1981; Brink et al., 1980; Kundu and Allen, 1976]. It has been suggested that they are the result of a rectification of coastally-trapped waves [Brink, 1986; Haidvogel and Brink, 1986; Holloway et al., 1989], although there have not been any observations which verify this theory.

In their discussion of plume dynamics that promote the transport of plume water in the direction opposing Kelvin wave propagation, McCreary et al. [1997] note that observed plumes flow predominantly in the direction of Kelvin wave propagation and spread offshore. It is likely that if the upstream propagation mechanism they discuss exists in nature, it is probably masked by the prevailing ambient currents. For the less common case of ambient flow fields in the direction opposing Kelvin wave propagation, some plume growth is expected in the direction of these opposing currents. Hickey et al. [1998] observe upstream plume growth for the Columbia plume in the presence of "adverse" ambient currents. Likewise, for the Amazon plume where rotation is less important, an adverse ambient current is effective at pushing plume waters upstream [Lentz and Limeburner, 1995]. Recent observations of the Chesapeake plume, under weak wind and ambient flow field conditions $(<5 \mathrm{~cm} / \mathrm{s})$, exhibit a distinct bulge and downstream coastal current which is approximately half as wide as the bulge [Boicourt, University of Maryland, pers. comm.]. 


\subsection{Summary}

This study has shown that in the absence of an ambient flow field, a surface-trapped river plume will develop a bulge. The bulge is consistent with the coastal current not transporting the entire fresh water volume input by the river. For the model runs considered, the bulge continues to grow and the plume does not reach a steady-state.

The freshwater transport is determined by the potential energy of the coastal current at the coastal wall. More energetic coastal currents are capable of transporting larger fractions of the discharged fresh water. The potential energy in the coastal current, and hence the the freshwater transport, is found to be principally dependent on the Rossby number associated with the river discharge. The mechanism controlling the magnitude of the coastal current appears to be related to the geometry of the bulge, which in turn determines the magnitude of $g^{\prime} h$ at the coast. For the wide range of forcing parameters considered in this study, the unforced plume is found not to transport all of the freshwater discharged by the river in the downstream coastal current.

Many natural plume systems including the western Gulf of Maine, Delaware, and South Atlantic Bight plumes have relatively narrow ( $<5 \mathrm{~km}$ wide) river mouths. This study has demonstrated that for these river mouth conditions $(O(1)$ Ro discharges), there will be a significant fraction of freshwater which is not transported in the unforced coastal current. Even for relatively wide river mouths, such as the Chesapeake Bay, most of the outflow occurs through a narrow channel on the right-hand side of the estuary mouth during peak runoff conditions [Boicourt, U. of Maryland, pers. comm.]. One might speculate that this type of plume system might also behave like the higher Rossby number cases studied here. 
It has been demonstrated that an ambient alongshore flow field can augment the freshwater transport and distort the bulge. For any ambient current in the direction of Kelvin wave propagation, there exists a quasi-steady bulge and maximum plume width. A secondary effect of an ambient flow in the downstream direction is to halt any upstream transport of freshwater. The upstream propagation physics discussed by Chapman and Lentz [1994] and McCreary et al. [1997] may exist in a natural plume system; however, the presence of a moderate amplitude ambient flow in the direction of Kelvin wave propagation is likely to retard the upstream intrusion and force the plume's buoyancy to be transported only downstream.

Plumes in nature rarely are unforced and plume behavior may be influenced by external forcing agents. This investigation has demonstrated that an ambient current can dramatically modify a plume's structure and freshwater transport characteristics. One would expect that the presence of a downwelling favorable wind would have a similar effect of distorting the bulge and augmenting the downstream freshwater transport of plume water. Because of their sensitivity to external forcing, plumes in nature do not always resemble the idealized, buoyancy-forced plumes studied in previous laboratory and numerical experiments. In many real plumes, the buoyant discharge and its ultimate fate may be strongly influenced by external forcing agents. Winds and ambient currents are likely to dominate the macroscopic behavior of a plume and the alongshore transport of fresh water.

This study has identified an ambient current as a potential means of reaching "steady-state" in a plume. It is worth noting that for fairly typical ambient flows of $5-10 \mathrm{~cm} / \mathrm{s}$, the time scale to steady-state is several days. For many plume systems found in nature, the correlation time scale for winds is similar or shorter. Coupled with the possible influence of tides, this suggests that plumes are by nature unsteady 
phenomena, even with a steady outflow. It is worth noting that winds have been neglected in this study, they can drive significant coastal currents. Therefore, any study hoping to understand or predict the freshwater transport of a plume needs to consider the influence of both winds and ambient flows. 


\title{
Chapter 3
}

\section{The wind-forced response of a buoyant coastal current: Observations of the western Gulf of Maine}

\author{
Calvin's Mom: "We don't really understand it, but there are so \\ many things we don't understand, and we just \\ have to do the best we can with the knowledge we \\ have."
}

Calvin: "I guess that makes sense."

Bill Watterson

\footnotetext{
${ }^{1}$ This chapter duplicates a paper of the same title by Derek A. Fong, W. Rockwell Geyer, and Richard P. Signell which appeared in the Journal of Marine Systems, August 1997, Volume 12, pages 69-81. (C) 1997 Elsevier Science. Reprinted with permission. All text, figures, and tables are identical with the exception of the relabeling of table, figure, and equation numbers. A few grammatical changes have been made; however, these changes do not change the scientific content of the chapter.
} 


\begin{abstract}
The freshwater plume in the western Gulf of Maine is being studied as part of an interdisciplinary investigation of the physical transport of a toxic alga. A field program was conducted in the springs of 1993 and 1994 to map the spatial and temporal patterns of salinity, currents, and algal toxicity. The observations suggest that the plume's cross-shore structure varies markedly as a function of fluctuations in alongshore wind forcing. Consistent with Ekman drift dynamics, upwelling favorable winds spread the plume offshore, at times widening it to nearly $50 \mathrm{~km}$ in offshore extent, while downwelling favorable winds narrow the plume width to as little as 10 $\mathrm{km}$.

Using a simple slab model, we find qualitative agreement between the observed variations of plume width and those predicted by Ekman theory for short time scales of integration. Near surface current meters show significant correlations between cross-shore currents and alongshore wind stress, consistent with Ekman theory. Estimates of the terms in the alongshore momentum equation calculated from moored current meter arrays also indicate a dominant Ekman balance within the plume. A significant correlation between alongshore currents and winds suggests that interfacial drag may be important, although inclusion of a Raleigh drag term does not significantly improve the alongshore momentum balance.
\end{abstract}




\subsection{Introduction}

Freshwater runoff from rivers into the ocean has an important influence on the dynamics of many coastal regions. Since the river outflow tends to be less saline than the ambient coastal water, a surface plume typically forms as the buoyant riverine water spreads away from the river mouth. In the northern hemisphere, the Coriolis force turns the plume toward the right and traps the buoyant water against the coast, often forming a buoyancy-driven coastal current flowing in the direction of Kelvin wave propagation (e.g., Chao and Boicourt [1986]). However, winds may alter the structure of the plume due to upwelling and downwelling phenomena (e.g., Chao [1988], Münchow and Garvine [1993]). This paper discusses a river plume in the Gulf of Maine, U.S.A. that shows significant influence from variations in wind forcing.

The Gulf of Maine is a region of continental shelf on the east coast of North America defined in extent by the Bay of Fundy to the north and Cape Cod to the south (Figure 3.1). The western Gulf of Maine plume (hereafter, GOM plume) is the result of river runoff from a series of rivers in the southwestern portion of the Gulf of Maine. The primary sources of the buoyant discharge for the Gulf of Maine are the Penobscot, Androscoggin/Kennebec, and Merrimack river systems (Figure 3.1). The majority of the freshwater inflow from the rivers occurs in the spring months with peak cumulative inflows of over $4000 \mathrm{~m}^{3} / \mathrm{s}[\mathrm{J}$. Nielsen, United States Geological Survey, pers. commun., 1995].

A toxic dinoflagellate Alexandrium tamarense is found in the plume during the spring freshet [Hurst and Yentsch, 1981; Shumway et al., 1988]; the toxin from this dinoflagellate is known to cause paralytic shellfish poisoning. Franks and Anderson 


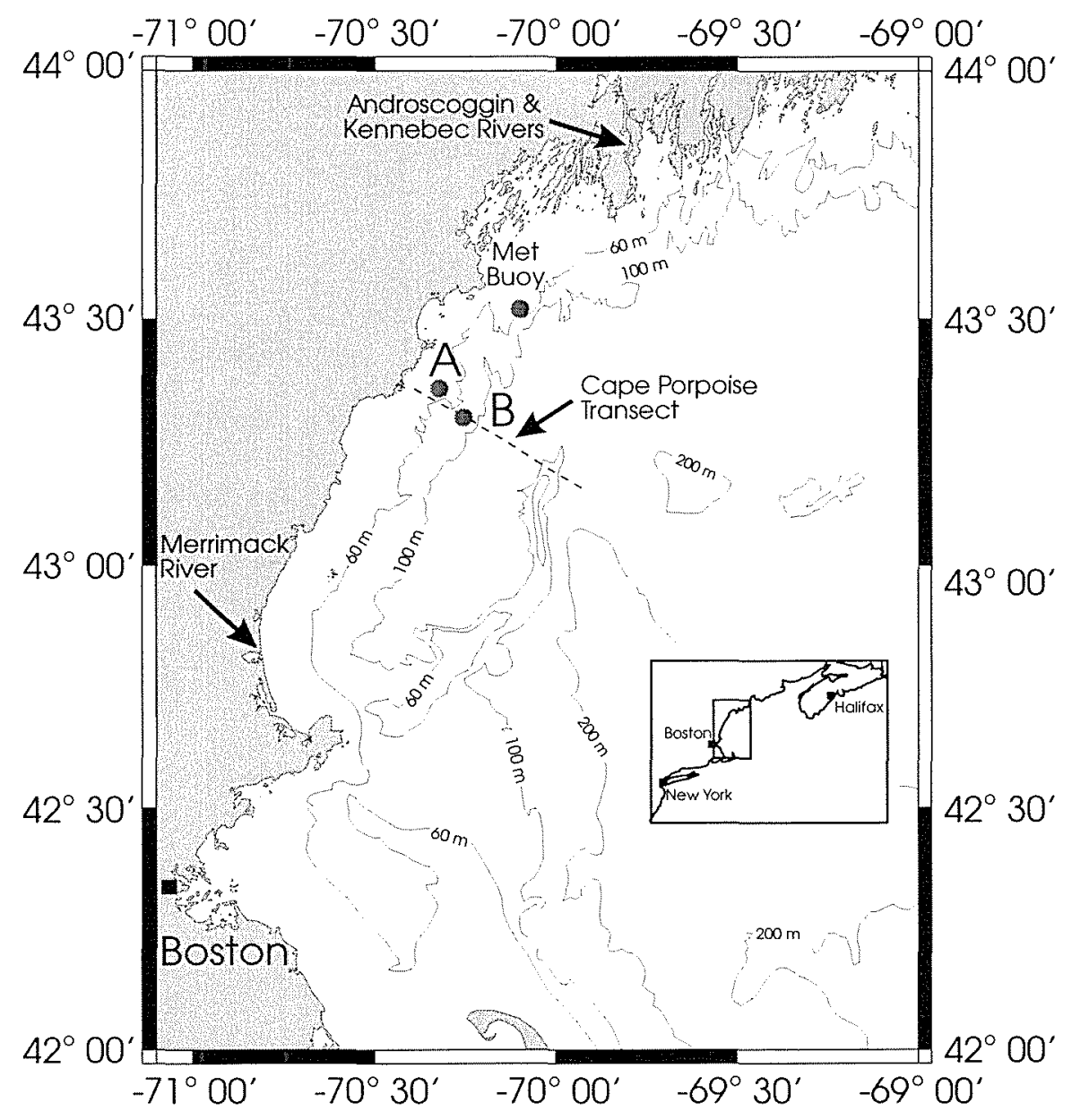

Figure 3.1: The study region: the western Gulf of Maine. The two major sources of freshwater are the Kennebec/Androscoggin and Merrimack River systems. The dashed line indicates CTD stations along the Cape Porpoise transect. The locations of moored current meter arrays $\mathrm{A}$ and $\mathrm{B}$ and the meteorological buoy are also indicated. The Penobscot river, not shown, is located to the north-east of the plotted region. 
[1992] proposed that the freshwater plume associated with these riverine discharges is directly responsible for the spatial and temporal distribution of $A$. tamarense blooms. Given the serious economic and health threats posed by this toxic alga, an interdisciplinary study was initiated to study transport properties of the GOM plume and its effect on the distribution of $A$. tamarense.

As is revealed in the data set presented below, the cross-shore extent of the GOM plume is strongly dependent on the direction and magnitude of wind forcing. This investigation examines the response and variability of the GOM plume's cross-shore structure and its relationship with the wind forcing.

In Section 3.2, we describe the field program. In Section 3.3, hydrographic and meteorological data are presented to illustrate the cross-shore variability of the GOM plume structure; a simple model is constructed to compare the observed hydrography with Ekman drift theory. In Section 3.4, moored current meter data are used to examine a shear alongshore momentum equation; discrepancies between Ekman theory and the observations are considered. The study's findings are discussed and summarized in Section 3.5 .

\subsection{Methods}

During the spring months of 1993 and 1994, a total of 13 hydrographic surveys were conducted in the western Gulf of Maine. This study focuses primarily on data collected along a transect off Cape Porpoise (Figure 3.1). This particular transect was chosen for two reasons: (1) its location is coincident with moored current meter arrays, (2) it was the most frequently sampled transect in the field program. In AprilJuly 1993, currents were measured at mooring B on the Cape Porpoise transect at 
the nominal depths of 5,27, and $50 \mathrm{~m}$ with a Vector Measuring Current Meter (VMCM) and two Vector-Averaging Current Meters (VACM), respectively. For

April-September 1994, currents were again measured at mooring B for the same depths, and an additional mooring A measured currents at nominal depths of $5 \mathrm{~m}$ and $27 \mathrm{~m}$ with a VMCM and VACM, respectively.

In addition, hourly wind speeds were recorded at a nearby meteorological buoy (Figure 3.1). These records were used to calculate cross- and alongshore components of wind stress using Large and Pond's [1981] quadratic drag law. The subsequent time series of wind stress and current meter measurements were low-pass filtered with a half power point at 33 hours [Beardsley et al., 1985]. Combining the calculated wind stresses and hydrographic and moored data sets, we examine how the crossshore plume structure varies as a function of local wind forcing.

\subsection{Hydrographic surveys}

Summary plots of alongshore wind stress, river inflow, and observed hydrography off of Cape Porpoise for 1993 and 1994 are shown in Figures 3.2 and 3.3, respectively. Plume widths based on salinity sections for each cruise are indicated using the 31 psu isohaline surface to define the extent of the plume. This choice is based on the observation that the 31 psu isohaline is almost always coincident with the maximum observed stratification. Based on a weighted average of winds prior to each hydrographic observation (using a one-sided Gaussian weighting with a decay time scale of three days), winds are classified as weak, upwelling favorable, or downwelling favorable, and denoted by a $W$, U, or $D$, respectively, in Figures 3.2 and 3.3. Weak winds are those with weighted averages less than $0.25 \mathrm{dyne} / \mathrm{cm}^{2}$. 

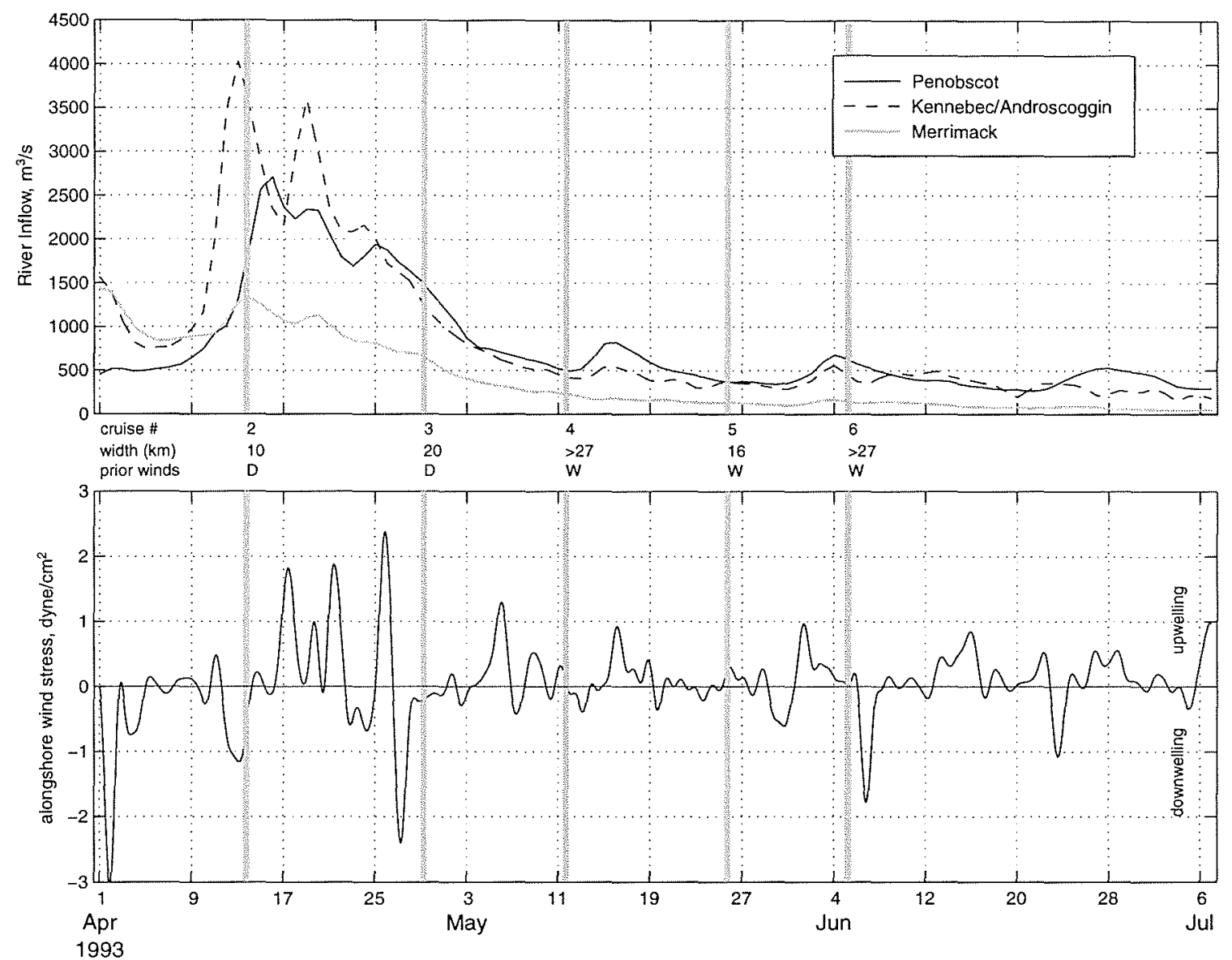

Figure 3.2: 1993 observations in the western Gulf of Maine. Time series of winds measured at the meteorological buoy and freshwater inflow from the Penobscot, Kennebec/Androscoggin, and Merrimack river systems are shown. The timing of hydrographic surveys at the Cape Porpoise transect are indicated by the gray vertical bands. The observed plume width during the surveys are indicated in $\mathrm{km}$ with a classification of the winds preceding each survey; D indicates downwelling favorable winds prior to the survey while upwelling favorable winds are labeled with a $U$; weak winds are denoted by a $W$. 

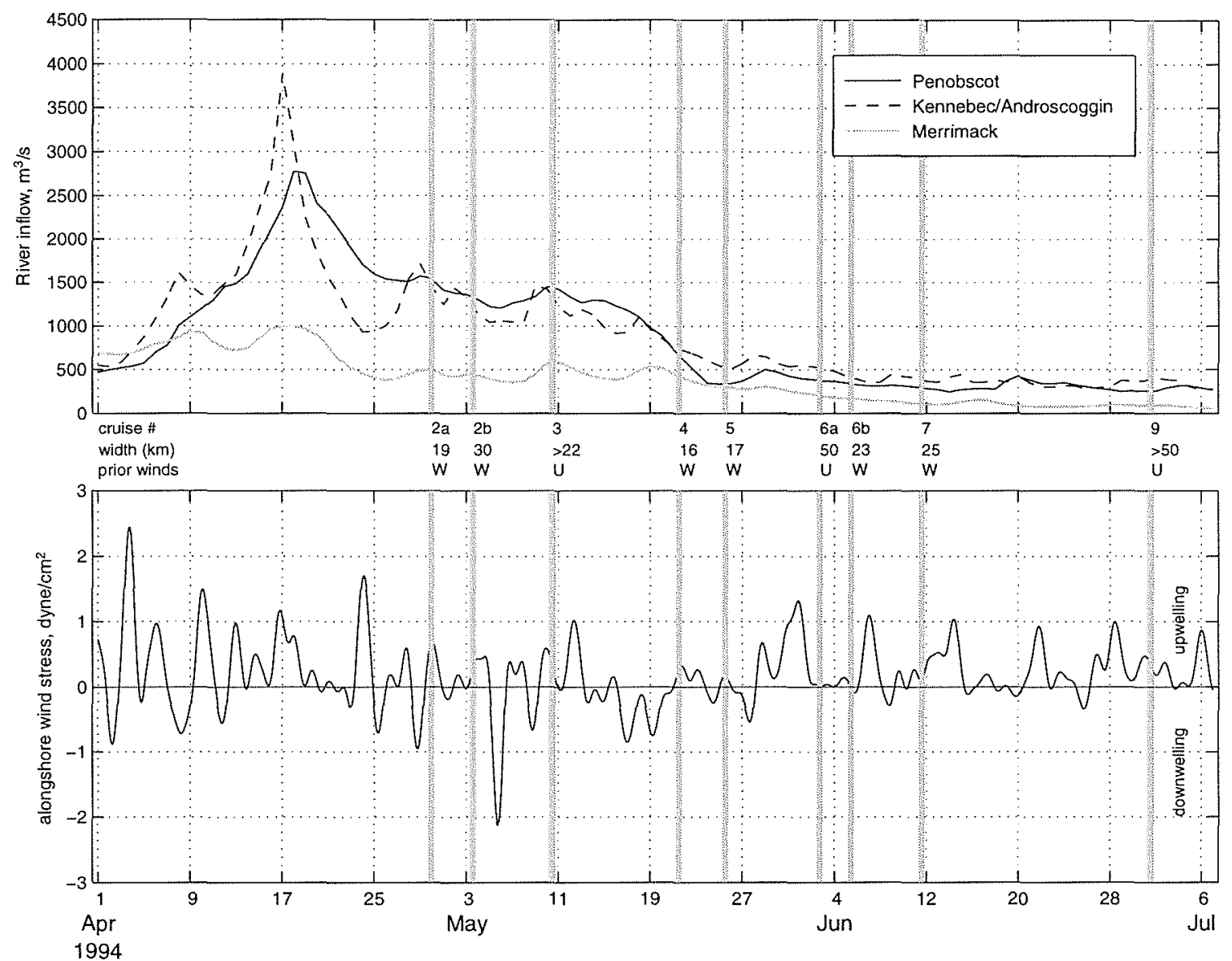

Figure 3.3: 1994 observations in the western Gulf of Maine (as in Figure 3.2). 
For both 1993 and 1994, the plume width is strongly influenced by the magnitude and direction of the alongshore wind forcing. Downwelling favorable (northeasterly) winds narrow the plume's cross-shore extent and confine it to a narrow region against the coast (Figure 3.4a). The minimum observed plume width was $10 \mathrm{~km}$, during Cruise 2 in 1993 in strong downwelling winds. In contrast, upwelling favorable (southwesterly) winds tend to drive the plume waters up to $50 \mathrm{~km}$ offshore, often beyond the extent of our hydrographic surveys. Figure $3.4 \mathrm{~b}$ provides an example of the influence of upwelling winds on the plume structure.

On the time scales of 1-2 weeks, the GOM hydrography suggests that the changes in observed plume width between the cruises are consistent with the direction of the alongshore wind-forced response predicted by Ekman drift dynamics. This is similar to the behavior observed in previous modeling studies of wind-forced freshwater plumes (e.g.,Chao [1987], Csanady [1977]). In light of the apparent consistency between the GOM plume's cross-shore width and the alongshore winds with Ekman theory, we next consider a simple model.

If we approximate the plume as being a layer of light fluid of density $\rho$, and assume that the Ekman balance dominates the alongshore momentum equation, we can express the alongshore momentum balance by

$$
f u=\frac{\tau^{y}}{\rho h}
$$

where $h$ is the thickness of the plume, $u$ is the depth-averaged cross-shore velocity within the plume, $f$ is the Coriolis parameter, and $\tau^{y}$ is the alongshore wind stress.

Solving (3.1) for $u$ and integrating in time, we can approximate an excursion 

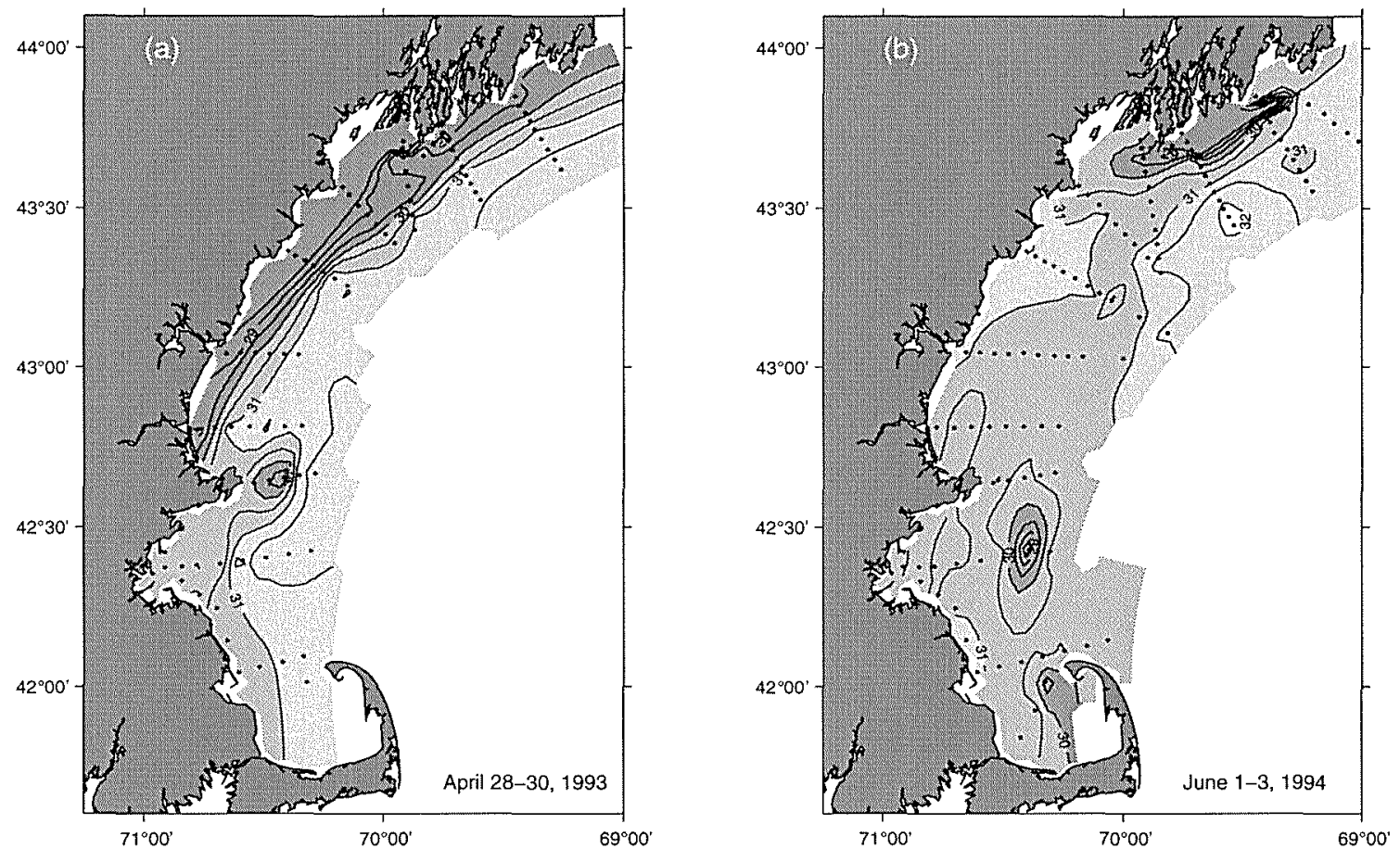

Figure 3.4: Horizontal sections of salinity at 2.5 meters depth based on Hydrographic surveys (stations indicated by dots). (a) Downwelling favorable wind conditions (Cruise 93-3: April 28-30, 1993), (b) Upwelling favorable conditions (Cruise 94-6a: June 1-3, 1994). 
length, $L_{e}$,

$$
L_{e}=\int_{t_{0}}^{t_{1}} u d t=\int_{t_{0}}^{t_{1}} \frac{\tau^{y}}{\rho h f} d t
$$

Therefore, assuming the validity of (3.1) as the appropriate alongshore momentum balance, we can use (3.2) to calculate the width of the plume as a function of time given an initial plume width and time series of alongshore wind forcing.

Equation (3.2) was used to estimate the Ekman-induced changes in the offshore position of the plume and compare it with the observed changes between hydrographic surveys. The plume thickness for the calculations was estimated by linearly interpolating the observed plume thickness at the front. The thickness at the edge of the plume (rather than its average thickness) is the relevant $h$ to use in (3.2) since the quantity of interest is the cross-shore motion of the plume boundary. The integration of (3.2) is also constrained such that the width of the plume never falls below a minimum value $L_{c}=3 \mathrm{~km}$, the baroclinic Rossby radius of the plume, which is roughly the lower limit of plume width based on modeling studies (e.g., Chao [1988]).

The results of the comparison between observed changes in plume width and equation (3.2) are shown in Table 3.1. There are large discrepancies for long integration time scales; however for the early cruises of 1994, the simple Ekman formulation predicts cross-shore plume excursions within $10 \mathrm{~km}$ of the observed motions when the time elapsed between cruises is less than 9 days. For example, equation (3.2) predicts the plume to widen by $41 \mathrm{~km}$ between cruises 5 and $6 \mathrm{a}$, similar to the observed change of $33 \mathrm{~km}$. In contrast, for the larger time integrations needed between cruises in 1993, prediction and observed motions often differ substantially. For Cruises 2 and 3 in 1993, equation (3.2) predicts the plume to widen $72 \mathrm{~km}$ while 
Table 3.1. Observed change in plume width off of Cape Porpoise vs. Prediction from Equation (3.2) for 1993 and 1994.

\begin{tabular}{ccccccc}
\hline Year & $\begin{array}{c}\text { Starting } \\
\text { Cruise }\end{array}$ & $\begin{array}{c}\text { Ending } \\
\text { Cruise }\end{array}$ & $\begin{array}{c}\text { Integration } \\
\text { time (days) }\end{array}$ & $\begin{array}{c}\text { Intial } \\
\text { Width }(\mathrm{km})\end{array}$ & $\begin{array}{c}\text { Observed } \\
\text { Change }(\mathrm{km})\end{array}$ & $\begin{array}{c}\text { Predicted } \\
\text { Change }(\mathrm{km})\end{array}$ \\
\hline 1993 & 2 & 3 & 15.5 & 10 & 10 & 72 \\
1993 & 3 & 5 & 26.5 & 21 & -5 & 35 \\
1993 & 5 & 6 & 10.5 & 16 & $>11$ & 18 \\
\hline 1994 & $2 \mathrm{a}$ & $2 \mathrm{~b}$ & 3.6 & 19 & 11 & 5 \\
1994 & $2 \mathrm{~b}$ & 3 & 6.9 & 30 & $<-8$ & -12 \\
1994 & 4 & 5 & 4.0 & 16 & 1 & 6 \\
1994 & 5 & $6 \mathrm{a}$ & 8.2 & 17 & 33 & 41 \\
\hline 1994 & $6 \mathrm{a}$ & $6 \mathrm{~b}$ & 2.8 & 50 & -27 & 2 \\
1994 & $6 \mathrm{~b}$ & 7 & 6.1 & 23 & 2 & 22 \\
1994 & 7 & 9 & 20.0 & 25 & $>25$ & 113 \\
\hline
\end{tabular}

the observed plume width increases by only $10 \mathrm{~km}$. Over these large time scales, the front loses its coherence. It appears that a new front formed before Cruise 3; the old front probably dissipated offshore, or has been transported downstream, out of the domain. Significant deviations also exist between predicted and observed plume widths in the latter cruises of 1994 despite short times of integration. These late observations are coincident with the low freshwater inflows, and hence, a weak plume. During these observations, the freshwater anomaly no longer dominates the density signal.

It is apparent from the hydrographic data that the fluctuations of the wind forcing, which typically occur on time scales of 1-2 days, severely decorrelate the observed plume between surveys. Given the typically large time intervals between the majority of cruises and the difficulty in applying this simple model to more than a few realizations, we next consider the time series data collected from the moored current meters at Cape Porpoise. 


\subsection{Moored Current Meter records}

The moored current meters provide us with a means of evaluating the cross-shore motions of the plume temporally, in contrast to the hydrographic data which offer a detailed spatial picture of the plume's structure with coarse temporal resolution. The time series data of alongshore winds, cross-shore velocities, and salinities from the moorings in 1994 are shown in Figure 3.5. We will focus primarily on the 1994 data set below because it includes two moorings that provide some cross-shore spatial resolution.

As is visually apparent in Figure 3.5, the cross-shore velocities at the Cape Porpoise moorings also suggest a wind-forced plume behaving consistently with Ekman drift theory. Correlations between cross-shore near surface currents and alongshore wind stress are 0.53 for 1993 and 0.73 for 1994 (Table 3.2), both significant at the 99\% confidence level [Glenberg, 1988]. Complex correlations between wind stress and near-surface $(5 \mathrm{~m})$ velocity vectors reveal 59 and 66 degree clockwise veerings (of velocity with respect to the wind) for 1993 and 1994, respectively, further suggesting a dominant Ekman balance in the near surface waters. Also noteworthy are significant correlations between the cross-shore winds and alongshore currents, and the alongshore winds and alongshore currents (see Table 3.2). The former is indicative of Ekman dynamics playing an active role in the cross-shore momentum equation; we will address the second of the correlations later in the paper. 

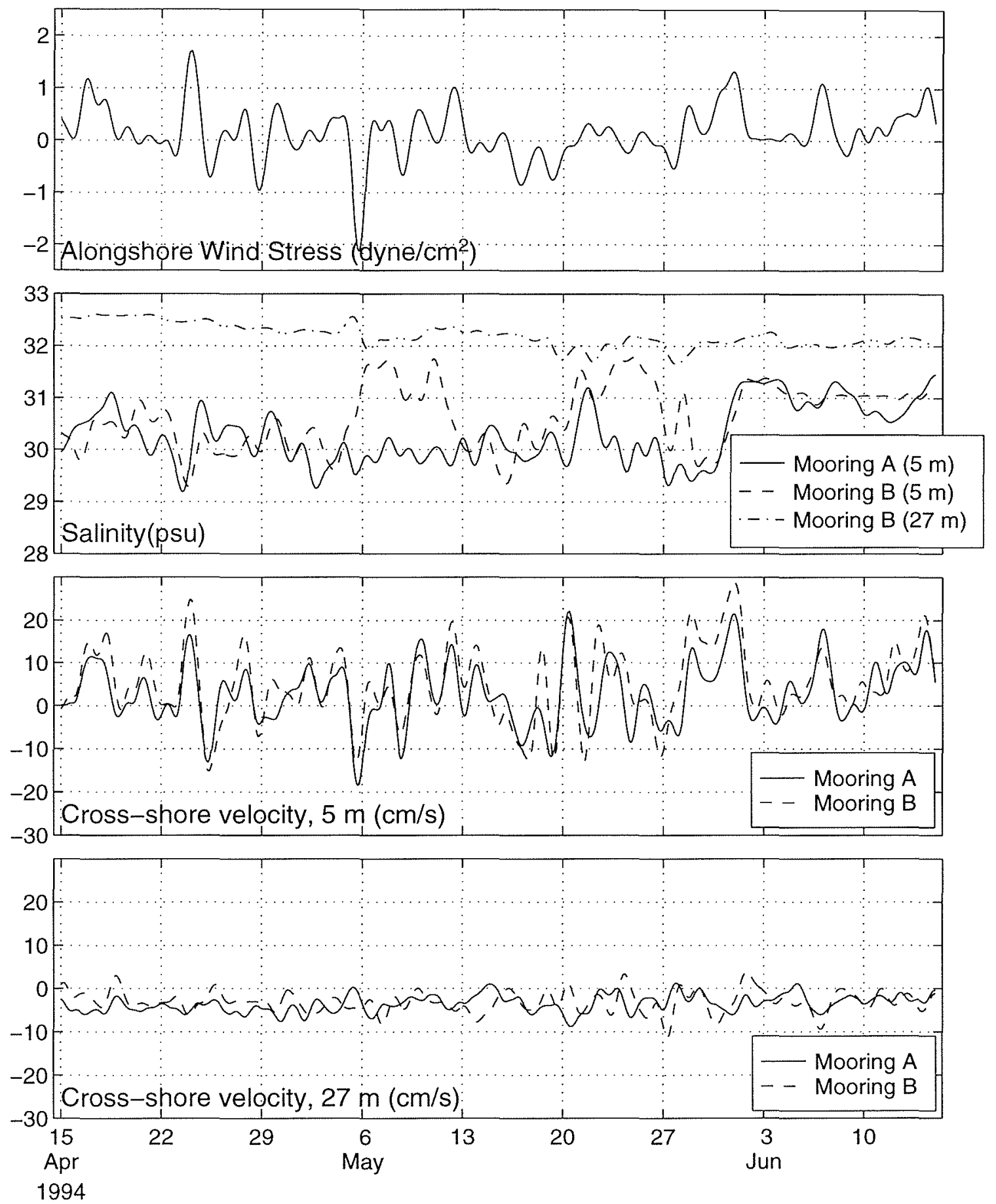

Figure 3.5: Time series of alongshore wind stress, salinity and cross-shore velocities measured at Cape Porpoise in 1994. 
Table 3.2. Low-Passed Correlation Coefficients for April 15-June 15 for 1993 and 1994 (top and bottom coefficients in table entries, respectively).

\begin{tabular}{|c|c|c|c|c|c|}
\hline & year & $\begin{array}{c}\text { Alongshore } \\
\text { Wind Stress }\end{array}$ & $\begin{array}{c}\text { Cross-shore } \\
\text { Wind Stress }\end{array}$ & $\begin{array}{c}\text { Alongshore } \\
\text { Velocity }\end{array}$ & $\begin{array}{c}\text { Cross-shore } \\
\text { Velocity }\end{array}$ \\
\hline Alongshore Wind Stress & 1993 & 1 & -0.37 & 0.51 & 0.53 \\
& 1994 & 1 & -0.18 & 0.43 & 0.73 \\
\hline Cross-shore Wind Stress & 1993 & & 1 & -0.39 & -0.08 \\
& 1994 & & 1 & -0.47 & 0.02 \\
\hline Alongshore Velocity & 1993 & & & 1 & -0.06 \\
& 1994 & & & 1 & 0.11 \\
\hline Cross-shore Velocity & 1993 & & & & 1 \\
& 1994 & & & & 1 \\
\hline
\end{tabular}

Zero-lag correlation coefficients were very near maximum lagged correlations. For a 50-hour integral time scale, correlations of 0.38 , and 0.49 are significant at the $95 \%$ and $99 \%$ levels, respectively. (Glenberg, 1988)

In order to better quantify the dominance of Ekman dynamics, we consider a layer-averaged alongshore momentum balance within the GOM plume:

$$
\frac{\partial v_{p}}{\partial t}+u_{p} \frac{\partial v_{p}}{\partial x}+v_{p} \frac{\partial v_{p}}{\partial y}+f u_{p}=-\frac{\rho g}{\rho_{0}} \frac{\partial \eta}{\partial y}-\frac{g h}{2 \rho_{0}} \frac{\partial \rho}{\partial y}+\frac{\tau^{y}}{\rho_{0} h}-\frac{r \Delta v}{h}
$$

where $u_{p}$ and $v_{p}$ are the vertically-averaged cross- and along-plume currents, respectively, $\rho$ is the plume density which is assumed to be independent of depth within the plume, $\frac{\partial \eta}{\partial y}$ is the alongshore surface slope, $\Delta v$ is the difference in alongshore velocity between the plume and ambient waters at depth, and $r$ is a Raleigh drag coefficient. Variations in sea surface elevations, $\eta$, are assumed to be much smaller than $h$. In waters beneath the plume, the vertically-averaged alongshore momentum balance can be expressed as:

$$
\frac{\partial v_{0}}{\partial t}+u_{0} \frac{\partial v_{0}}{\partial x}+v_{0} \frac{\partial v_{0}}{\partial y}+f u_{0}=-\frac{\rho g}{\rho_{0}} \frac{\partial \eta}{\partial y}-\frac{g h}{\rho_{0}} \frac{\partial \rho}{\partial y}
$$


where the stresses in the waters below the plume are assumed to be small. Subtracting (3.4) from (3.3) to eliminate the surface slope term yields a shear alongshore momentum equation:

$$
\begin{aligned}
& \text { Ekman balance } \\
& \frac{\partial \Delta v}{\partial t}+\Delta\left(u \frac{\partial v}{\partial x}\right)+\Delta\left(v \frac{\partial v}{\partial y}\right)+f \Delta u=\frac{g h}{2 \rho_{0}} \frac{\partial \rho}{\partial y}+\frac{\tau^{y}}{\rho_{0} h}-\frac{r \Delta v}{h}, \\
& \begin{array}{lllllll}
\text { A } & \text { B } & \text { C } & \text { D } & \text { E } & \text { F } & \text { G }
\end{array}
\end{aligned}
$$

where $\Delta u=u_{p}-u_{0}, \Delta v=v_{p}-v_{0}$, and $\Delta$ preceding the nonlinear terms $\mathrm{B}$ and $\mathrm{C}$ denote differences of each term between the plume and ambient waters.

Terms A, B, D and F can be estimated from the two moorings deployed at Cape Porpoise in the spring of 1994. The acceleration and Coriolis terms on the left-hand side of (3.5) are estimated by averaging the shear velocities ( $\Delta u$ and $\Delta v)$ at moorings $\mathrm{A}$ and $\mathrm{B}$. The nonlinear term $\mathrm{B}$ is estimated by computing the gradient of alongshore velocities measured between the moorings at the two depths and subtracting $\left.u \frac{\partial v}{\partial x}\right|_{25 m}$ from $\left.u \frac{\partial v}{\partial x}\right|_{5 m}$. The alongshore plume wind stress (term F) is computed using wind measurements from the meteorological buoy as discussed in Section 3.2, and linearly interpolating the plume thickness $h$ at the hydrographic survey stations coincident with the mooring locations.

The resulting time series of terms A, B, D, and F are shown in Figure 3.6. The top panel compares the shear Coriolis force term with the surface wind stress term. The second plot contains the same two variables, but the contribution of the mean shear over the record of $7 \mathrm{~cm} / \mathrm{s}$ has been removed to make it easier to compare the variations. The third and fourth panels are the cross-shore advection of alongshore 
momentum and time dependencies, respectively.

\subsubsection{Ekman balance}

Consistent with the hydrography and time series correlations, the surface wind stress and shear Coriolis force terms have the largest magnitudes and are highly correlated: 0.75 (see Table 3.3). The nonlinear term B is consistently small except for one shortlived event. The alongshore acceleration (term A) is of moderate size, but is not correlated with the wind stress.

Table 3.3. Low-Passed Correlation Coefficients for April 30-June 10, 1994 for shear alongshore momentum components.

\begin{tabular}{c|ccccc}
\hline & $\frac{\tau^{y}}{\rho h}$ & $f \Delta u$ & $\Delta\left(u \frac{\partial v}{\partial x}\right)$ & $\frac{\partial \Delta v}{\partial t}$ & $\frac{r \Delta v}{h}$ \\
\hline$\frac{r^{y}}{\rho h}$ & 1 & 0.75 & -0.15 & 0.11 & $\mathbf{0 . 6 4}$ \\
$f \Delta u$ & & 1 & 0.23 & 0.03 & 0.32 \\
$\Delta\left(u \frac{\partial v}{\partial x}\right)$ & & & 1 & 0.09 & 0.06 \\
$\frac{\partial \Delta v}{\partial t}$ & & & 1 & & 0.01 \\
$\frac{r \Delta v}{h}$ & & & & & 1 \\
\hline
\end{tabular}

For a 55-hour integral time scale, bold-faced entries indicate correlations significant at the $99 \%$ level (Glenberg, 1988).

Despite the high correlations between the wind stress and Coriolis terms, the time series (Figure 3.6) reveal several events in which there is a marked discrepancy between the two terms. These discrepancies are due in part to the crudeness of the layer-averaged approach, particularly during strong upwelling when the plume may be thinner than $5 \mathrm{~m}$, the depth of the near-surface current meters. Some of the 

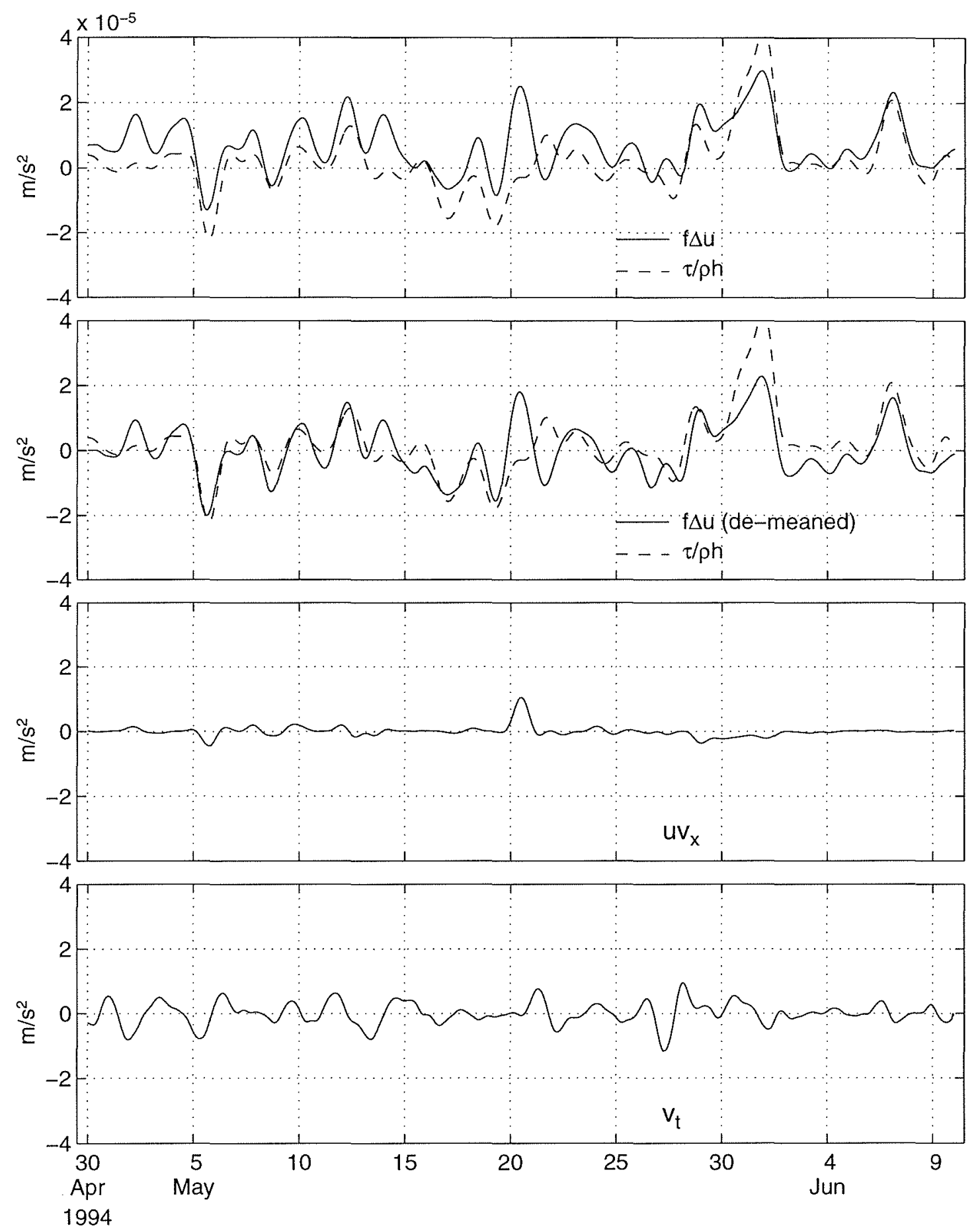

Figure 3.6: Time series of different terms in the shear alongshore momentum equation. Subscripts indicate partial differentiation. 
discrepancies are also due to other terms in the momentum balance.

\subsubsection{Other contributors to the alongshore momentum bal- ance}

As has been discussed, $\frac{\partial \Delta v}{\partial t}$ and $\Delta\left(u \frac{\partial v}{\partial x}\right)$ are significantly smaller than either the Coriolis or wind stress terms. Furthermore, neither of these terms are correlated with the wind stress (Table 3.3). If we account for these two terms in trying to balance out the wind stress (i.e, $\frac{\partial \Delta v}{\partial t}+\Delta\left(u \frac{\partial v}{\partial x}\right)+f \Delta u$ vs. $\left.\frac{\tau^{y}}{\rho h}\right)$, we get a lower correlation (0.66). Figure 3.7a shows the comparison of the wind stress to the other terms.

There are three terms in (3.5) which we could not compute from our time series data: the alongshore advection of alongshore momentum, the baroclinic pressure gradient, and the interfacial drag. In order for the first two of these terms to be important, the alongshore length scales of variability must be small, i.e., less than $10 \mathrm{~km}$. The hydrographic data only resolved scales of $30 \mathrm{~km}$ in the along-shore direction, over which there was minimal variability during downwelling conditions and modest variations during upwelling. It is possible that there were unresolved variations at smaller scales, but there is no evidence for it.

It is also difficult to specify the friction term $G$. If we perform an analysis similar to Lentz's [1995] analysis of friction in the Amazon River plume we can obtain an estimate of $r$. Using an empirical fit for the observed variations in wind stress, along-plume, and across-plume velocities at the moorings for both 1993 and 1994, we estimate a Rayleigh drag coefficient $O\left(10^{-4}\right) \mathrm{m} / \mathrm{s}$. This value is surprisingly large. Interpreting $r$ as the product of a mean velocity times a drag coefficient (i.e., $r=C_{i}|\Delta \vec{u}|$ where $\Delta \vec{u} \sim\left(1 \times 10^{-1} \mathrm{~m} / \mathrm{s}\right)$ is the difference in velocity between the 
two layers), we estimate $C_{i} \sim O\left(10^{-3}\right)$, almost an order of magnitude larger than Lentz [1995] found in the Amazon River plume, and comparable to a bottom drag coefficient.

Using the above estimate of $r$, the correlation between $\left(f \Delta u+\frac{r v_{p}}{h}\right)$ and $\frac{\tau^{y}}{\rho h}$ is 0.83. Figure 3.7b plots the sum of $\left(\frac{\partial \Delta v}{\partial t}+\Delta\left(u \frac{\partial v}{\partial x}\right)+f \Delta u+\frac{r v_{p}}{h}\right)$ vs. $\frac{\tau^{y}}{\rho h}$. The inclusion of the interfacial friction term is not a significant improvement from the previous balance neglecting it, and does not consistently account for the difference between the wind stress and Coriolis terms in Figure 3.6. Thus, this analysis does not provide conclusive evidence of a large interfacial drag term; only that such a magnitude would be consistent with the data. It is plausible that the correlation between the alongshore velocity and alongshore winds is purely an Ekman-based response generated by a coupling of the two momentum equations: the alongshore wind is responsible for a cross-shore Ekman transport that displaces the isohalines, thereby readjusting geostrophic velocities in the cross-shore momentum balance, and resulting in a correlation between along-shelf winds and along-shelf currents without appreciable interfacial drag.

\subsection{Discussion and Summary}

The western Gulf of Maine plume's responses to different orientations of wind forcing have tendencies consistent with Ekman drift dynamics. Using a simple, idealized model of Ekman dynamics, we find qualitative agreement with the observed plume's cross-shore motions and that predicted by the model; however, the applicability of the model is limited to short periods of integration over which the plume front maintains its coherence. The wind fluctuations over time scales of a few days suggest 

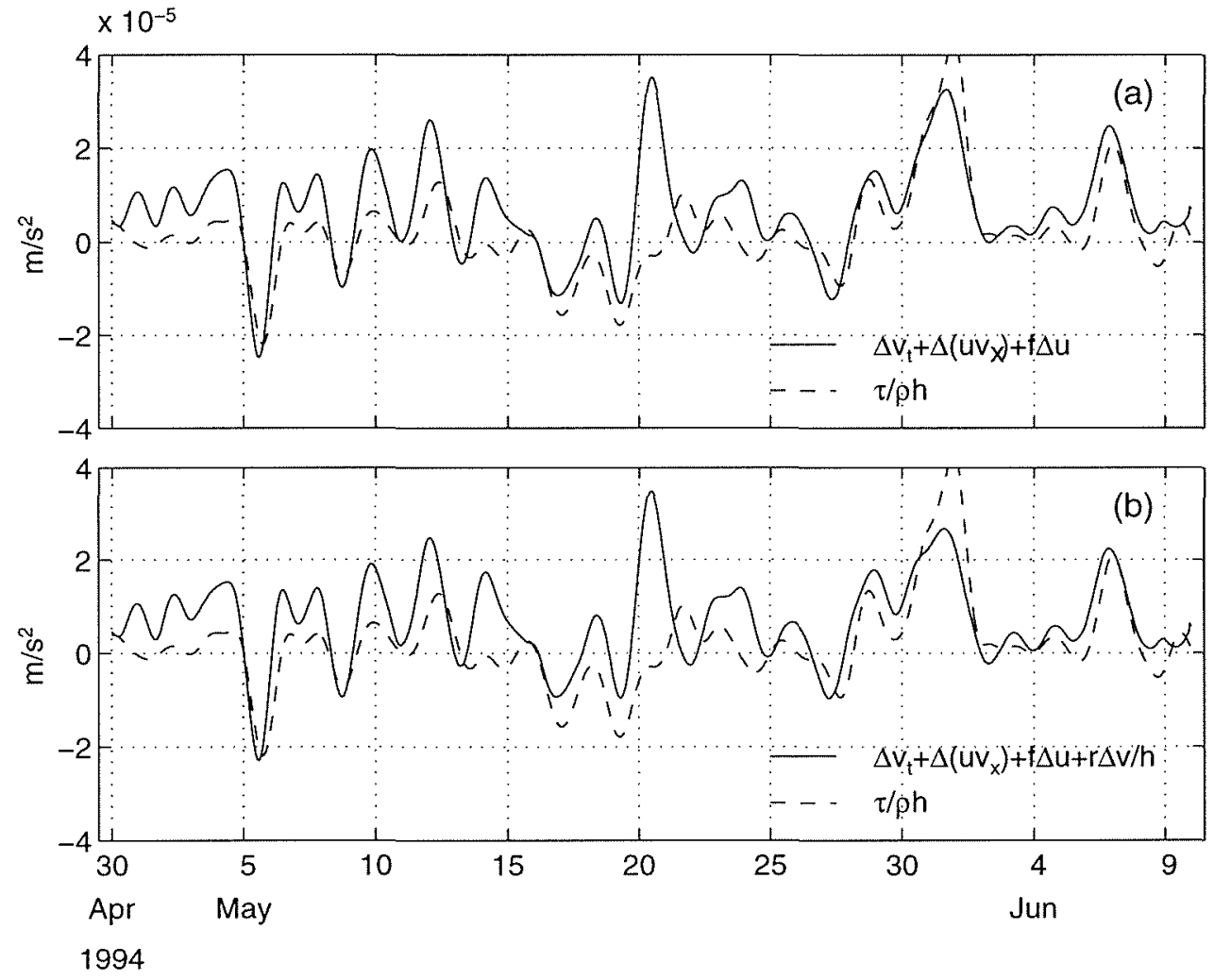

Figure 3.7: Balancing the shear alongshore momentum: (a) excluding interfacial friction (b) including interfacial friction. 
that the correlation time scales of the plume are short.

The moored observations also support the dominance of Ekman dynamics: crossshore plume velocities are highly correlated with alongshore winds and tend to dominate the shear alongshore momentum balance. Alongshore acceleration effects are non-trivial although they do not improve the balance of terms in the momentum equation. This suggests that some other terms such as friction and the alongcoast baroclinic pressure gradient may be important. An empirical analysis of the interfacial friction suggests a large Rayleigh friction factor, although it may be an artifact of the coupling between the two momentum equations.

Some of the discrepancies between the observed time series of wind stress and Coriolis terms are likely the result of errors in accurately specifying the plume thickness as a function of time. The plume's thickness is a quantity which is likely to vary over short-time scales. The plume's thickness is related to both the orientation and magnitude of wind forcing. For downwelling favorable winds, the plume is typically thick, sometimes nearing $20 \mathrm{~m}$ thickness. In contrast, thinner plumes are predominantly found under upwelling favorable wind conditions. There may be a correlation between the wind stress and plume thickness, which would lead to an asymmetric response to variations in wind forcing.

The moored current meters exhibit a significant mean offshore surface velocity that is not explainable by any mean wind-forcing conditions. There is little suggestion that this is a result in measurement error, nor is there any indication from the data that there is some underlying physical process that would produce a mean offshore surface current. A significant along-coast density gradient would be required to support an $\mathrm{O}(5 \mathrm{~cm} / \mathrm{s})$ mean flow; this does not seem plausible based on these 
observations nor previous studies of the Gulf of Maine (e.g., Brown and Irish [1992]). The offshore mean in the surface flow field may be the result of some asymmetry in the plume's response to upwelling and downwelling winds causing a rectification of the Ekman transport offshore. Alternatively, there could be small scale bathymetric variations that are not resolved by the available bathymetric data, which cause a local deflection of the the alongshore currents at Cape Porpoise.

One of the severe limitations of the above analysis is the approximation of the GOM plume as a two-dimensional phenomenon. The hydrographic observations suggest this assumption is primarily valid during downwelling favorable wind conditions; for strong upwelling favorable wind conditions, there is much greater alongshore variability. Downstream of Cape Porpoise, in the southern portions of the western Gulf of Maine, the cross-shore topography diverges (see Figure 3.1), leading to likely variability in alongshore plume behavior. In addition, the variation in freshwater discharge is an inherent problem in considering the plume over the long time scales between hydrographic surveys. The water mass observed during one hydrographic survey is clearly different than waters observed in a subsequent one.

We have also neglected to consider the coupling of the cross-shore momentum equation and how cross-shore winds might drive cross-shore plume motions. Despite the smaller magnitude of the cross-shore wind component with respect to the alongshore component, a small, yet significant (to $95 \%$ confidence level) correlation between alongshore and cross-shore winds in 1993 suggests that the cross-shore winds may play a role in determining cross-shore plume variability.

The inherent simplifications of using the moored near-surface measurements of velocity to describe a depth-averaged plume motion is another source of error; the 
approximation of the plume as a layer of homogeneous light water overlying fixed density coastal waters is a crude picture of a plume. The detailed vertical and horizontal structure of the plume are obviously important for a number of processes including the alongshore transport within the plume and the influence of wind forcing with respect to depth.

Issues related to the alongshore transport in the GOM plume are currently being studied. A suite of three-dimensional numerical modeling experiments is being conducted which addresses some of the limitations of this study. A combination of such modeling studies with additional studies of the moored current meter and surface drifter data sets should further our understanding of the western Gulf of Maine plume's dynamics. 


\section{Chapter 4}

\section{The response of a river plume during an upwelling favorable wind event}

Hobbes: "Are you sure this is such a good idea?" Calvin: "This is is a brilliant idea."

Hobbes: "I'd hate to be accused of inhibiting scientific progress." Bill Watterson 


\begin{abstract}
The response of a surface-trapped river plume to an upwelling favorable wind stress is studied using a three-dimensional model in a simple, rectangular domain. Model simulations demonstrate that the plume thins and is advected offshore by the cross-shore Ekman transport. The thinned plume is susceptible to significant mixing due to the vertically sheared horizontal currents.

The Ekman dynamics and shear-induced mixing result in a plume that evolves to a quasi-steady uniform thickness which is estimated by,

$$
h_{c} \approx\left[\frac{4 R i_{c}\left(\frac{\tau^{w}}{\rho f}\right)^{2}}{g \frac{\Delta \rho}{\rho_{0}}}\right]^{1 / 3}
$$

where $\tau^{w}$ is the applied alongshore wind stress, $\Delta \rho$ is the density difference between the plume and ambient water, $\rho_{0}$ is the density of the ambient water, $f$ is the Coriolis parameter, $g$ is the gravitational acceleration, and $R i_{c}$ is a critical bulk Richardson number.

Although the mixing rate decreases slowly in time, mixing continues under a sustained upwelling wind until the plume is destroyed. Mixing persists for all time at the seaward plume front owing to an Ekman straining mechanism, where there is a balance between the advection of cross-shore salinity gradients and vertical mixing. The plume mixing rate observed is consistent with the mixing power law suggested by previous studies of 1-D mixing. Numerical simulations also suggest that for large amplitude winds, the shears associated with inertial motions will play a significant role in the mixing of a plume.
\end{abstract}




\subsection{Introduction}

It has long been recognized that local winds play an important role in the dynamics of river plumes. A theoretical study by Csanady [1978] demonstrates that steady alongshore winds must act to advect the seaward front associated with a plume either on- or off-shore in a manner consistent with Ekman dynamics. Observations [Masse and Murthy, 1990; Münchow and Garvine, 1993] as well as numerical simulations [Chao, 1987; Chao, 1988; Kourafalou et al., 1996a] of river plumes are consistent with Csanady's [1978] results: upwelling winds tend to spread plume waters offshore.

Although the basic tendency for the plume to spread offshore during upwelling winds has been observed in the aforementioned studies, none of these studies quantifies the plume motions in response to upwelling winds, nor determines whether or not the Ekman physics is the only important part of the dynamical balance. Chapter 3 provides the first quantification of the plume response to alongshore winds. Observations of the western Gulf of Maine plume suggest that the motions at the seaward front of the plume are fairly well-described by an Ekman-dominated alongshore momentum balance. Using a simple slab model, it is shown that the Ekman dynamics can be used to predict the motion of the seaward plume front over short time scales. It is likely that the Ekman physics is important for the entire plume behavior, and one might expect the Ekman response to place strong constraints on how the structure of the plume is modified during an upwelling favorable wind event. The previous studies suggest that one consequence of upwelling winds is to thin the plume. The details of this thinning process have not been quantified or described in any detail.

Furthermore, it is possible that an upwelling wind may have the additional in- 
fluence of enhancing the likelihood of the plume mixing with the ambient coastal waters. The stratification associated with the plume is expected to arrest the vertical transfer of the momentum input by the wind and trap the energy within the plume, so it is probable that the energy from the winds may be available to mix the plume and the ambient waters.

The wind-induced mixing of a river plume has received little attention in previous studies. Masse and Murthy [1992] observe the spreading of the thermally-driven Niagara River plume to behave qualitatively consistently with the Ekman response. They suggest that the secondary effect of winds is to act as a dissipative forcing agent that mixes plume and ambient waters. They argue that strong upwelling winds will enhance plume mixing by blowing the plume offshore and weakening the vertical density gradients. The enhanced shears induced by the thinning plume may make the plume more susceptible to shear-induced turbulent mixing. Souza and Simpson [1997] also note that winds may be important in driving mixing in a plume, but do not describe the mechanism by which it would be accomplished. There is a need to examine how the thinning and spreading of the plume waters during upwelling winds induce plume mixing.

Although the plume is a three-dimensional phenomenon, it is likely that some of the concepts developed in previous studies of one-dimensional mixing may be helpful in understanding the wind-induced mixing in the plume. There have been several investigations which have studied the one-dimensional mixing of a stratified fluid forced by a surface-stress (as reviewed by Fernando [1991]). A recent study by Trowbridge [1992] shows that the deepening of a stratified fluid driven by a surface-stress can be modeled as a gradient transport process where turbulent mixing is strong enough to maintain a gradient Richardson number at a critical 
value throughout the boundary layer. This conceptual model of mixing is consistent with both laboratory experiments [Kantha et al., 1977; Kato and Phillips, 1969] and oceanic measurements [Price et al., 1978; Price et al., 1986].

The mechanism by which mixing is achieved in these studies is stress-induced turbulence: the surface stress induces a sheared horizontal flow field within the boundary layer. If the shears are large enough to adjust the potential energy of the fluid, shear instability may result, and hence, turbulent mixing. For a plume that thins during an upwelling wind event, horizontal velocity shears should be enhanced, and hence, the likelihood of mixing.

The purpose of this study is to describe the response of a river plume during an upwelling favorable wind event. In particular, the chapter attempts to accomplish two objectives: (1) to determine how advective processes change the shape of the plume, and (2) to investigate the consequences of these advective motions on the mixing of the plume with ambient coastal waters.

In order to accomplish these objectives, two different methods are employed. In Section 4.2, a simple conceptual model is developed, employing simple physics and ideas developed in previous studies of one-dimensional mixing. The intuition developed from the conceptual model is then tested using a process-oriented numerical modeling experiment which is described in Section 4.3. While highly idealized, the numerical model provides a framework for investigating the important physical processes involved in the advection and mixing of a river plume. In Section 4.4, the numerical model is used to study the response of the plume to a moderate amplitude upwelling favorable wind event. These results are generalized for different forcing conditions in Section 4.5. In Section 4.6, the mixing during upwelling is compared 
with mixing during downwelling winds. The chapter is summarized and discussed in Section 4.7.

\subsection{Theory}

\subsubsection{Parameterizing vertical mixing in the plume}

It has been shown in previous studies of one-dimensional mixing that the stability of a stratified fluid, forced by a surface stress, can be characterized by a bulk Richardson number (e.g., Kantha et al. [1977], Kato and Phillips [1969])

$$
R i_{b}=\frac{B}{\|\vec{u}\|^{2}}
$$

where

$$
B=\frac{g}{\rho_{0}} \int_{-h}^{0}\left(\rho_{0}-\rho\right) d z
$$

$g$ is the gravitational acceleration, $h$ is the thickness of the plume, $\rho_{0}$ is the density of the ambient water, $z$ is the vertical direction, and $\|\vec{u}\|^{2}$ is the magnitude of the horizontal surface velocity.

If the alongshore momentum is primarily in Ekman balance (see Chapter 3), the mean cross-shore plume velocity can be estimated as,

$$
\bar{u}=\frac{\tau^{w}}{\rho h f}
$$

where $\tau^{w}$ is the wind stress and $f$ is the Coriolis parameter. For an upwelling wind event, it is expected that the alongshore plume velocity field will weaken and that 


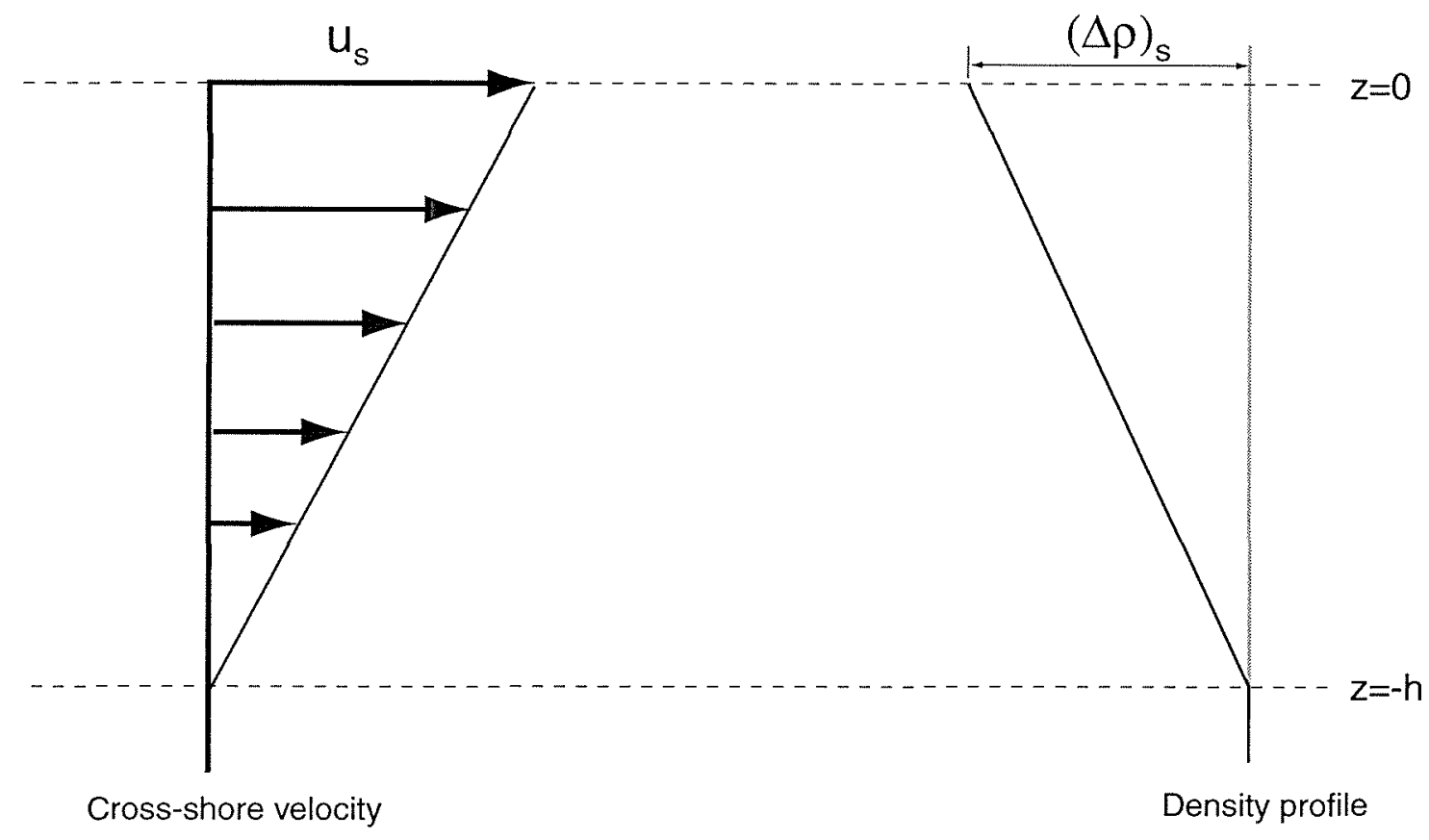

Figure 4.1: Velocity and density profiles in simple theory. The cross-shore velocity varies linearly from $u_{s}$ a the surface to the bottom of the plume $(z=-h)$ and vanishes beneath the plume. The density anomaly is also assumed to vary linearly within the plume with its maximum at the surface $(\Delta \rho)_{s}$. Note: the mean density anomaly $\overline{\Delta \rho}=(\Delta \rho)_{s} / 2$.

the mean cross-shore plume velocity will be larger than the mean along-shore plume velocity, i.e., $u_{s} \gg v_{s}$. If it is assumed that the cross-shore velocity field varies linearly with depth, the bulk Richardson number is estimated by

$$
R i_{b} \approx \frac{g^{\prime} h^{3}}{4\left(\frac{\tau}{\rho f}\right)^{2}}
$$

where $g^{\prime}$ is the mean reduced gravity $\left(g \frac{\overline{\Delta \rho}}{\rho_{0}}, \overline{\Delta \rho}\right.$ is the mean plume density anomaly), and the factor of four comes from assuming a linear velocity profile within the plume (Figure 4.1).

During an upwelling favorable wind event, the plume should become wider as 
the seaward front is advected offshore. If the buoyancy of the plume is conserved, this implies that the plume must become thinner. The scaling in (4.3) indicates, therefore, that an upwelling favorable wind will tend to reduce the bulk Richardson number in the plume, thus enhancing the likelihood of mixing.

\subsubsection{A simple conceptual model}

Based on simple Ekman physics and the Richardson number stability criterion discussed above, a simple conceptual model is now developed. Although the model will not explicitly include mixing physics, it will provide some insight into the advective plume response to an upwelling wind, and offer a starting point from which to examine the expected mixing dynamics of a plume.

Assuming the momentum input by the wind is largely confined within the stratification of the plume, and the alongshore momentum is dominated by an Ekman balance, the mean cross-shore plume velocity is estimated by (4.2). Furthermore, the continuity equation, integrated over the plume layer is,

$$
\frac{\partial h}{\partial t}+\frac{\partial}{\partial x}(\bar{u} h)=0
$$

For a spatially uniform wind stress, equation (4.2) requires that $\bar{u} h=$ constant, so

$\frac{\partial h}{\partial t}=0$ in the plume. In other words, these equations indicate that the plume thickness is locally constant. These assumptions, however, break down at the edges of the plume. The thickness at the seaward edge of the plume is set by other physics. It should be noted that the above constraint does not imply that the shape of the plume does not change in time: only at a fixed location in space does the plume thickness remain constant. The advected plume, in response to the Ekman 
dynamics, is stretching in the moving reference frame owing to cross-shore variations in plume thickness that result in divergences in the cross-shore velocity field.

To complete the conceptual model, a boundary condition is needed at the seaward front of the plume. The thickness at the seaward front sets the speed at which the plume spreads offshore. One expects that for a finite stress, the plume will have some finite thickness at the seaward edge. One hypothesis is that this thickness is set by the stability of the front to shear-induced turbulence.

As the simplest means of choosing the boundary condition for the seaward front, (4.3) can be solved for $h$ with the bulk Richardson number set to some critical value, $R i_{c}$, such that

$$
h_{c} \approx\left[\frac{4 R i_{c}\left(\frac{\tau^{w}}{\rho f}\right)^{2}}{g \frac{\Delta \rho}{\rho_{0}}}\right]^{\frac{1}{3}}
$$

It is expected that the critical bulk Richardson number $R i_{c}$ will fall in the range of 0.5-1.0 [Pollard et al., 1973; Price et al., 1986]. Because $h_{c}$ depends on $R i_{c}{ }^{1 / 3}$, the uncertainty of $R i_{c}$ can only change $h_{c}$ up to $14 \%$. It is worth noting that the expression (4.5) is equivalent to the depth scale found in Pollard et al. [1973] for a linearly stratified fluid with $R i_{c}$ set to unity.

The thickness $h_{c}$ at the seaward edge of the front subsequently determines the evolution of the plume (Figure 4.2). Substituting (4.5) into (4.2), the rate at which the seaward front moves offshore can be solved for,

$$
\bar{u}_{\text {front }}=\frac{\tau^{w}}{\rho f h_{c}}
$$



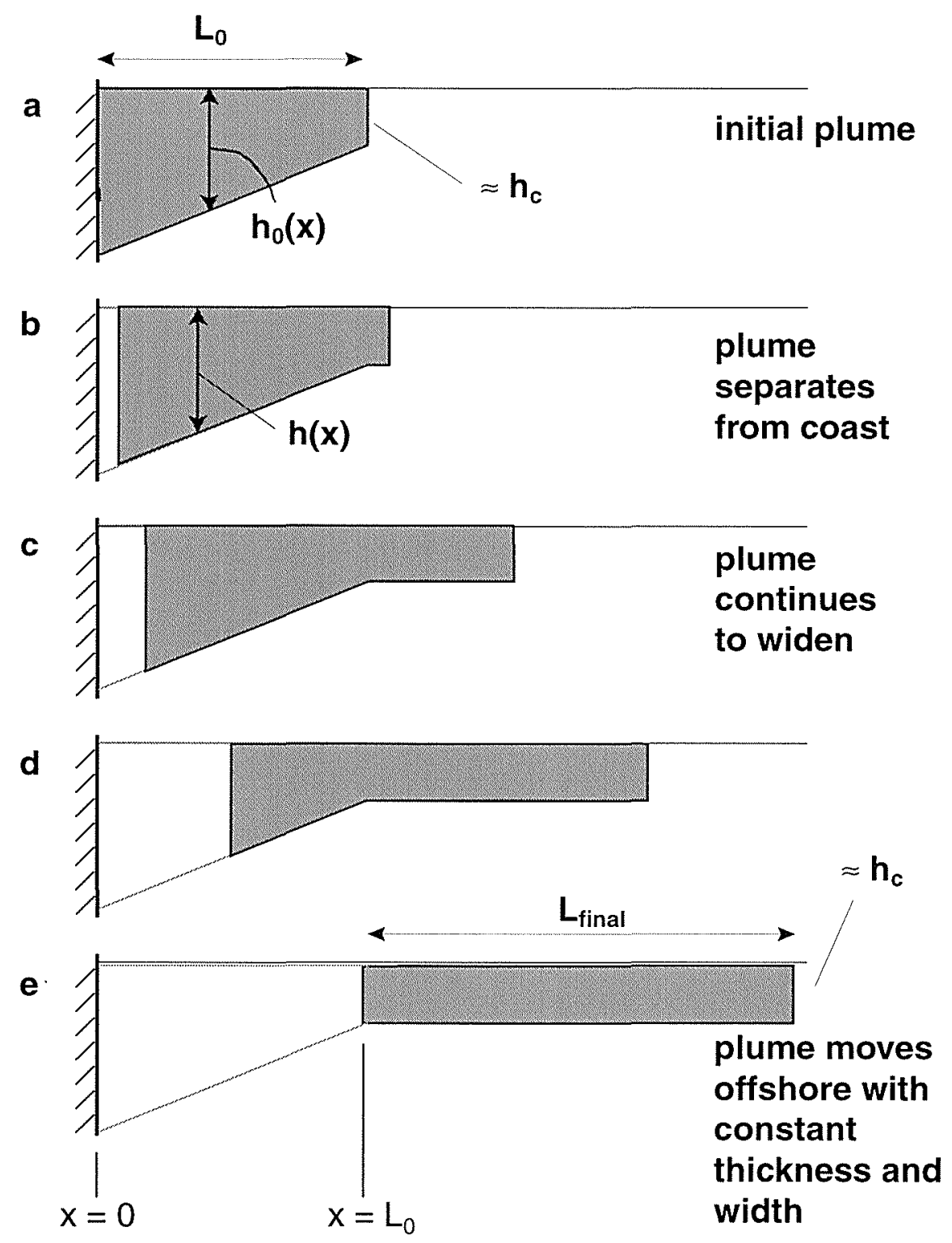

Figure 4.2: Cartoon of conceptual model plume response to a steady upwelling favorable wind. 
Similarly, the Ekman balance can be used to diagnose the motion at the shoreward edge of the plume,

$$
\bar{u}_{\text {rear }}= \begin{cases}\frac{\tau^{w}}{\rho f h_{0}(x)} & 0 \leq x<L_{0} \\ \frac{\tau^{w}}{\rho f h_{c}} & x \geq L_{0}\end{cases}
$$

where $h_{0}(x)$ is the initial plume thickness, and $L_{0}$ is the initial plume width.

Finally, as mentioned earlier, the conceptual model does not explicitly include any mixing or entrainment physics. Therefore, if the plume is assumed two-dimensional with no alongshore variations, then the area of the plume must be conserved.

The kinematics implied by the simple model are illustrated by the cartoon shown in Figure 4.2 where the plume's structure is denoted by the dark gray shading, and its initial structure is shown by the light gray outline. The seaward edge of the plume moves offshore at a rate inversely proportional to $h_{c}$. The plume will widen as long as the wind forcing persists and there are cross-shore variations in plume thickness. Eventually, the plume will cease widening once its thickness is uniform. The uniform thickness plume will continue to be advected offshore for as long as the wind forcing continues.

Again, it is important to emphasize that the conceptual model described above does not include any explicit parameterization of the mixing physics. It only uses a mixing criterion to set the offshore plume boundary condition. Despite lacking mixing dynamics, the conceptual model physics do suggest something about the mixing in the plume.

Equation (4.5) predicts that for portions of the plume thicker than $h_{c}$, the plume should be stable and not susceptible to shear-induced turbulence. However, as any 
portion of the plume approaches a thickness $h_{c}$, the Richardson number will approach the critical value, leading to the likelihood of turbulent mixing. If there are no cross-shore gradients in buoyancy within the plume, then mixing will cause a reduction in the salinity anomaly and an increase in thickness, with the total buoyancy remaining constant. However, if the plume deepens, then the bulk Richardson number, which is dependent on the plume buoyancy times the square of the plume thickness (see equation (4.3)), should increase and the plume should restabilize. Therefore, without any cross-shore buoyancy gradients within the plume, one expects none or very little mixing to take place.

To summarize, the conceptual model suggests that the response of a plume to a sustained upwelling wind involves the plume being advected offshore and stretching as long as there are cross-shore variations in plume thickness. If the wind event is sustained long enough, the plume will eventually stop widening and approach a steady-state uniform thickness. After the widening process ends, little mixing is expected to take place without any cross-shore buoyancy gradients.

The conditions at the ends of the slab in conceptual model, where there are significant gradients, have not been considered. In the next section, a processoriented numerical modeling experiment is described. The numerical model will be used to test the behavior predicted by the conceptual model and to describe the influence of physics not incorporated in the conceptual model, particularly those related to the seaward front. 


\subsection{3-D Model description}

A three-dimensional, primitive equation hydrodynamic model [Blumberg and $\mathrm{Mel}$ lor, 1987] is used to study the wind-induced mixing of a river plume. The model domain, shown in Figure 4.3, is a rectangular basin which is an idealized version of the moderately steep nearshore bathymetry found on many continental shelves. Freshwater is discharged via a short river/estuary system at the coast in the upper left hand corner of the $95 \mathrm{~km} \mathrm{x} 450 \mathrm{~km}$ model basin (Figure 4.3). In order to resolve the spatial variability of the plume, a spatially-varying, high resolution grid with $50 \times 140 \times 23$ grid cells is employed. The vertical grid varies in proportion to depth, a "sigma-coordinate" system. The sigma levels are unevenly spaced with a higher concentration of levels near the water surface with the goal of resolving the structure of the surface-trapped plume. Grid cell centers are indicated by dots in Figure 4.3. For the surface-trapped plume features of interest, resolution is better than 1 meter in the vertical, $1.5-3 \mathrm{~km}$ in the cross-shore direction, and $3-6 \mathrm{~km}$ in the alongshore direction. For the downwelling case considered in Section 4.6, the cross-shore resolution is $0.75-1.5 \mathrm{~km}$.

The model solves the hydrostatic, Boussinesq equations with sub-grid-scale motions parameterized by eddy coefficients for momentum and scalar diffusion. The coefficients are calculated using the Mellor-Yamada level 2.5 turbulence closure scheme [Mellor and Yamada, 1982]. This scheme has a gradient Richardson number threshold of 0.24 [Mellor and Yamada, 1982; Nunez Vaz and Simpson, 1994], similar to the criteria used by Trowbridge [1992]. It is expected that this will be a reasonable

parameterization of the shear-induced turbulent mixing generated by an upwelling favorable wind stress. The horizontal diffusivities are held constant at $10 \mathrm{~m}^{2} / \mathrm{s}$. The 

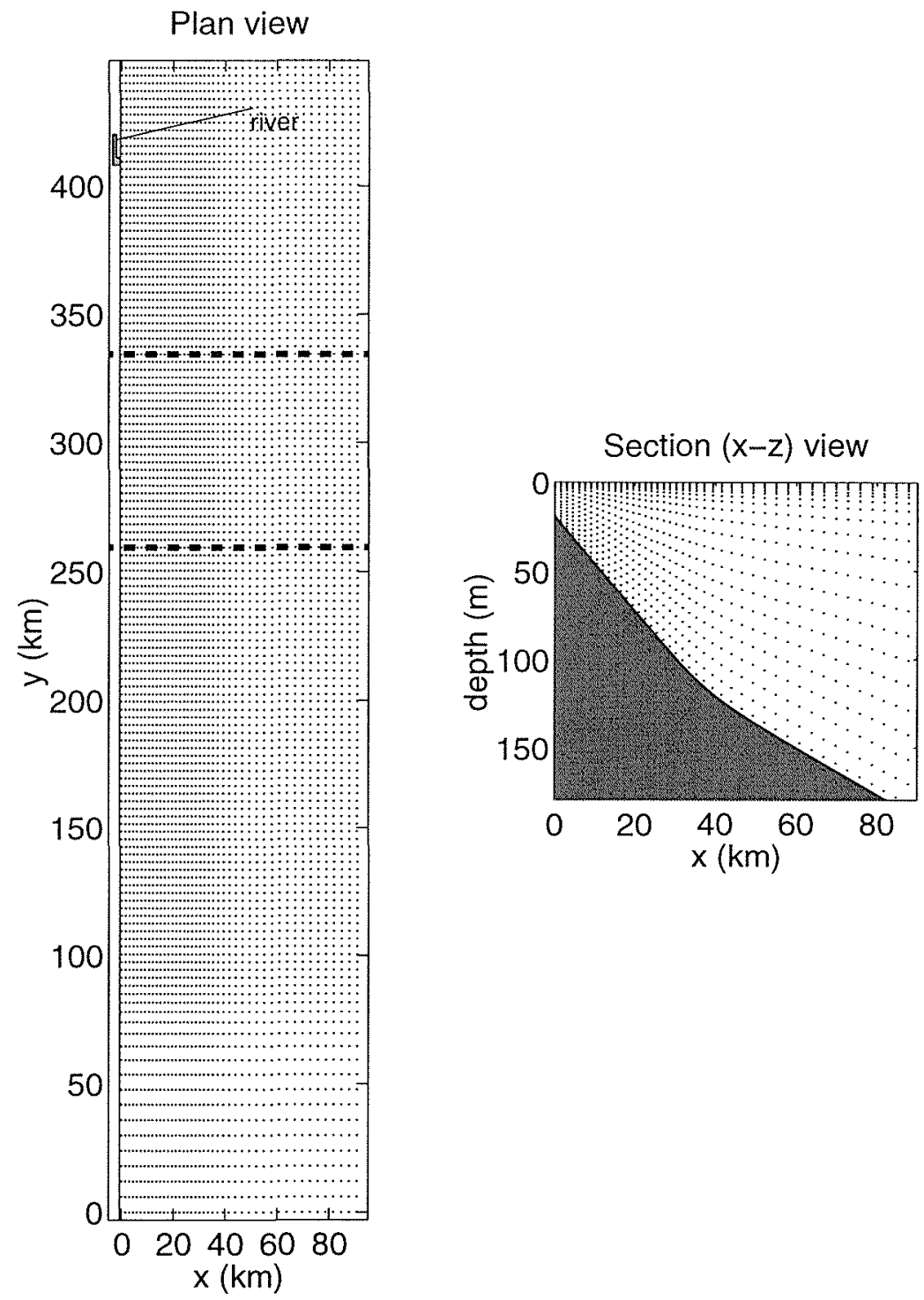

Figure 4.3: Model configuration. Blumberg and Mellor's Estuarine Coastal Ocean Model-3d (ECOM-3D) is run on a $95 \mathrm{~km} \times 450 \mathrm{~km} \times 200 \mathrm{~m}$ grid. Grid resolution is indicated by small dots in both plan and section views. Vertical sigma levels are closely spaced at the surface to resolve the near surface plume behavior. The topography is chosen as an idealized version of a moderately steep continental shelf and is uniform in the alongshore $(y)$ direction. Freshwater is discharged at the head of the estuary/river system shaded in gray in the northwestern (upper-left corner of the plan view) of the model basin. Dashed lines indicate the region over which a composite, alongshore-averaged cross-section is constructed to plot different property distributions. 
influence of rotation is implemented with a constant Coriolis parameter $f=10^{-4} \mathrm{~s}^{-1}$.

Horizontal derivatives are calculated explicitly while vertical differencing is implicit. The model employs a split time step for internal and external modes. The external mode is two-dimensional, time-stepped in small increments to satisfy the CFL condition associated with surface-gravity waves while the slower internal mode time step is based on the internal wave speed. For the simulations presented in this chapter, the external time step is ten seconds, and the internal time step is seven minutes. The detailed model characteristics are described in Blumberg and Mellor [1987] and only differences from that model formulation are discussed here.

In advecting the salt and temperature fields, a recursive Smolarkiewicz scheme [Smolarkiewicz and Grabowski, 1990] is used. This scheme has less numerical diffusion than other schemes, which is important when studying fronts.

\subsubsection{Boundary conditions}

At the coastal wall, the normal velocity is zero, and a free-slip boundary condition is used for the tangential velocity. The solution does not change appreciably if a semi-slip or no-slip condition is used instead because of the shallow depth at the wall. At the ocean bottom, the fluxes of salt and heat are zero. There is no flow normal to the topography; the bottom stress is specified using the velocities at the bottom grid cell and a quadratic drag law.

The surface boundary conditions are no flux of salt and heat (no solar radiation, heating, evaporation, nor precipitation), and wind stresses are applied such that, 


$$
K_{M}\left[\frac{\partial u}{\partial z}, \frac{\partial v}{\partial z}\right]=-\frac{\left[\tau^{w x}, \tau^{w y}\right]}{\rho_{0}}
$$

where $\tau^{w x}$ and $\tau^{w y}$ are the applied cross-shore and alongshore wind stress at the surface grid cells, respectively.

As discussed by Oey and Mellor [1993] and Kourafalou et al. [1996b], open boundary conditions are specified to allow internal waves and bores that propagate along the coast to pass through the model basin. A clamped zero elevation is specified at the offshore ( $x=95 \mathrm{~km}$; see Figure 1) boundary (no tidal forcing) and a modified Sommerfield radiation condition [Orlanski, 1976] employed at the downstream $(y=0$ $\mathrm{km}$ ) boundary. This implementation is similar to that used by Oey and Mellor [1993]. In addition, the model also has enhanced alongshore diffusion at the grid cells near the downstream boundary $(y=0-50 \mathrm{~km})$ in the model domain. At the upstream $(y=450 \mathrm{~km})$ boundary, a steady inflow of $10 \mathrm{~cm} / \mathrm{s}$ is applied to represent an ambient coastal flow field in the direction of Kelvin wave propagation. This value is representative of the ambient current found on many continental shelves.

Freshwater discharge is implemented via a small river/estuary region shown in gray in Figure 4.3 at $y=408 \mathrm{~km}$. The river/estuary system is one grid cell wide and $15 \mathrm{~m}$ deep. The freshwater is discharged at the head of the estuary uniformly over the entire $15 \mathrm{~m}$ depth.

\subsubsection{Initializing a freshwater plume}

In order to study the influence of an upwelling wind event on a plume, the model plume is "spun up" in the absence of winds for a period of 36 days of buoyancy

forcing ( 0 psu water) at a constant rate of $1500 \mathrm{~m}^{3} / \mathrm{s}$ at the head of the estuary. 
The freshwater is discharged into an initially homogeneous domain of 32 psu water; the freshwater and ambient water are both the same temperature $\left(4^{\circ} \mathrm{C}\right)$. In addition, a constant ambient flow field of $32 \mathrm{psu}$ water at $10 \mathrm{~cm} / \mathrm{s}$ in the direction of Kelvin wave propagation (hereafter, referred to as the downstream direction) is applied at the northern boundary of the domain to simulate a typical ambient current observed in many river plume systems.

It is worth noting that rarely in nature does a river plume develop in the absence of significant wind forcing for more than a week, so this initialization is somewhat artificial. The motivation for establishing the initial plume over a long time period is threefold. First, the long spin up allows for the study of mixing processes in isolation of the buoyancy source. Therefore, the plume is developed for a long enough period such that a cross-shore section can be studied far downstream of the buoyancy source. A second motivation for the long spin-up time is to produce a significant buoyancy signal prior to a wind-mixing event. By studying the wind-induced mixing of a well-developed plume, one can study how an upwelling wind event transports and mixes a large buoyancy anomaly associated with a plume. Finally, the steady inflow over several days removes the influence of transient phenomena associated with variations in freshwater inflow. In reality, wind and freshwater inflow fluctuations interact to influence plume conditions. However, these interactions are beyond the scope of this study.

After establishing the unforced plume (see Figure 4.4a), a steady alongshore wind stress of upwelling favorable direction is applied (in the positive $y$ direction for the model plume system shown in Figure 4.3) for a period of three days. 

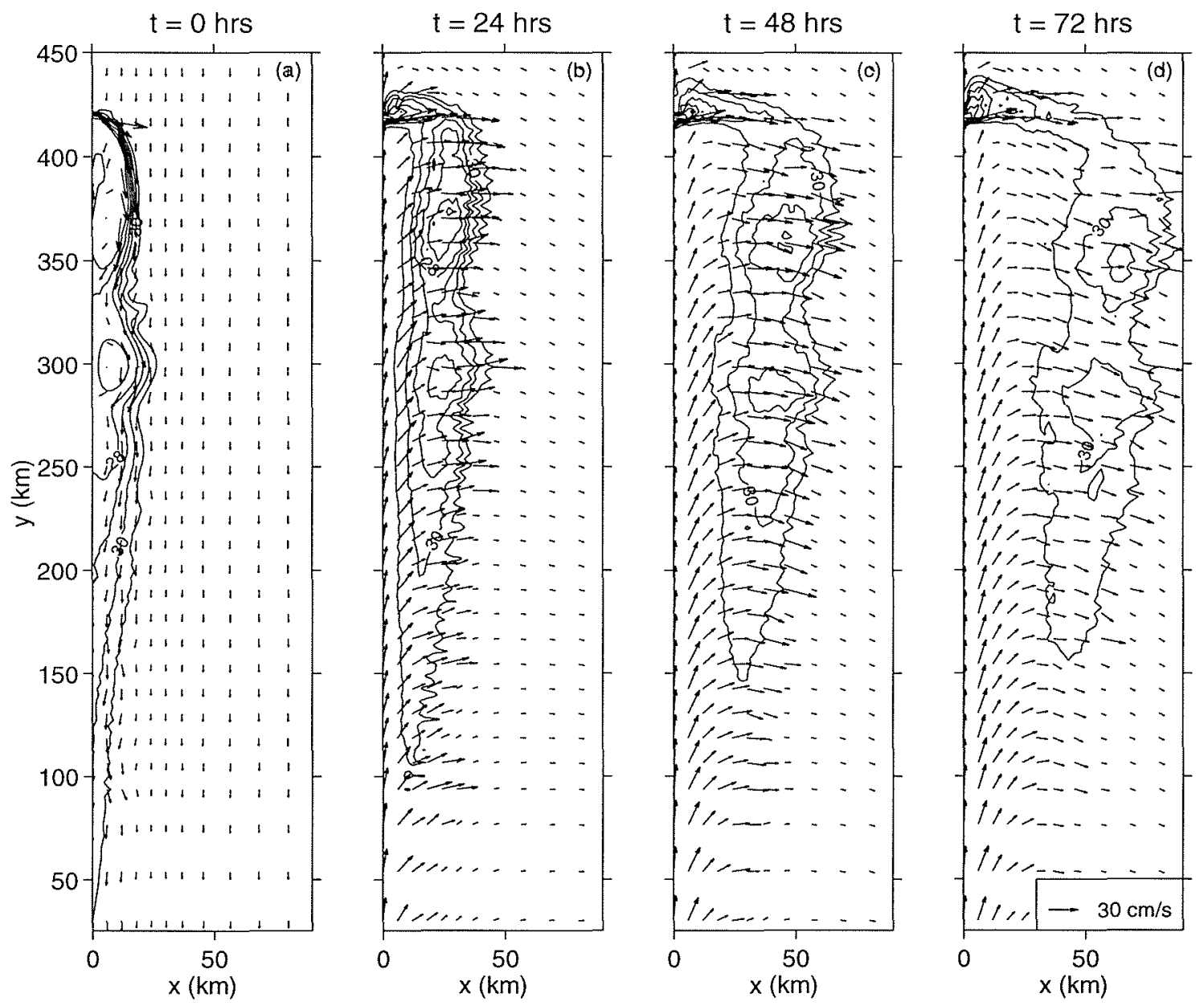

Figure 4.4: Surface Salinity for River Plume forced by a 1 dyne $/ \mathrm{cm}^{2}$ upwelling wind. (a) Initial plume structure after 1 month of buoyancy forcing in the absence of winds. Freshwater discharge is steady, $Q=1500 \mathrm{~m}^{3} / \mathrm{s}$, and an ambient southward current is applied at $y=450 \mathrm{~km}$. (b)-(d) plume structure after $t=24,48$, and 72 hours of wind forcing, respectively. Horizontal surface velocity vectors are superimposed. 


\subsection{Plume response to a moderate amplitude wind}

In this section, the response of a plume to a steady 1 dyne $/ \mathrm{cm}^{2}$ upwelling favorable wind event is presented. The results are generalized and discussed for different amplitudes of wind stress and buoyancy forcing in Section 4.5.

\subsubsection{Basic plume response}

A plot of the surface salinity after "spin up" is shown in Figure 4.4a. After over a month of buoyancy forcing, in the absence of winds, the plume has developed into a large feature, propagating at $\sim 10 \mathrm{~km} /$ day in the downstream direction. The plume narrows at its leading edge to a thin coastal current that transports some of the fresh water downstream at a greater velocity.

After being forced with a steady $1 \mathrm{dyne} / \mathrm{cm}^{2}$ upwelling wind, the surface salinity and velocity fields clearly indicate the basic Ekman response of the plume being advected offshore (Figure 4.4). After twenty-four hours of wind forcing, the plume has separated from the coast. The influence of mixing throughout the plume is indicated by the reduction of the salinity anomaly.

While the plume does exhibit some alongshore variability, the response is roughly two-dimensional: the plume is advected offshore at all alongshore locations. The motion of the plume is primarily in the offshore direction. The wind-driven surface velocities are larger within the plume than they are further offshore in the unstratified waters. This is consistent with the paradigm of the stratification associated with the plume compressing the vertical Ekman scale. Since the cross-shore velocity is inversely proportional to this depth scale (see equation 4.2), velocities are largest within the the stratified plume. 
The transverse plume structure, which is a composite section averaged in the alongshore region between $\mathrm{y}=260 \mathrm{~km}$ and $\mathrm{y}=335 \mathrm{~km}$ (see Figure 4.3), is shown in Figure 4.5. In response to the upwelling wind, the plume deepens at its seaward front and is advected offshore. As the plume is advected offshore, it widens due to divergence in the cross-shore velocity induced by cross-shore variations in plume thickness. After three days of steady wind forcing, the plume is an almost uniformly thick parcel of fluid being advected offshore, after which its thickness remains nearly uniform, in agreement with the behavior predicted by the conceptual model. In addition, there is a significant reduction in the salinity anomaly, indicating significant mixing occurs.

The stress distribution in the plume indicates that the stratification of the plume is effective at confining the influence of the wind stress to within the halocline of the plume, $\sim 5 \mathrm{~m}$ from surface (Figure 4.5 ). The stress at the base of the plume is less than ten percent of the amplitude of the applied surface stress. In contrast, the stress field is much stronger at depth in the unstratified regions of the model domain; the Ekman depth in the unstratified waters is over $40 \mathrm{~m}$ in the model run presented (note that this is much deeper than the depths shown in Figure 4.5).

The Ekman balance within the plume is evident in profiles of the stress divergence and Coriolis terms in the alongshore momentum balance after forty-eight hours of wind forcing (Figure 4.6). The Ekman balance is dominant throughout the plume. The horizontal diffusion and pressure gradient terms are two orders of magnitude smaller than either term of the Ekman balance; the local acceleration and nonlinear terms are one order of magnitude smaller.

Although the plume has nearly uniform thickness after two days of wind forcing, 

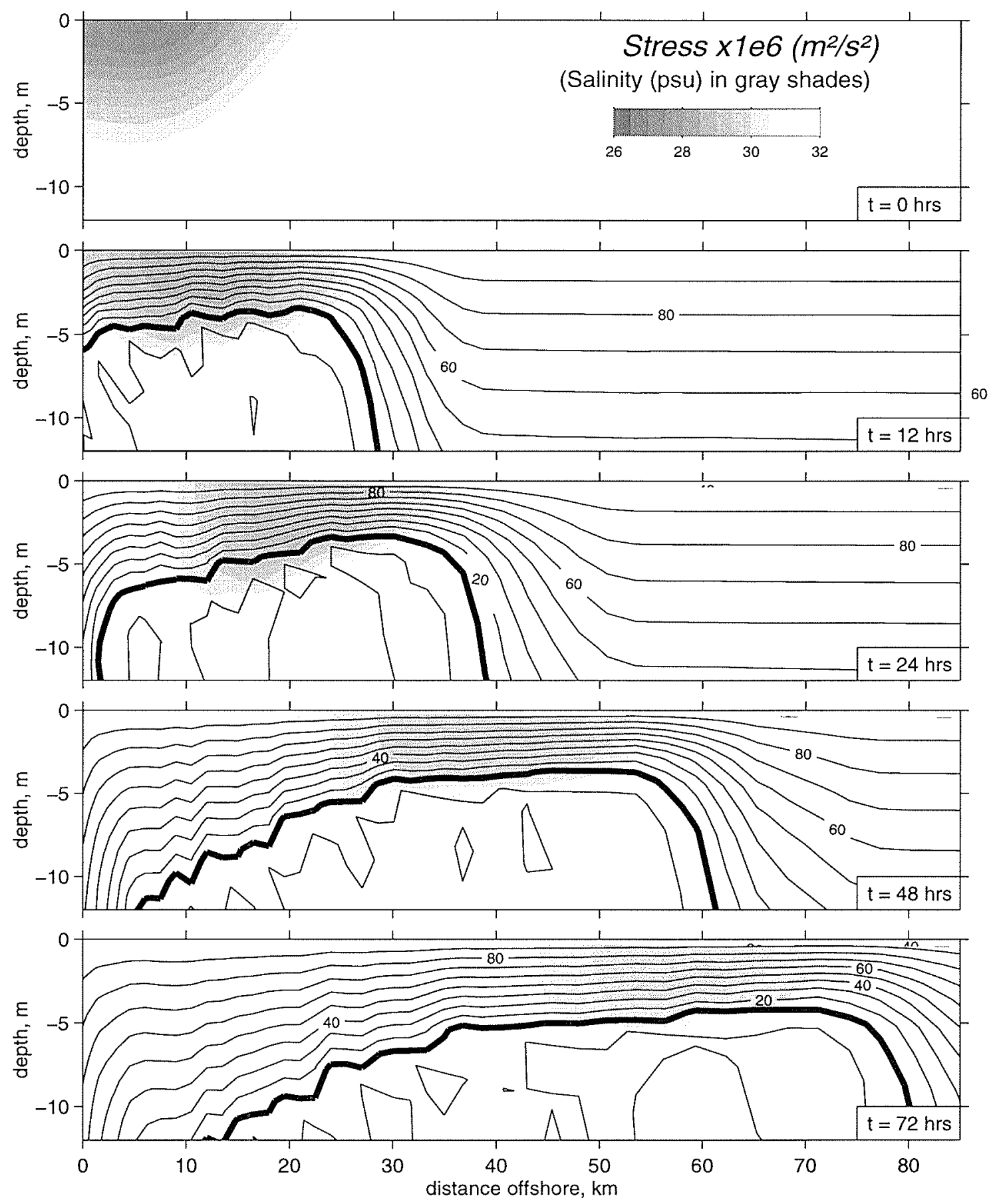

Figure 4.5: Contours of stress and salinity for $\mathrm{t}=0,12,24,48$, and 72 hours. Gray contours are used to indicate salinity contours in intervals of $0.5 \mathrm{psu}$. Superimposed on the gray shading are contours of magnitude of the total stress in solid contour lines ( 0.1 dyne $/ \mathrm{cm}^{2}$ intervals). The thick contour line is stress which is $10 \%$ of the applied surface stress. 

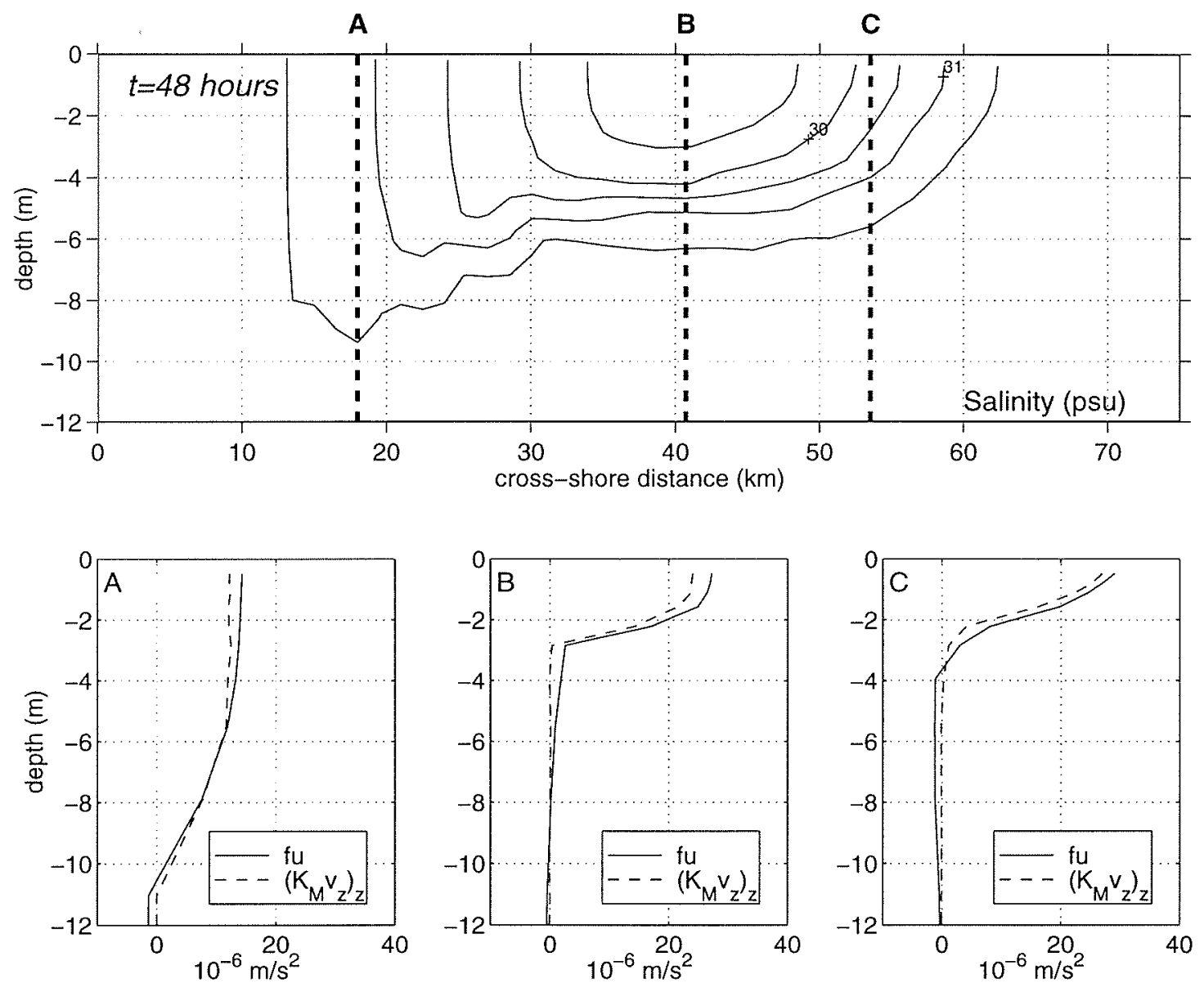

Figure 4.6: Profiles of Coriolis and stress divergence terms of the alongshore momentum balance (Ekman terms) at $t=48$ hours for the shoreward front (A), plume core (B), and seaward front (C). Other terms are significantly smaller (see text for discussion and Figure 4.7 for more details). $K_{M}$ is the turbulent diffusivity of momentum. 
there are small cross-shore variations even after three days. The plume is slightly deeper on its shoreward side, in contrast to the conceptual model. One possible explanation for the small cross-shore variations in thickness are the nonlinear terms in the along-shore momentum balance (Figure 4.7). There are cross-shore shears in the alongshore velocity due to the cross-shore salinity gradients. The small, negative cross-shore advection of alongshore shears $\left(u \frac{\partial v}{\partial x}\right)$ at the shoreward edge of the plume causes a small divergence in cross-shore transport, and hence, a small deepening tendency. Turning off the nonlinear terms in the momentum equations in the model reduces the cross-shore variations in plume thickness observed at $t=48$ and 72 hours. Some variations, however, still exist in the absence of momentum advection.

Entrainment also contributes to the deviations from a purely flat-bottom plume. With any mixing in the plume, the right-hand side of (4.4) will be nonzero. Therefore, since there is mixing of the plume with ambient waters, small cross-shore variations in cross-shore transport and plume thickness exist.

The cross-shore momentum balance is dominated by three terms. Before the wind stress is applied, the plume is geostrophically-balanced in the cross-shore direction, but as the cross-shore velocities increase after the wind stress is applied, the vertical stress divergence becomes important. The cross-shore momentum, during an upwelling favorable wind event, is in geostrophic balance with a superimposed Ekman spiral, and an approximate balance exists between the Coriolis, pressure gradient, and stress divergence terms (Figure 4.8). The vertical structure of alongshore velocity mimics the curvature of the stress divergence profile while the pressure gradient is nearly uniform in the vertical. There is a barotropic alongshore flowfield associated with imposed ambient currents. The vertical structure in the alongshore velocity is mainly attributable to the Ekman response, with a downstream flow near 

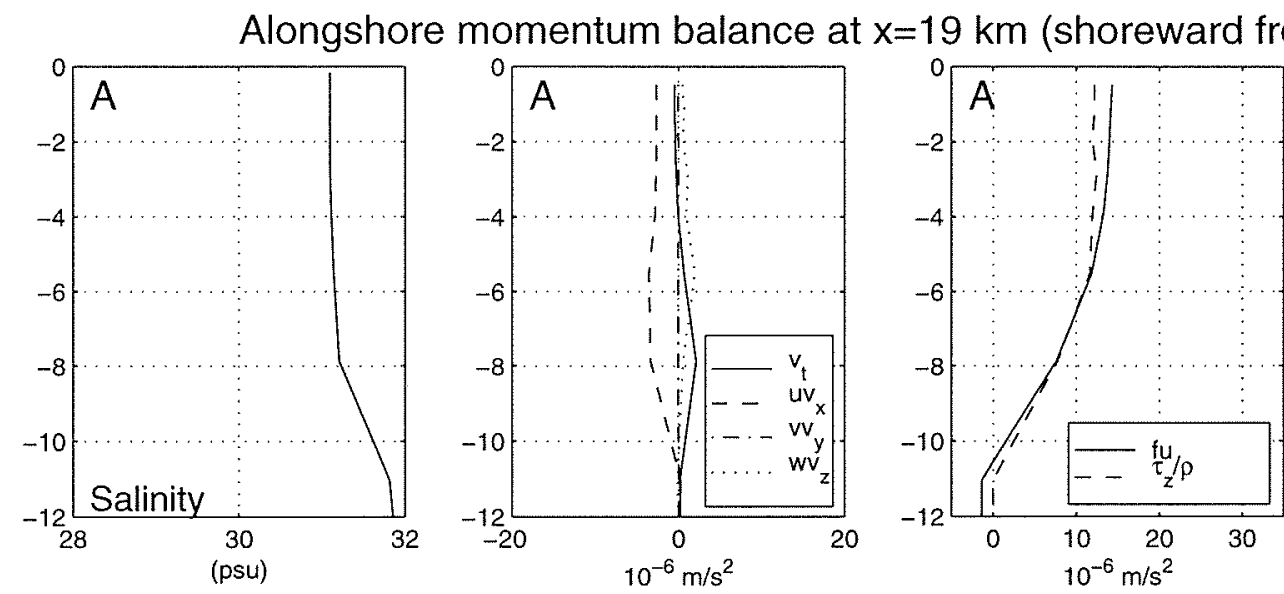

Alongshore momentum balance at $\mathrm{x}=41 \mathrm{~km}$ (plume center)
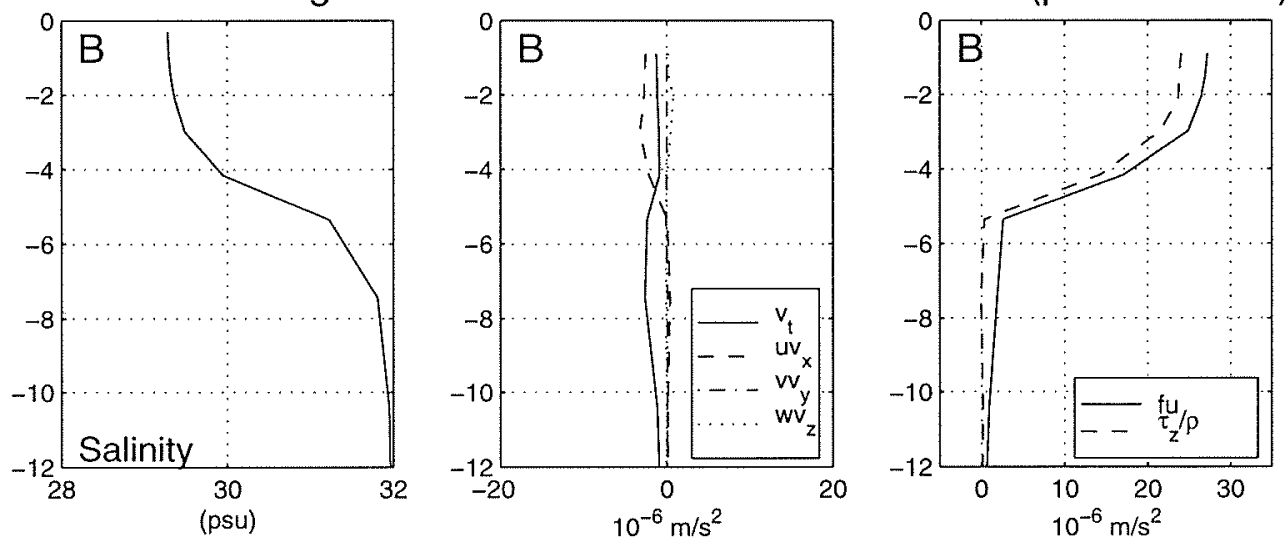

Alongshore momentum balance at $\mathrm{x}=54 \mathrm{~km}$ (seaward front)
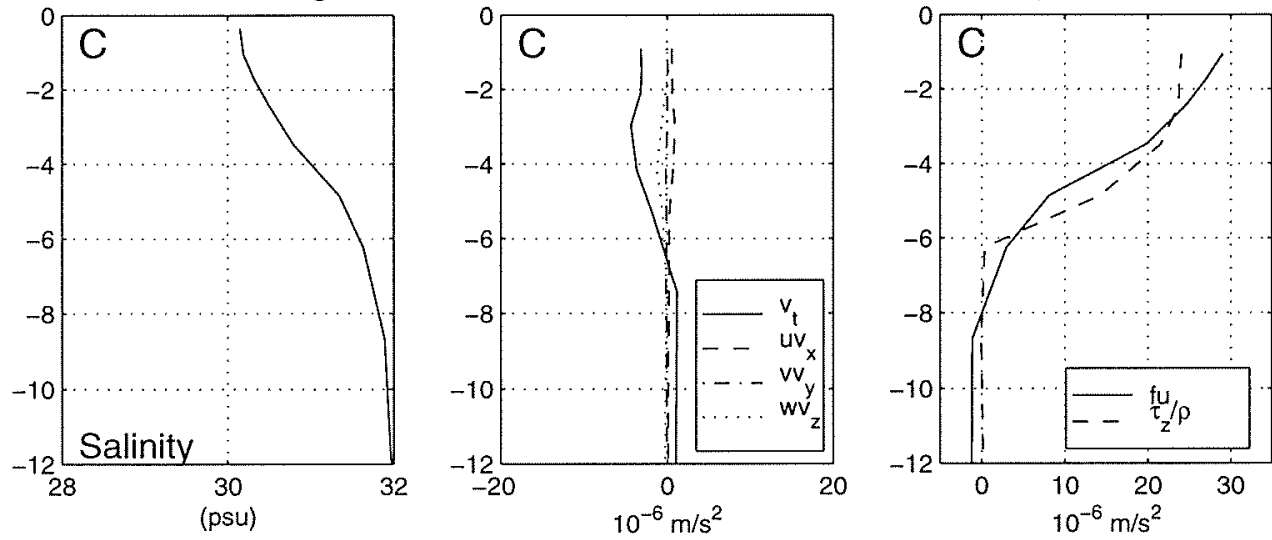

Figure 4.7: Salinity and Alongshore momentum balance terms at shoreward front (A),plume center (B), and seaward front (C) at $\mathrm{t}=48$ hours. (for locations of profiles $\mathrm{A}, \mathrm{B}$, and $\mathrm{C}$, see Figure 4.6). As noted in text, alongshore pressure gradient and horizontal diffusion terms are more than two orders of magnitude smaller than the Coriolis and stress divergence terms. 
the surface of the plume and a upstream flow at its base. Geostrophic shears at the shoreward and seaward fronts also contribute to small vertical shears in alongshore velocity.

The basic plume response observed in the numerical model is roughly consistent with the response suggested by the conceptual model. The seaward front initially mixes to a finite thickness, and as the wind event persists, the plume is advected offshore, and stretched. For later time, the plume approaches nearly uniform thickness. The numerical experiment differs, however, from the behavior of the conceptual model in two important ways. Due to entrainment and cross-shore advection of momentum, the plume is not exactly a uniform thickness. In addition, the numerical model differs from the conceptual model by exhibiting mixing; the salinity anomalies are significantly reduced in time. While the conceptual model did not incorporate mixing physics explicitly, the basic features of it implied that mixing should shut down shortly after the widening process ends. The conceptual model also neglected shears in the alongshore velocity field.

The mixing dynamics of the numerical model will next be presented. It will be shown that the persistent mixing in the numerical model is a result of the cross-shore variations within the plume and the details of the seaward plume front. Both these plume characteristics are missing from the conceptual model presented in Section 4.2 .2 .

\subsubsection{Plume mixing dynamics for a moderate amplitude wind}

In order to quantify the vertical mixing of salt within the plume due to wind forcing,

the vertical salt flux ( $K_{H} \frac{\partial S}{\partial z}$, where $K_{H}$ is the vertical eddy diffusivity of salt) is 


\section{Cross-shore momentum balance at $x=19 \mathrm{~km}$ (shoreward front)}
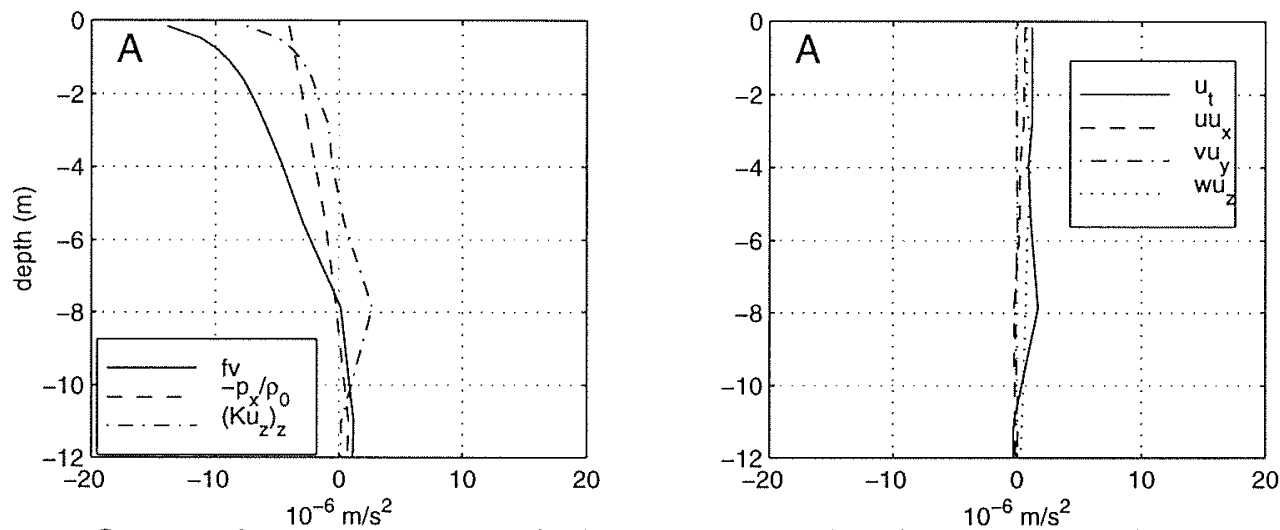

Cross-shore momentum balance at $\mathrm{x}=41 \mathrm{~km}$ (plume center)
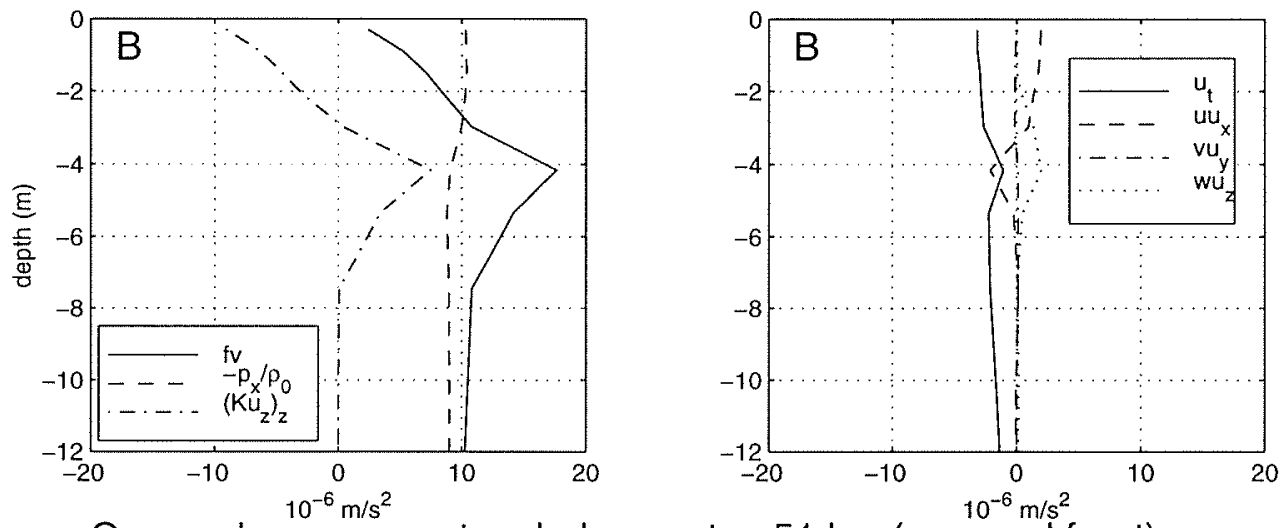

Cross-shore momentum balance at $\mathrm{x}=51 \mathrm{~km}$ (seaward front)
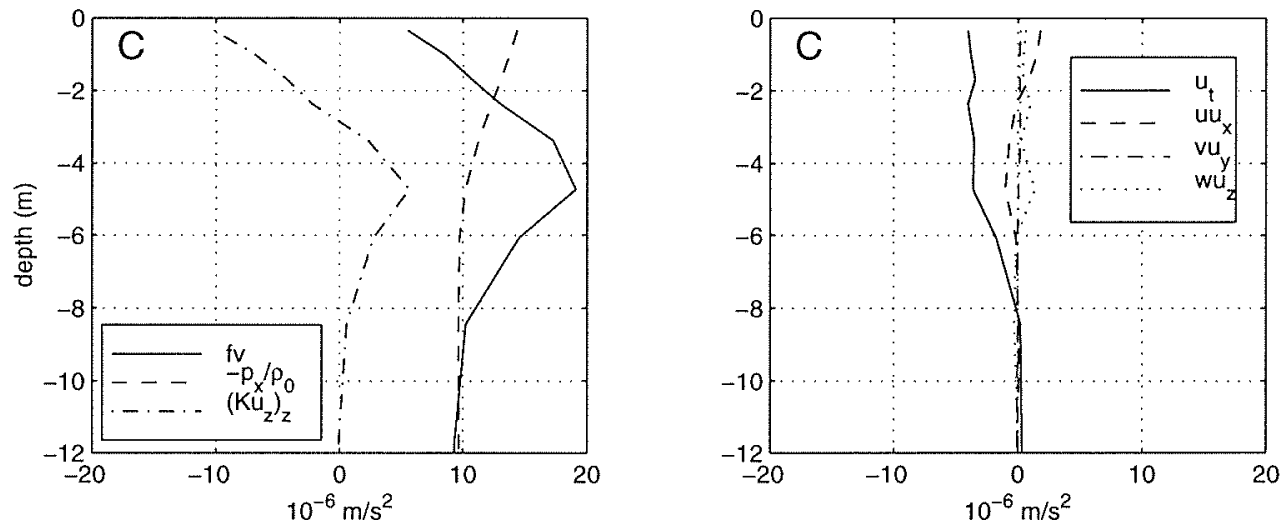

Figure 4.8: Cross-shore momentum balance at the shoreward front (A), plume center (B), and seaward front $(\mathrm{C})$ at $\mathrm{t}=48$ hours (for locations of profiles $\mathrm{A}, \mathrm{B}$, and $\mathrm{C}$, see Figure 4.6). The horizontal diffusion terms (not shown) are approximately an order of magnitude smaller than the advective terms. 
computed. During the early stages of the wind event ( $t=12$ hours) mixing takes place throughout the entire plume (Figure 4.9). This mixing is attributable to three different sources of shear-induced mixing. Shears are generated by the developing Ekman velocities, the alongshore geostrophic current associated with the cross-shore salinity gradients, and the transient response to the wind. The latter contribution results from the impulsively applied wind stress which is ramped up over a time interval of a few hours. The importance of the transients and inertial response will be discussed in Section 4.5.

After the initial transient response ( $\mathrm{t}=24$ hours), mixing is predominantly in the seaward portion of the plume, which is thinner than the shoreward region. After forty-eight hours, mixing is occurring throughout the uniformly thinned plume. After seventy-two hours, the mixing intensity has fallen, but mixing continues. For times greater than 12 hours, the highest intensity mixing occurs near the seaward front.

The cross-shore integrated vertical salt flux is given in the lower left corner of each panel in Figure 4.9. This quantity gives an estimate of the total mixing in the plume. It is proportional to the change in potential energy in a 1-D column of fluid [Simpson and Bowers, 1980]. The values shown in Figure 4.9 (for $\mathrm{t} \geq 12 \mathrm{hrs}$ ) correspond to an average entrainment velocity in the plume of $\mathrm{O}\left(10^{-5}\right) \mathrm{m} / \mathrm{s}$. The total integrated salt flux during the wind event is an order of magnitude larger than the flux observed prior to the wind event.

In spite of the vertically-averaged shear in the plume being dominated by the cross-shore component of the Ekman response, both along- and cross-shore shears are important in driving the mixing in the plume. Figure 4.10 shows profiles of 


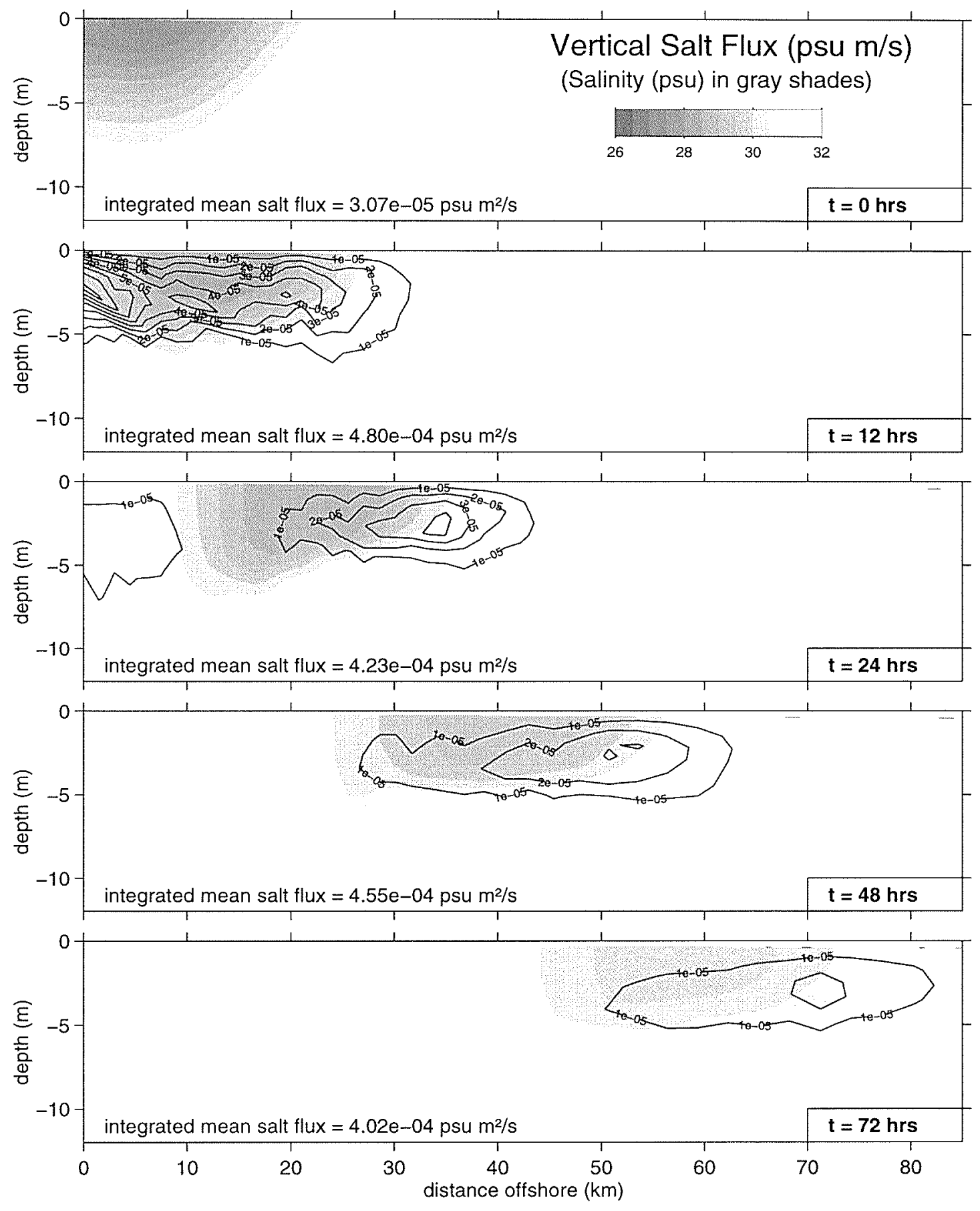

Figure 4.9: Contours of vertical salt flux and salinity for $t=0,12,24,48$ and 72 hours. Gray contours are used to indicate salinity contours in intervals of 0.5 psu. Superimposed on the gray shading are contours of vertical salt flux in solid contour lines $\left(10^{-5} \mathrm{psu} \mathrm{m} / \mathrm{s}\right.$ intervals $)$. The cross-shore integrated mean vertical salt flux is indicated in the lower left corner of each panel. 
along- and cross-shore shears in different regions of the plume. Both the along- and cross-shore components of shear contribute to the shear-induced turbulent mixing. It is important to emphasize that the bulk Richardson number, which quantifies the net shear in velocity between the surface of the plume and the water beneath it, does not account for any contribution of the alongshore shear (difference in velocity between the surface and beneath the plume) to the shear-induced turbulence in the plume since the depth-averaged alongshore velocity shear is zero. The velocity profiles in Figure 4.10, however, illustrate that there are significant along- and crossshore shears within the plume that promote turbulent mixing. It should be noted that the model set up promotes the zero depth-averaged velocity shear since the ambient current opposes the wind-induced alongshore velocity response. There is also significant variability in the shears and the intensity of mixing at the different cross-shore plume locations. The largest mixing occurs at the seaward front; this behavior is explained below.

A comparison of the stratification and stress profiles within the plume at $t=72$ hours (Figure 4.11) explains why the maximum vertical salt flux is at the seaward plume front. The stress profiles are similar at all cross-shore plume locations, but the stratification varies considerably. Mixing is largest at the seaward front because there is significant stratification close to the surface where the stress-induced turbulence is greatest. In contrast, weaker mixing occurs in the middle and shoreward portions of the plume since stratification is weak where the stress is large. In order for the stratification to be maintained in the presence of mixing, there must be some mechanism for replenishing the stratification.

The near surface stratification at the seaward front is maintained by the straining of the cross-shore density gradient by the sheared cross-shore Ekman flow field. 

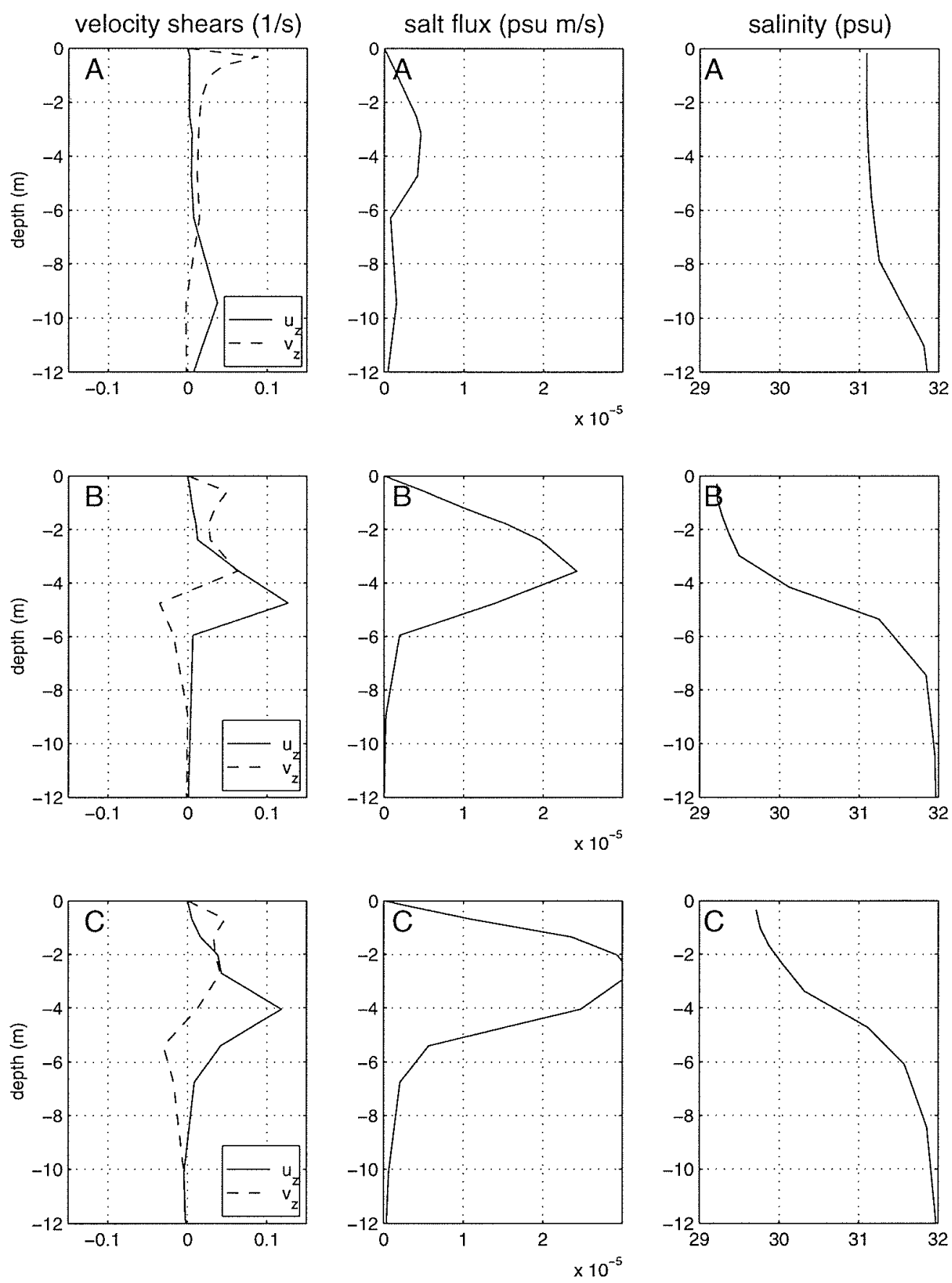

Figure 4.10: Profiles of velocity shears, salt flux, and salinity at the shoreward front (A), plume center (B), and seaward front (C) at $t=48$ hours (for locations of profiles $\mathrm{A}, \mathrm{B}$, and $\mathrm{C}$, see Figure 4.6). 

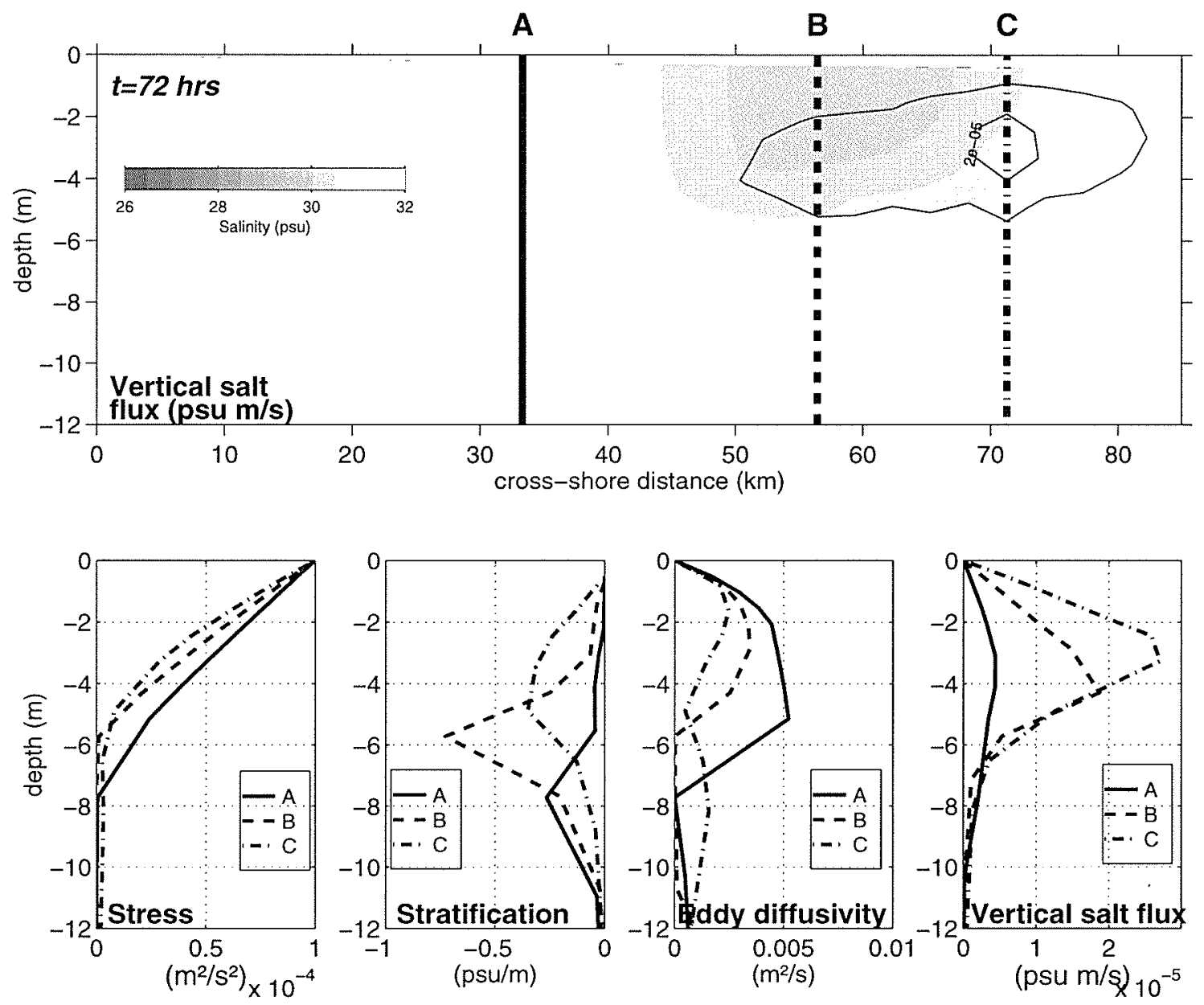

Figure 4.11: Contours of salinity (gray shades) and vertical salt flux are shown in the upper panel at $\mathrm{t}=72$ hours. Profiles of stress, stratification, eddy diffusivities of salt, and vertical salt flux are plotted in the lower panels for the shoreward front (A), plume core (B), and seaward front (C). 
The sheared cross-shore velocity acts on the horizontal density gradient associated with the front and creates vertical stratification; vertical mixing induced by the wind opposes the development of the stratification and tends to make the isohalines vertical. The balance between advection of the horizontal density gradient tending to flatten the isohalines and vertical mixing making them vertical is analogous to the advective-diffusive balance that takes place in a stratified estuary [Simpson et al., 1990]. Instead of the subtidal estuarine shear maintaining the stratification, the Ekman-induced cross-shore currents strain the isohalines of the seaward front in an upwelling wind-forced plume. The advective-diffusive balance achieved by this "Ekman straining" mechanism will continue as long as the upwelling wind field persists. For a sufficiently long upwelling favorable wind event, mixing will continue via Ekman straining until the plume is destroyed.

Mixed water from the seaward front is transported to the other portions of the plume, because the cross-shore flow field is sheared and horizontally divergent. This is illustrated with a plot of the velocity field within the plume (Figure 4.12). The velocity field shown is the model velocity minus the observed cross-shore velocity at the centroid of the plume (indicated by the dot in Figure 4.12). Within this reference frame, recirculation occurs between the central and seaward portions of the plume. There is a net transport of fresher water into the frontal portion and a net transport of saltier water to the plume center. These exchanges weaken the stratification shoreward of the seaward front, thereby weakening the stratification in the central plume and making the central plume water more prone to mixing.

It is worth noting that although there is only weak vertical mixing in the shoreward front of the plume, there is small, but significant horizontal mixing at the shoreward front which coincides with the entrainment of ambient water. The cross- 


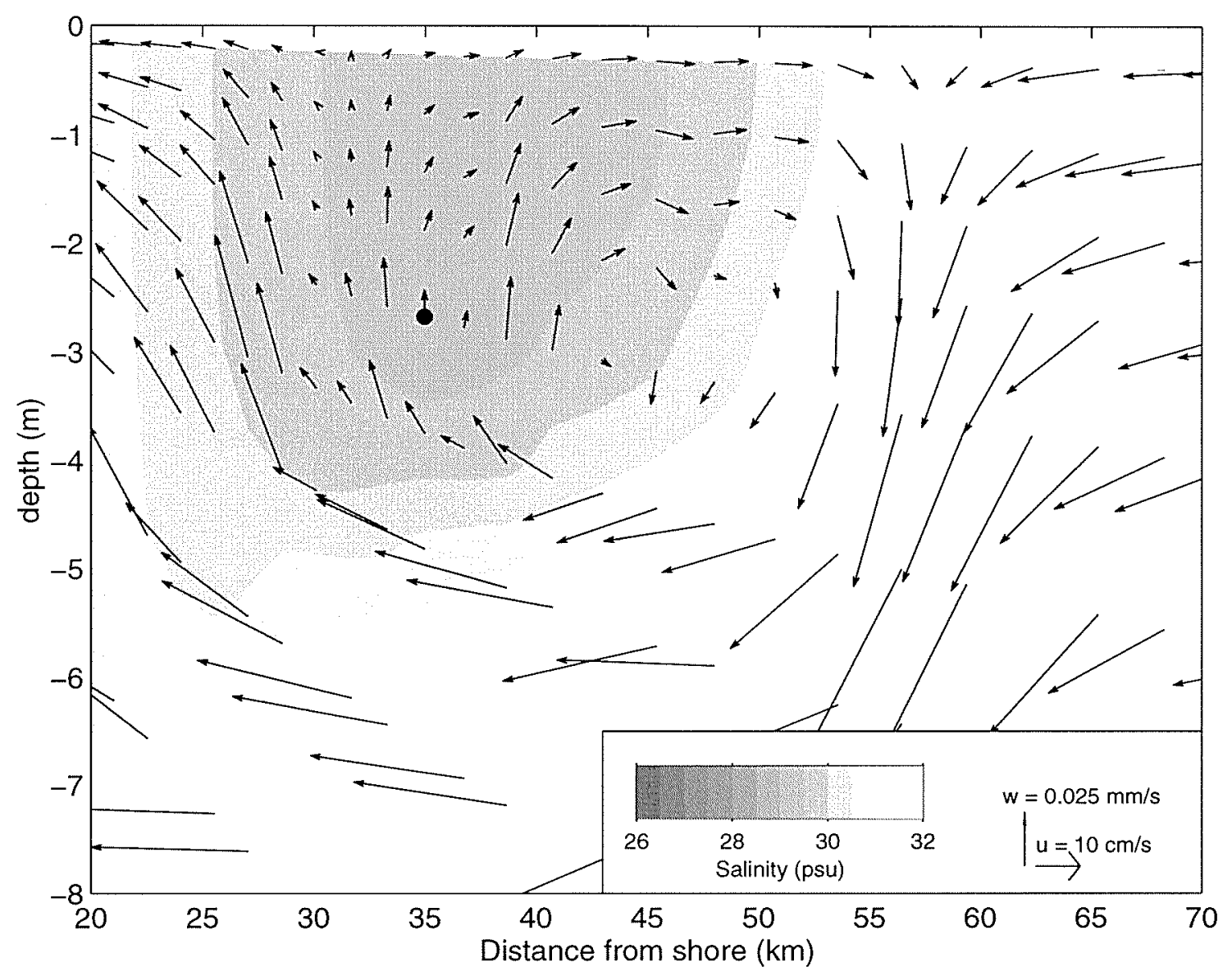

Figure 4.12: Contours of salinity with circulation pattern in the reference frame of the advected plume at $t=72$ hours. The velocity vectors shown are based on a model velocity field minus the cross-shore component of the velocity at the centroid of the plume (indicated by bold dot). 
isohaline flux at the shoreward front causes the shoreward portion of the plume to widen even after $t=48$ hours (Figure 4.9 ).

The mixing of the plume in the numerical model is due to stress-induced turbulence which erodes the stratification maintained by the Ekman straining mechanism. The conceptual model formulated in Section 4.2.2 did not predict significant mixing because it did not account for fronts at the seaward and shoreward edges of the plume. The details at the front of the plume are important to the mixing dynamics during upwelling winds.

\subsection{Sensitivity to forcing conditions}

The results in the previous section describe the response of a surface-trapped plume to a moderate amplitude upwelling wind event. In this section, the advection and mixing of the plume are examined for different forcing conditions in order to generalize the mixing dynamics discussed in the previous section and to establish the robustness of the scaling expressed in (4.5). Three model parameters are varied: the mean initial plume thickness $\overline{h_{0}}$, and initial plume density anomaly $\left(\overline{\Delta \rho_{0}}\right)$, and the magnitude of the upwelling favorable wind stress $\tau^{w}$. The first two parameters are varied by adjusting the thickness and magnitude of the initial discharge $\left(h_{i}, Q_{i}\right)$. Table 4.1 summarizes the forcing conditions for the different numerical simulations. The mean plume thickness is estimated by calculating the cross-shore averaged depth of the 31.5 psu isohaline. For most conditions, this isohaline is a reasonable proxy for the thickness of the buoyancy anomaly, the depth of penetration of stress, and the level at which mixing ceases.

The responses of the same initial plume described in Section 4.4 (Figure 4.4) to 
Table 4.1. Parameters of numerical calculations presented in Section 4. Variables are defined in the text.

\begin{tabular}{cccccc}
\hline $\begin{array}{c}\text { Run } \\
\text { No. }\end{array}$ & $\begin{array}{c}Q_{i} \\
(\mathrm{~m} 3 / \mathrm{s})\end{array}$ & $\begin{array}{c}h_{i} \\
(\mathrm{~m})\end{array}$ & $\begin{array}{c}\tau^{w} \\
\left(\text { dyne } / \mathrm{cm}^{2}\right)\end{array}$ & $\begin{array}{c}\overline{h_{0}} \\
(\mathrm{~m})\end{array}$ & $\begin{array}{c}(\overline{\Delta \rho})_{0} \\
\left(\mathrm{~kg} / \mathrm{m}^{3}\right)\end{array}$ \\
\hline 1 & 1500 & 15.0 & 0.1 & 5.65 & 2.04 \\
2 & 1500 & 15.0 & 0.25 & 5.65 & 2.04 \\
3 & 1500 & 15.0 & 0.5 & 5.65 & 2.04 \\
4 & 1500 & 15.0 & 0.75 & 5.65 & 2.04 \\
5 & 1500 & 15.0 & 1.0 & 5.65 & 2.04 \\
6 & 1500 & 15.0 & 1.5 & 5.65 & 2.04 \\
7 & 1500 & 15.0 & 2.0 & 5.65 & 2.04 \\
8 & 1500 & 15.0 & 2.5 & 5.65 & 2.04 \\
9 & 1500 & 15.0 & 3.0 & 5.65 & 2.04 \\
\hline 10 & 3000 & 15.0 & 0.5 & 6.20 & 2.74 \\
11 & 3000 & 15.0 & 1.0 & 6.20 & 2.74 \\
12 & 3000 & 15.0 & 1.5 & 6.20 & 2.74 \\
13 & 3000 & 15.0 & 3.0 & 6.20 & 2.74 \\
\hline 14 & 200 & 1.5 & 0.1 & 1.90 & 0.93 \\
15 & 200 & 1.5 & 1.0 & 1.90 & 0.93 \\
16 & 200 & 1.5 & 3.0 & 1.90 & 0.93 \\
\hline 17 & 600 & 3.0 & 0.5 & 3.57 & 1.42 \\
18 & 600 & 3.0 & 1.0 & 3.57 & 1.42 \\
19 & 600 & 3.0 & 1.5 & 3.57 & 1.42 \\
20 & 600 & 3.0 & 3.0 & 3.57 & 1.42 \\
\hline
\end{tabular}


weaker $\left(0.5\right.$ dyne $\left./ \mathrm{cm}^{2}\right)$ and stronger $\left(2.0 \mathrm{dyne} / \mathrm{cm}^{2}\right)$ winds are shown in Figure 4.13 . Similar to the 1.0 dyne $/ \mathrm{cm}^{2}$ case shown in Figure 4.9, both the weak and strong wind simulations (Runs 3 and 7 ) exhibit a plume approaching roughly uniform thickness during a sustained upwelling wind event. The stronger winds force the plume to approach its quasi-steady structure more quickly due to both the larger cross-shore Ekman transport and a deeper "equilibrium" depth which is comparable to the mean initial plume thickness. Similar to the base case presented in Section 4.4, the bottom of the plume for neither the stronger nor weaker winds is perfectly flat. The plume is slightly deeper on its shoreward side and shallower at its seaward edge. This is likely due to both mixing and the advection of momentum (see Section 4.4).

Furthermore, both strong and weak wind simulations exhibit cross-shore variations in mixing with the most intense mixing on the seaward side of the plume, and mixing persists during all three days of steady wind forcing (Figure 4.13). The plume is deeper for the case of strong winds (Run 7), and the mixing is also more intense in comparison to the weak winds (Run 3). The variations of mean plume thickness and mixing intensity for different forcing conditions are discussed below.

\subsubsection{Quasi-steady plume thickness}

In developing the conceptual model, an expression for the equilibrium plume thickness $h_{c}$ was derived (equation 4.5) based on assuming Ekman physics and that the shear-induced turbulence from the wind stress would maintain the bulk Richardson number within the plume at a critical level, $R i_{c}$. This simple scaling is next tested for a wide range of forcing conditions.

Table 4.2 compares the "steady-state" numerical model plume structure to that 
(a) $\tau_{w}=0.5$ dyne $/ \mathrm{cm}^{2}$
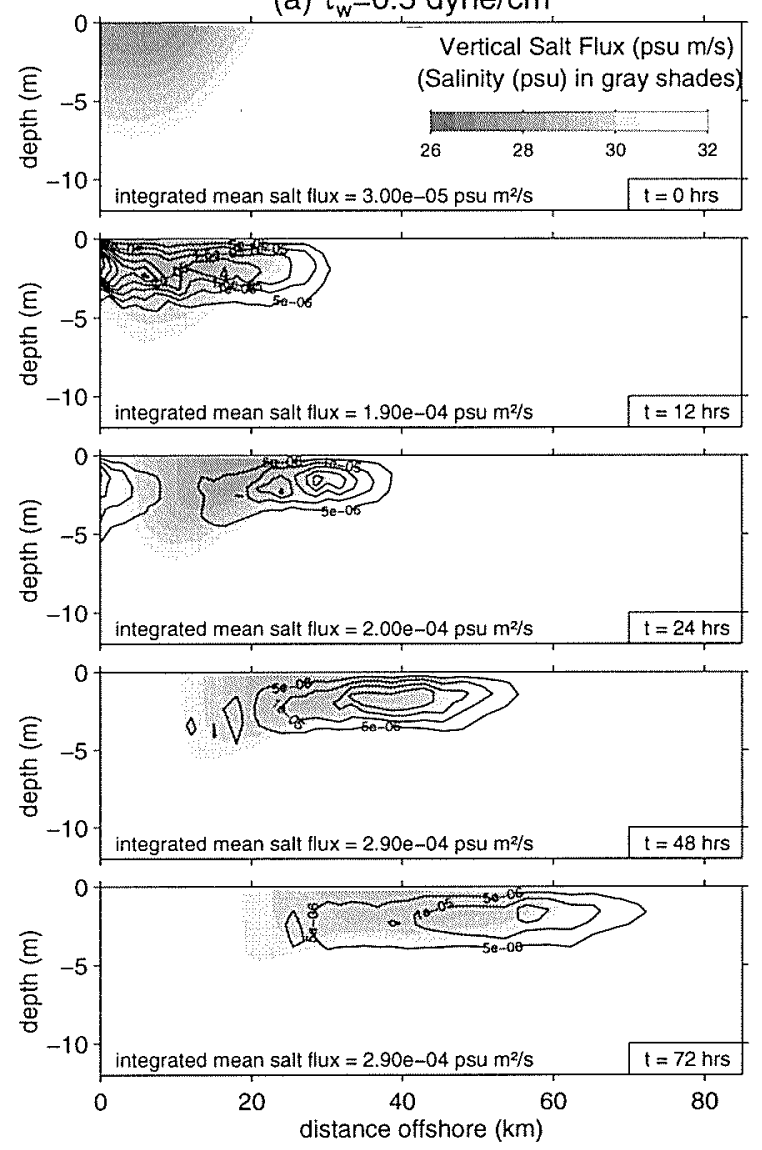

(b) $\tau_{\mathrm{w}}=2.0 \mathrm{dyne} / \mathrm{cm}^{2}$
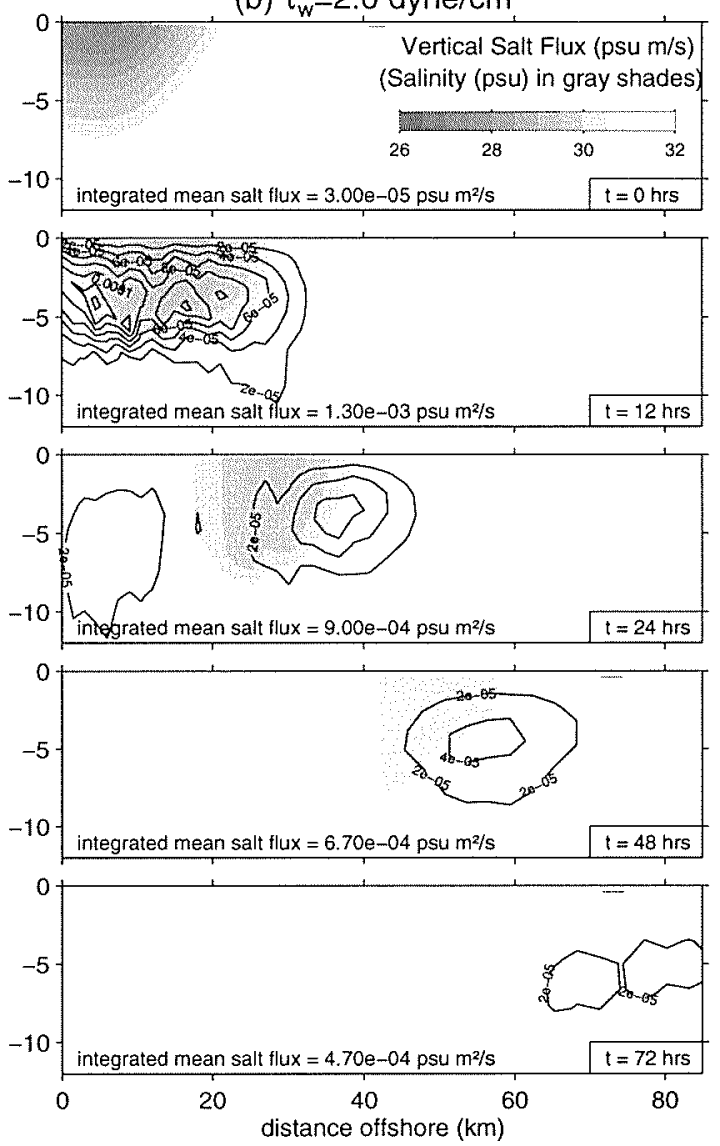

Figure 4.13: Contours of salinity (in gray shades) and vertical salt flux at $t=0$, $12,24,48$, and 72 hours for (a) weak $\left(\tau_{w}=0.5\right.$ dyne $\left./ \mathrm{cm}^{2}\right)$ and (b) strong $\left(\tau_{w}=\right.$ 2.0 dyne $/ \mathrm{cm}^{2}$ ) winds. The cross-shore integrated mean vertical salt flux is indicated in the lower left corner of each panel. Note: vertical salt flux contour levels shown are different for the two wind cases: contours are spaced $5 \times 10^{-6} \mathrm{psu} \mathrm{m} / \mathrm{s}$ for the 0.5 dyne $/ \mathrm{cm}^{2}$ wind case and every $2 \times 10^{-5} \mathrm{psu} \mathrm{m} / \mathrm{s}$ for the $2.0 \mathrm{dyne} / \mathrm{cm}^{2}$ wind case. 
predicted by equation (4.5). The steady-state plume thickness $h_{s}$ is defined as the mean model plume thickness at $t=72$ hours. For instances when the entire plume has not approached a "nearly uniform" thickness (Figure $4.13 \mathrm{a}$ ), $h_{s}$ is chosen to be the mean thickness in the plume offshore of the inflection point at the base of the plume (e.g., approximately at $\mathrm{x}=30 \mathrm{~km}$ in Figure 4.13a). The density anomaly used is the mean plume anomaly $(\overline{\Delta \rho})_{s}$ at $\mathrm{t}=72$ hours.

For the twenty model runs listed in Table 4.2, the expression given by (4.5) predicts an equilibrium plume thickness that agrees well with the observed mean plume model thickness for a wide range of forcing conditions (Figure 4.14). Two values of $h_{c}$ are compared with $h_{s}$ in Figure 4.14, corresponding to using a critical bulk Richardson number equal to 0.5 and 1.0. All but one of the observed model plume thicknesses fall within the range of $h_{c}$ predicted with $R i_{c}=0.5-1$.

The cross-shore averaged bulk Richardson number (as defined by equation (4.1) within the plume is plotted in Figure 4.15 as a function of wind stress amplitude. (All the runs plotted are based on the standard river inflow of $1500 \mathrm{~m}^{3} / \mathrm{s}$ : Runs 1-9) For a large range of wind stresses, $R i_{b} \sim O(1)$, consistent with previous studies [Pollard et al., 1973; Price et al., 1986] and the assumption of a critical bulk Richardson number threshold used to derive (4.5).

It is noteworthy that for moderate to strong winds, the fit of $h_{s}$ versus $h_{c}$ in Figure 4.14 is better for $R i_{c}=0.5$, in contrast to the computed model $R i_{b}$ which is closer to 1.0 (Figure 4.15). This difference may be a consequence of the bulk Richardson number formulation not accounting for the alongshore velocity shears within the plume. For the weak wind stresses (Runs 1,2, 10, 14), $h_{s}$ and $h_{c}$ are more closely matched with $R i_{c}$ equal to unity (Figure 4.14), although the mean 
Table 4.2. Comparison of numerical simulations with conceptual model predictions (equation $(4.5)) .(\Delta \rho)_{s}$ is the mean plume density anomaly at $t=72$ hours. All other variables are defined in the text. All steady state plume thicknesses $h_{s}$ are calculated by computing the mean plume thickness at $t=72$ hours. The plume is defined as all water of less than 31.5 psu salinity. Null entries in table indicate plume is mixed sufficiently so that no water remains of less than 31.5 psu salinity.

\begin{tabular}{|cccc|c|cc|}
\hline Run & $\overline{h_{0}}$ & $(\overline{\Delta \rho})_{0}$ & $(\overline{\Delta \rho})_{s}$ & $h_{s}$ & \multicolumn{2}{|c|}{$h_{c}(\mathrm{~m})$} \\
\cline { 5 - 6 } No. & $(\mathrm{m})$ & $\left(\mathrm{kg} / \mathrm{m}^{3}\right)$ & $\left(\mathrm{kg} / \mathrm{m}^{3}\right)$ & $(\mathrm{m})$ & $R i_{c}=\frac{1}{2}$ & 1 \\
\hline 1 & 5.65 & 2.04 & 1.89 & 1.35 & 1.07 & 1.35 \\
2 & 5.65 & 2.04 & 1.76 & 2.35 & 1.98 & 2.50 \\
3 & 5.65 & 2.04 & 1.52 & 3.68 & 3.17 & 3.95 \\
4 & 5.65 & 2.04 & 1.36 & 4.65 & 4.11 & 5.18 \\
5 & 5.65 & 2.04 & 1.37 & 5.25 & 4.98 & 6.27 \\
6 & 5.65 & 2.04 & 1.00 & 7.13 & 6.52 & 8.22 \\
7 & 5.65 & 2.04 & 0.85 & 7.94 & 7.90 & 9.96 \\
8 & 5.65 & 2.04 & 0.81 & 9.38 & 9.17 & 11.55 \\
9 & 5.65 & 2.04 & - & 10.51 & 10.35 & 13.05 \\
\hline 10 & 6.20 & 2.74 & 2.04 & 3.32 & 2.79 & 3.52 \\
11 & 6.20 & 2.74 & 1.67 & 4.80 & 4.43 & 5.58 \\
12 & 6.20 & 2.74 & 1.48 & 6.52 & 5.81 & 7.82 \\
13 & 6.20 & 2.74 & 0.93 & 9.77 & 9.22 & 11.61 \\
\hline 14 & 1.90 & 0.93 & 0.78 & 1.78 & 1.45 & 1.83 \\
15 & 1.90 & 0.93 & - & - & 6.73 & 8.48 \\
16 & 1.90 & 0.93 & - & - & 14.00 & 17.64 \\
\hline 17 & 3.57 & 1.42 & 0.88 & 3.54 & 3.58 & 4.52 \\
18 & 3.57 & 1.42 & - & - & 5.69 & 7.17 \\
19 & 3.57 & 1.42 & - & - & 7.46 & 9.40 \\
20 & 3.57 & 1.42 & - & - & 11.82 & 14.89 \\
\hline
\end{tabular}




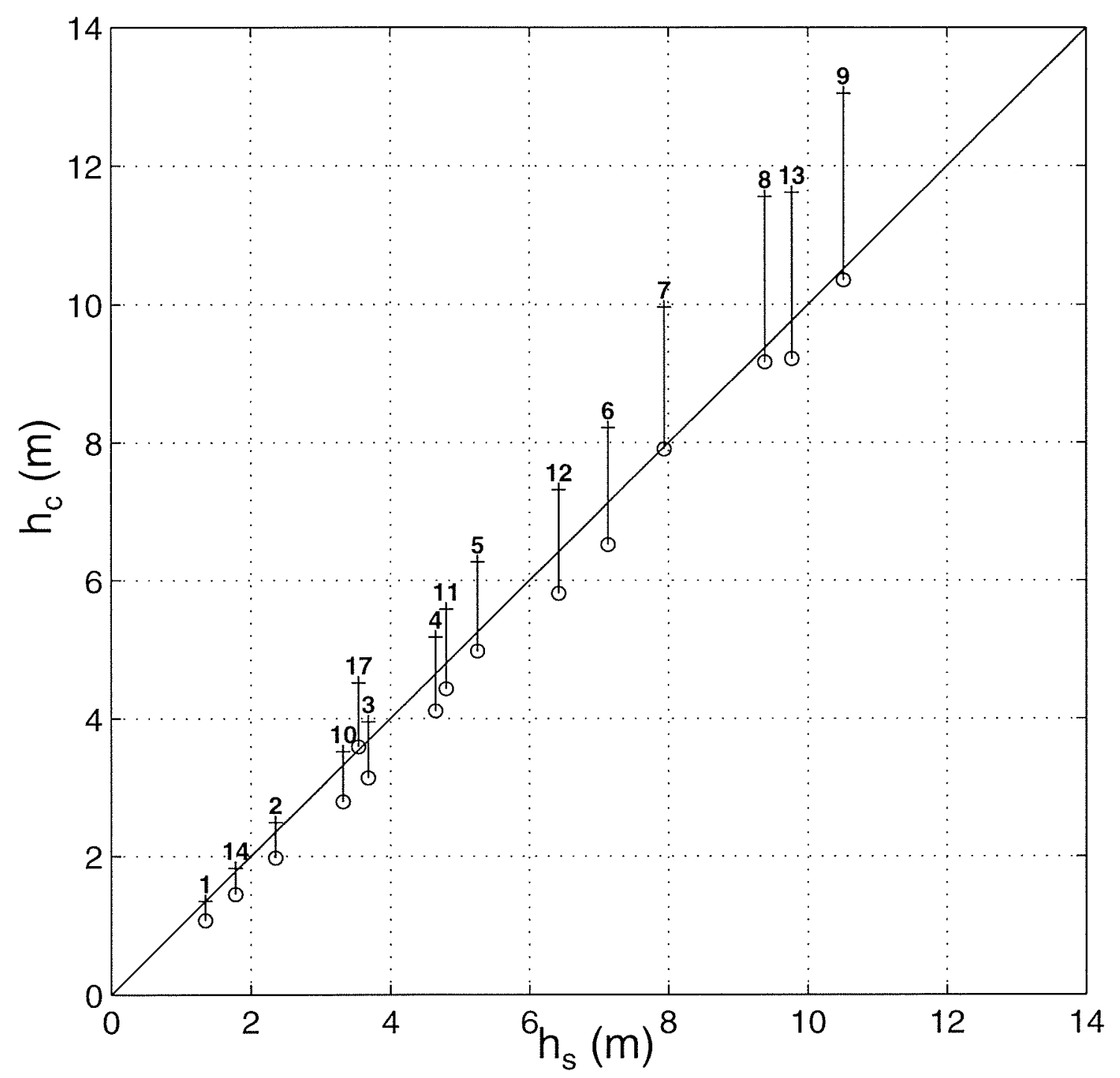

Figure 4.14: Numerical model plume thickness (at $\mathrm{t}=72$ hours) $h_{s}$ versus equilibrium thickness $h_{c}$ for $R i_{c}=\frac{1}{2}(\mathrm{o})$ and $R i_{c}=1(+)$ 


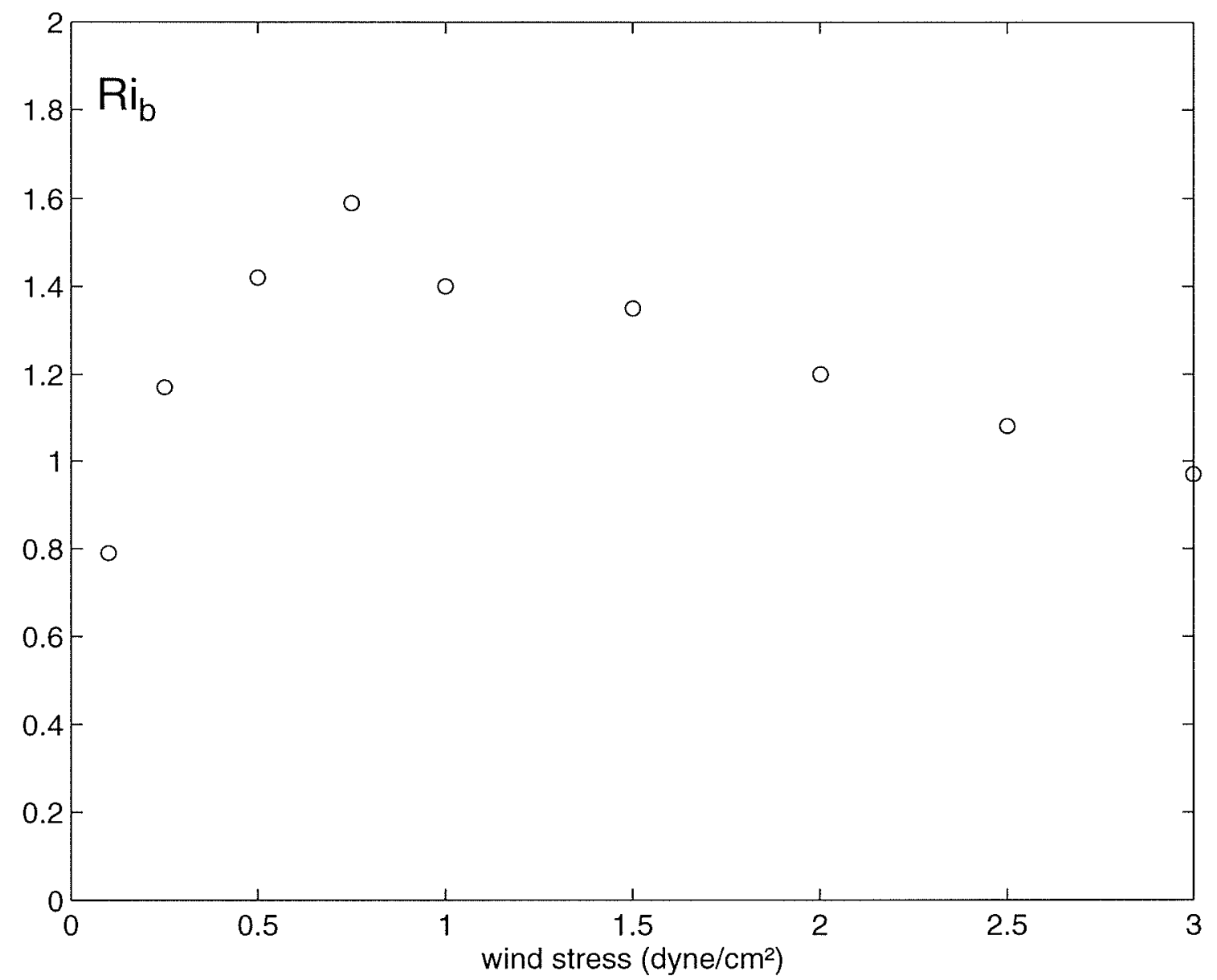

Figure 4.15: Mean bulk Richardson number as a function of wind stress (Runs 1-9). 
$R i_{b}$ tends to be smaller for weaker winds (Figure 4.15). This discrepancy may be partly attributable to the momentum of the weak winds being trapped only within the upper portions of the plume. The agreement between $h_{c}$ and $h_{s}$ for $R i_{c}=1 / 2$ improves for the weak wind cases if the plume defining isohaline is somewhat less than $31.5 \mathrm{psu}$. Additional differences between $h_{c}$ and $h_{s}$ can be accounted for in the assumption of a linear velocity profile in (4.5).

Within the uncertainty of $R i_{c}$, however, the differences between $h_{c}$ and $h_{s}$ are small. The scaling given by (4.5) provides a basic framework for discerning the dependence of the plume thickness on wind stress and buoyancy. Stronger winds produce a thicker plume, and as the density difference decays due to mixing, the plume gradually deepens.

It is important to emphasize that the scaling given by (4.5) does not explain the time-dependence of $g^{\prime}$ (or the plume density anomaly), i.e., the rate at which the plume mixes. Equation (4.5) only estimates the plume thickness for a given wind stress amplitude and known buoyancy anomaly. Next, the numerical model results are used to infer the rate of mixing in the plume for different forcing conditions.

\subsubsection{Plume mixing rates}

As was noted in Section 4.4, the mixing in a plume forced by an upwelling wind varies temporally. The cross-shore and vertically integrated salt flux is shown as a function of time in Figure 4.16 for different wind conditions $\left(\mathrm{Q}=1500 \mathrm{~m}^{3} / \mathrm{s}\right.$, Runs 1-9). All cases exhibit maximum mixing at $t=12$ hours when inertial shears are largest, and decay in mixing for longer times. The larger amplitude winds take longer to approach a steady-state mixing rate. It is plausible that this behavior is 


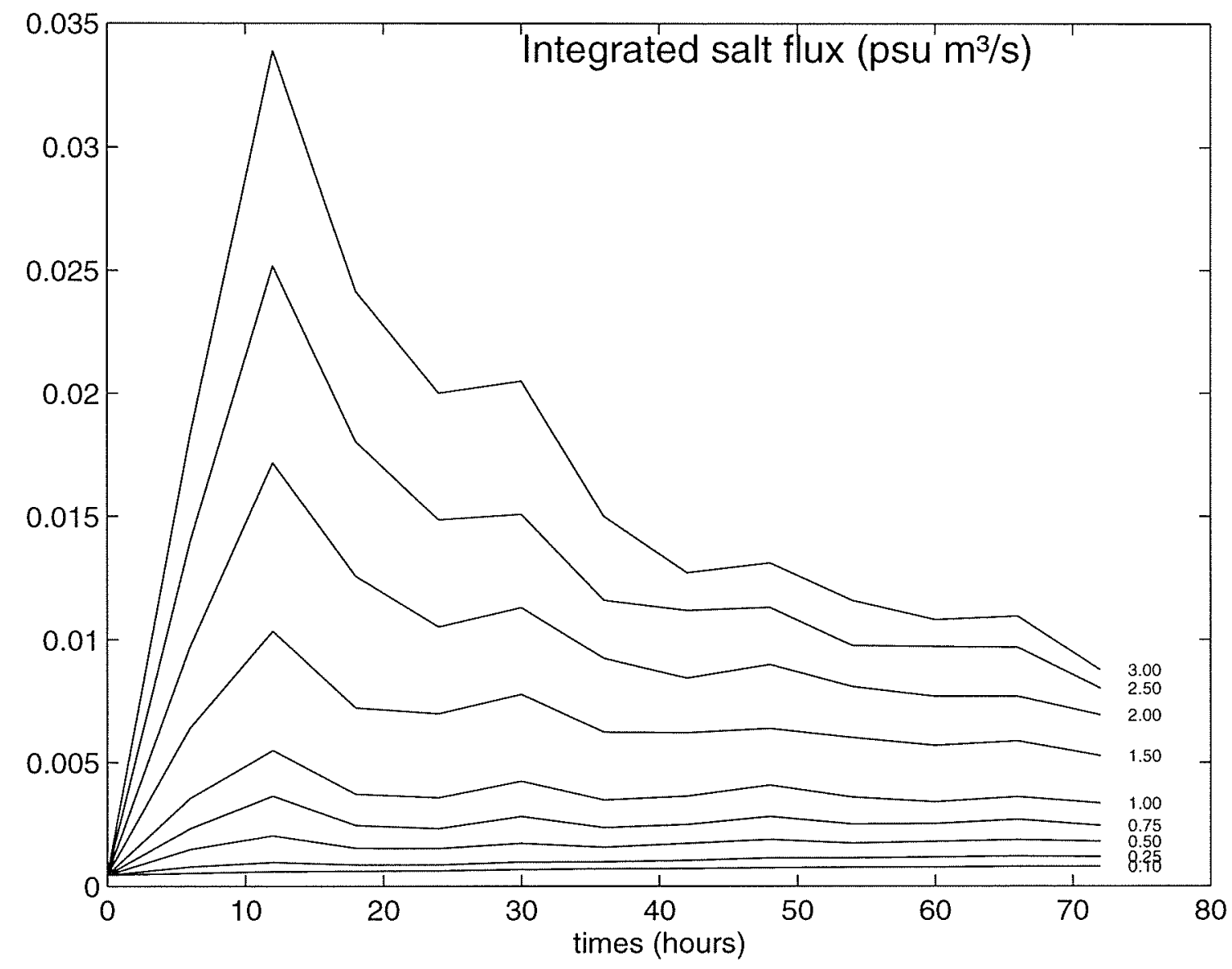

Figure 4.16: Integrated salt flux as a function of time for different wind stresses (in dyne $/ \mathrm{cm}^{2}$ ) for Runs 1-9. 
explained by inertial oscillations being dependent on the thickness of plume, and hence the amplitude of the wind stress. It can be shown through scaling that the time scale of decay of the inertial oscillations is proportional to $\tau^{1 / 6}$ (see Appendix). For strong winds, the inertial shears will take longer to decay.

For the large amplitude winds, the transient mixing effects can account for a large fraction of the total mixing. For example, for a two day upwelling event of 2.5

dyne $/ \mathrm{cm}^{2}$, the transient mixing effects account for nearly half the observed mixing. For weaker winds, transient effects are less important, and steady-state mixing rates are reached within 18-24 hours.

\subsubsection{Comparison of plume mixing with 1-D mixing studies}

In Section 4.1, it was hypothesized that some of the results from previous studies of one-dimensional mixing might bear some relation to mixing in a plume. The mixing rates in the plume are next compared with previous entrainment estimates from one-dimensional mixing experiments.

In order to quantify the overall mixing in the plume, a bulk entrainment rate is formulated. The local entrainment rate in the plume is defined as

$$
w_{e}=-\frac{1}{\Delta S} K_{H} \frac{\partial S}{\partial z}
$$

where $K_{H}$ is the eddy diffusivity of salt, $\Delta S=S_{0}-S$ is the salinity difference between ambient and plume waters. A depth-averaged entrainment rate, $\bar{w}_{e}$ can then be expressed, 


$$
\bar{w}_{e}=\frac{1}{h} \int_{-h}^{0} w_{e} d z
$$

Finally, the total buoyancy flux, i.e., mixing, in the plume can be computed in terms of the depth-averaged entrainment rate. Since the density of the plume is only a function of salinity in the numerical experiments, the salinity anomaly is approximately proportional to a density anomaly (assuming a linear equation of state). Therefore, the salinity anomalies can be expressed in terms of density anomalies, and a spatially-averaged entrainment rate can be defined

$$
\tilde{w}_{e}=\frac{\int_{x_{1}}^{x_{2}} \bar{w}_{e} B d x}{\int_{x_{1}}^{x_{2}} B d x}
$$

where

$$
B=\int_{-h}^{0} g^{\prime} d z
$$

and $x_{1}$ and $x_{2}$ are the cross-shore plume limits. The bulk entrainment rate $\tilde{w}_{e}$ is next compared with the observed mean entrainment rates in previous studies of $1-\mathrm{D}$ mixing for the different forcing conditions listed in Table 4.2.

Trowbridge [1992] shows that the mixing rates observed in several laboratory and numerical experiments of one-dimensional mixing (e.g., Kato and Phillips [1969], Kranenburg [1984], Kundu [1981]) can be collapsed into a simple non-dimensional entrainment rate law,

$$
w_{e *}=\frac{\tilde{w}_{e}}{u_{*}} \propto R i_{*}{ }^{-\frac{1}{2}}
$$


where

$$
R i_{*}=\frac{\frac{g}{\rho_{0}} \int_{-h}^{0}\left(\rho_{0}-\rho\right) d z}{u_{*}{ }^{2}}
$$

and $u_{*}{ }^{2}=\frac{\tau}{\rho}$. Trowbridge [1992] demonstrates that this mixing rate dependence is consistent with a simple model that assumed mixing is a gradient transport process where mixing continues with the mixed layer held at a critical gradient Richardson number.

The simulations presented in this study closely approximate the relationship given by (4.9). The non-dimensional entrainment rate $w_{e *}$ as a function of $R i_{*}$ at $\mathrm{t}=72$ hours is shown in Figure 4.17. Power law regression gives $n=-0.49 \pm 0.04$ (where $n$ is the best fit of $R i_{*}{ }^{n}$ for $w_{e *}$ with Runs 1,2 , and 14 excluded). The very weak wind cases (Runs 1,2, and 14) do not obey the power law in (4.9) because the wind is not strong enough to influence the entire thickness of the plume. Therefore, for weak winds, $R i_{*}$, which is based on the entire buoyancy of the plume, is an overestimate of the effective buoyancy stabilizing the plume "against" the applied wind stress.

The coefficient of proportionality for (4.9) can be computed using the moderate to large amplitude wind cases. A least squares fit yields the relationship,

$$
w_{e *} \approx 0.038 R i_{*}^{-\frac{1}{2}}
$$

The coefficient of proportionality falls below all values attained in laboratory experiments which have ranged from 0.07-0.75 [Fernando, 1991; Trowbridge, 1992]. One reason for the low value of the coefficient is the spatial averaging performed in (4.8); entrainment is up to three times larger at the seaward front than it is in the shoreward portions of the plume. More importantly, rotation may be largely responsible for the small coefficient since rotation tends to decrease the efficiency 


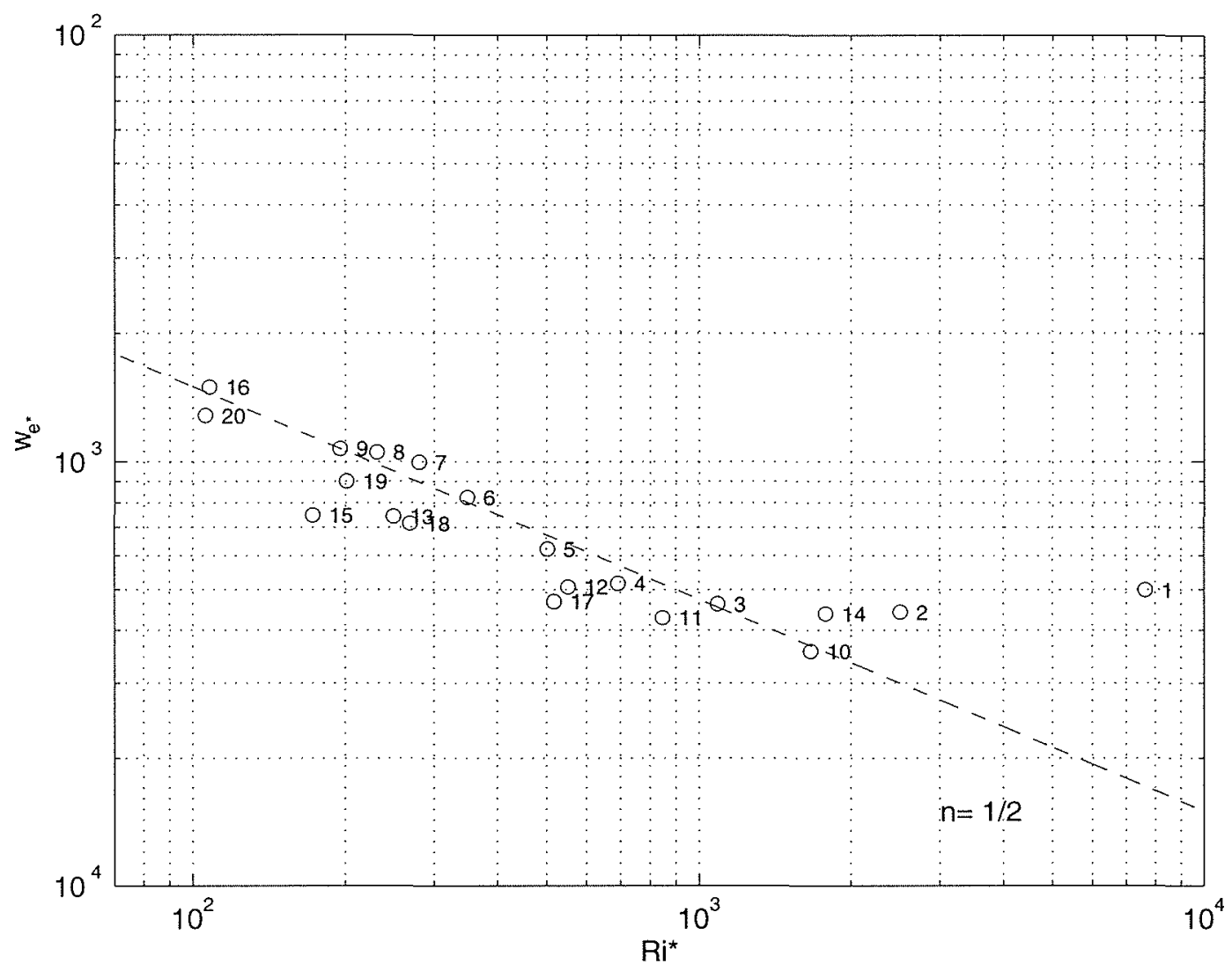

Figure 4.17: Log-log plot of $R i_{*}$ versus non-dimensional entrainment rate $w_{e *}$ at $t=72$ hours. Slopes of $n=-1$ (solid line) and $n=-1 / 2$ (dashed line) are indicated. 
of entrainment [Fluery et al., 1991; Trowbridge, 1992]. Trowbridge [WHOI, pers. comm] finds that the steady-state entrainment rate drops by almost an order of magnitude when rotation is added to his model.

It is not clear why the overall mixing rates observed in the plume simulations studied obey the same power law relationship as previous studies of 1-D mixing. Mixing rates calculated by averaging entrainment in the seaward front of the plume

do not collapse to the $w_{e *}=\frac{\tilde{w} \tilde{e}_{*}}{u_{*}} \propto R i_{*}{ }^{-\frac{1}{2}}$ proportionality. It appears the collapse of the model runs shown in Figure 4.17 is largely due to the shoreward portions of the plume where the mixing is less intense.

It is important to emphasize that mixing in a wind-forced river plume is a twodimensional process. The mixing is strongest at the seaward front and is fed by the Ekman straining mechanism that depends on both the cross-shore and vertical salinity gradients. The Ekman straining process is necessary to maintain the mixing at both the seaward front and center of the plume.

\subsection{Comparison with downwelling winds}

This chapter has focused only on the upwelling orientation of alongshore wind forcing. In this section, a brief comparison is made between the mixing induced by upwelling and downwelling wind conditions.

Using the same initial plume shown in Figure 4.4, the plume is forced by a steady 1 dyne $/ \mathrm{cm}^{2}$ downwelling favorable (in the negative $y$ direction in Figure 4.3) wind stress. The basic plume response is consistent with Ekman dynamics (Figure 4.18). Downwelling winds confine the plume against the coast owing to the induced onshore surface Ekman flow field. In contrast to the upwelling winds, the plume 

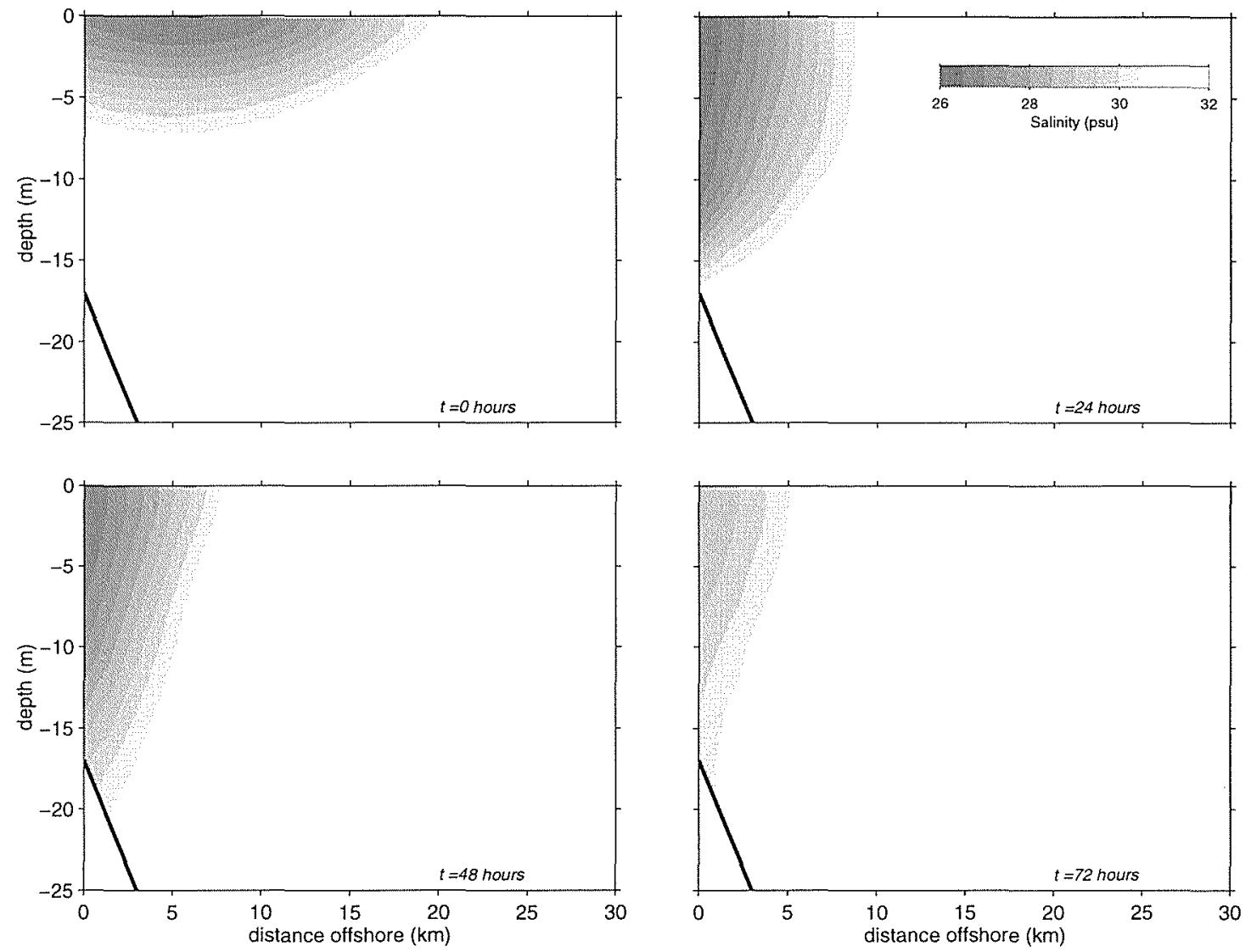

Figure 4.18: Contours of salinity during a downwelling wind event for $t=0,24,48$, and 72 hours (indicated by gray shades in 0.5 psu intervals). Topography is indicated with thick black line. 
becomes narrower and thicker and its vertical stratification at the seaward edge is reduced. The response is not as two-dimensional as it is for upwelling winds. There is marked reduction in total buoyancy in the section shown during the three days of downwelling wind stress, due to an alongshore divergence in freshwater transport. The large buoyancy anomaly associated with the initial plume has been transported downstream of the alongshore location shown in Figure 4.18.

The downwelling winds also induce significant mixing in the plume. The observed vertical salt flux is the same order of magnitude as that found during upwelling favorable conditions (Figure 4.19). The total mixing during downwelling winds is, however, significantly less in comparison to the upwelling favorable conditions. The cross-shore integrated mean salt flux during downwelling is less than a third of that observed during upwelling conditions. While the local vertical salt fluxes are only slightly smaller for downwelling winds, the amount of plume area exposed to wind stress is considerably smaller. This difference in plume area mainly explains the difference in integrated mixing.

For upwelling winds, the plume is spread offshore, with a tendency to widen in cross-shore extent. In contrast, the plume is narrowed during downwelling winds. If the energy from the wind were transferred with equal efficiency to mixing processes for both upwelling and downwelling conditions, more total wind energy would be available for mixing during upwelling winds due to the larger surface area of the plume exposed to the wind. In other words, with a greater surface area over which wind energy can be input for mixing the plume, more mixing occurs during upwelling winds. It is important to emphasize, however, that mixing does not take place over the entire plume width under upwelling conditions. One would therefore not expect the total mixing to exactly scale with the surface area of the plume. 

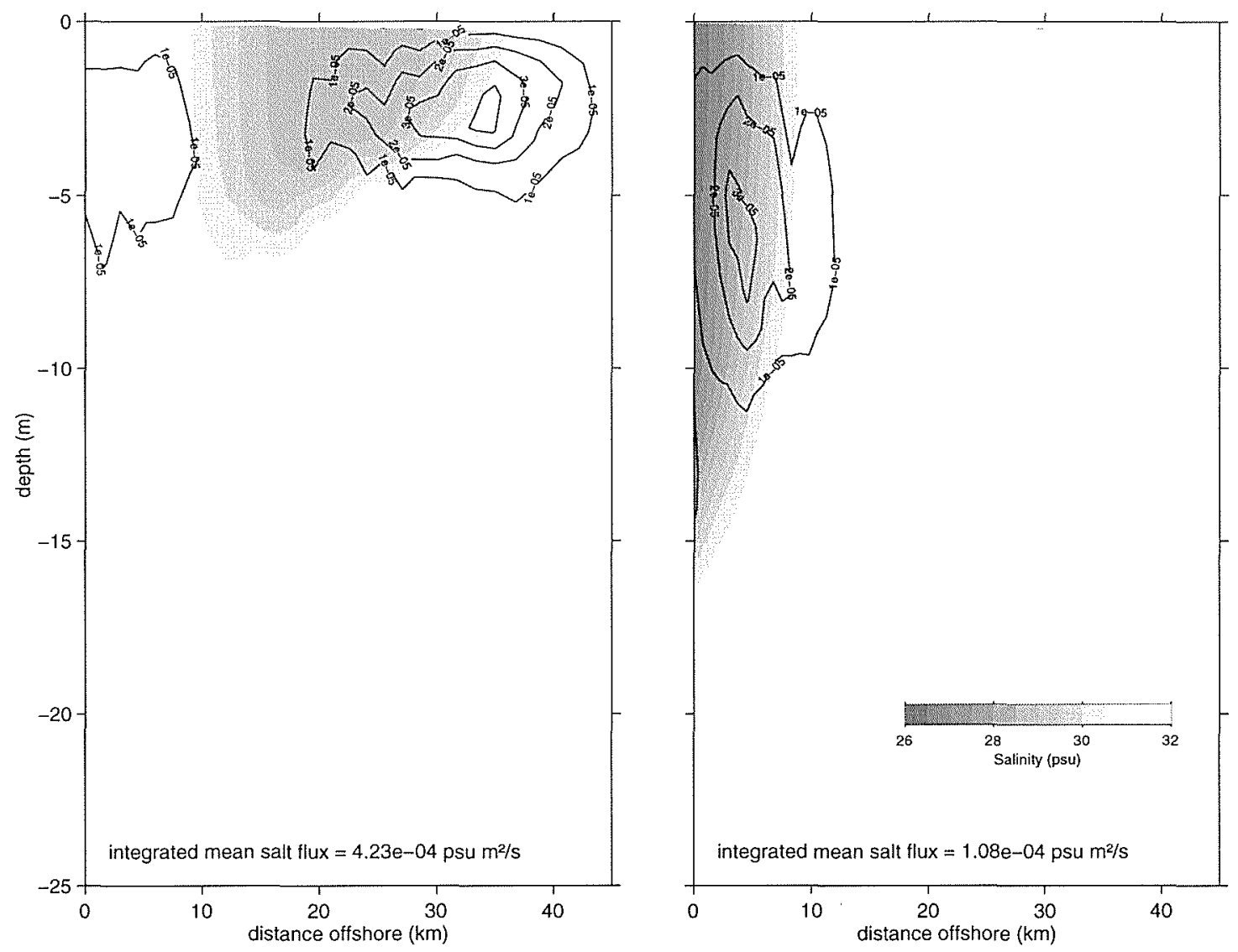

Figure 4.19: Comparison of mixing during upwelling and downwelling. Salinity (in gray shades) and vertical salt flux (lines) are contoured for $1 \mathrm{dyne} / \mathrm{cm}^{2}$ upwelling favorable (left panel) and downwelling favorable (right panel) alongshore wind stress after 24 hours of forcing. The cross-shore integrated mean vertical salt flux is indicated in the lower left corner of each panel. 
The mechanisms by which mixing is achieved during downwelling winds are likely to be different than those present during upwelling conditions due to differences in stratification and plume thickness. The mixing dynamics associated with downwelling wind are beyond the scope of this study, and require future investigation.

\subsection{Discussion and summary}

An idealized numerical simulation has been used to study the response of a river plume during an upwelling favorable wind event. The basic response of a freshwater plume to an upwelling favorable wind event is consistent with Ekman dynamics. Cross-shore Ekman currents tend to widen and thin the plume. As a result, the thinned plume is susceptible to mixing by shear instability generated by the vertically sheared along- and cross-shore currents.

A moderate amplitude upwelling wind lasting a few days induces significant mixing in the plume and advects and spreads the plume large distances offshore. The basic plume response is explained by Ekman dynamics for the alongshore momentum and a shear instability mixing criterion at the seaward front for a large range of initial conditions and wind forcing. The plume tends to evolve towards a nearly uniform, quasi-steady thickness for a sustained upwelling wind event.

The numerical model exhibits strong mixing at the seaward front well after the plume has reached a nearly uniform thickness. The enhanced mixing is a result of large stresses in regions of significant stratification. A balance between advection and vertical mixing is maintained at the seaward front in all the model runs for $t \geq 12$ hours. This balance is achieved by an Ekman straining mechanism: the sheared cross-shore Ekman currents make the isohalines horizontal, creating vertical 
stratification which is destroyed by vertical mixing. For a sustained upwelling wind event, this balance is likely to be maintained until the plume is eventually destroyed.

This study has only considered a very idealized version of a river plume. For example, the influence of tides has been neglected. In the coastal ocean, tides can play a significant role in mixing processes [Blanton and Atkinson, 1983]. In the presence of weak wind forcing, tidal oscillations are expected to play a significant role in mixing a plume $[$ Chao, 1990]. However, winds should be the dominant mixing agent for the short-time scales associated with mixing by the moderate to large amplitude upwelling wind events found during the spring runoff of many coastal plume systems, and also in deep receiving waters in which bottom-generated turbulence has little effect on the plume.

The amount of mixing produced in these simulations depends on the MellorYamada 2.5 (MY-2.5) closure used to parameterize the eddy diffusivities. While the results presented are quantitatively dependent on the mixing parameterization used in the numerical model, the MY-2.5 scheme employs a Richardson number mixing criterion, similar to Trowbridge [1992] who showed that a Richardson number threshold is a reasonable parameterization of shear-induced turbulence in laboratory experiments. Therefore, assuming that the Richardson number is a reasonable proxy for the likelihood of shear-induced turbulent mixing in the plume, the results presented above should at least qualitatively describe the basic mixing response of a plume during an upwelling wind event.

Allen et al. [1995] consider the influence of different mixing parameterizations in their study of upwelling circulation. They find qualitative agreement in the basic flow field between the MY-2.5 and another Richardson number-dependent 
parameterization by Pacanowski and Philander [1981]. The latter scheme exhibits somewhat weaker along front velocity gradients. For the problem considered in this study, weaker frontal gradients would imply weaker mixing in the frontal portions of the plume. This, however, would not change the Ekman straining mechanism which is expected to drive the quasi-steady state mixing of the plume.

In addition, the model and closure scheme used in this study assume mixing of a river plume is only the result of shear-induced mixing. Craig and Banner [1994] show that turbulence is significantly enhanced by the action of surface waves. Because there was no surface source of turbulent kinetic energy, the implementation of the MY-2.5 used in this study may underestimate the amount of mixing induced by winds [Craig, 1996].

In studying the upwelling-induced mixing in a plume, only the two-dimensional aspects of the model plume have been considered, by using an alongshore-averaged section far downstream from the source of buoyancy. It is clear from Figure 4.4 that the response of a river plume to an upwelling wind event is a three-dimensional phenomenon. Mixing will certainly exhibit some variations in the alongshore direction, and the dynamics presented in this chapter will most likely fail near the river mouth. However, the two-dimensional paradigm of mixing under upwelling conditions should be valid over a large part of the plume where the alongshore momentum physics are primarily Ekman-driven.

One interesting feature of the numerical simulations is the vigorous mixing that takes place during the first twelve hours of wind forcing (see Figures 4.9 and 4.16). It is during this time period when inertial oscillations are induced by the sudden application of a wind stress. Depending on the timing within the inertial period, 
total velocity shears will be either enhanced or relaxed [Federiuk and Allen, 1996].

It should be emphasized that an upwelling wind influences the fate of a freshwater plume in two ways, advection and mixing. The advective processes induced by upwelling winds are important in modifying the shape of the plume and these shape changes are essential to driving mixing processes in the plume. By mixing the plume, upwelling winds reduce the buoyancy signal associated with the plume and subsequently may reduce the geostrophic alongshore transport of fresh water. In advecting the plume significant distances offshore during a several day wind event, upwelling winds also affect the plume fate by exposing the buoyancy to large-scale ambient circulation patterns. The ambient coastal currents may be significantly different in the inshore and offshore regions of a continental shelf.

In nature, the forcing of a freshwater plume is significantly more complex than these idealized simulations. In many river plume systems, the spring runoff coincides with winds that exhibit large fluctuations in both direction and magnitude. Often, an upwelling wind event is followed by a comparable amplitude downwelling favorable event that may re-advect the plume water onshore. Although it has been shown that downwelling winds mix a plume less than comparable strength upwelling winds, downwelling winds do induce appreciable mixing in the plume. Downwelling winds also enhance the alongshore transport of freshwater. The details of mixing and advection dynamics associated with downwelling winds are important problems that need to be addressed in future studies. 


\section{Chapter 5}

\section{Summary and discussion}

Calvin: "That's plenty, by the time we add an introduction, a few illustrations, and a conclusion, it will look like a graduate thesis."

Bill Watterson 


\section{$5.1 \quad$ Summary}

This thesis has addressed the dynamics of a freshwater plume, including the alongshore transport of fresh water in the plume, and its response to alongshore wind forcing.

In Chapter 2, an idealized numerical modeling experiment was used to study the alongshore transport of fresh water in a surface-trapped river plume. The fresh water veers to the right (in the Northern Hemisphere) upon entering the coastal ocean, forming a plume of two distinct dynamical regions, a bulge and a narrow coastal current. This plume behavior is consistent with previous modeling studies (e.g., Chao and Boicourt [1986], Oey and Mellor [1993]). The work of Chapter 2 shows that the bulge is accompanied by a downstream coastal current only transporting a fraction of the discharged fresh water. The water which is not transported in the coastal current recirculates in a continually growing bulge region near the river mouth. In the absence of any ambient current, the plume does not reach a steady-state. This marks a departure from many previous studies that have treated the plume as a steady-state system [Garvine, 1995; Garvine, 1996; Yankovsky and Chapman, 1997].

The size of the freshwater transport in the coastal current, and thus the prominence of the bulge, depends on the river mouth conditions. Low Rossby number discharges exhibit the largest coastal current transport, transporting up to $75 \%$ of the fresh water supplied by the river. For high Rossby number discharge conditions $(R o \sim \mathrm{O}(1))$, the freshwater transport is less than half of the river discharge. Many plumes, including the Chesapeake, Delaware, and western Gulf of Maine plumes, are observed to fall into this class of discharge [Boicourt, 1981; Geyer et al., 1998; 
Münchow and Garvine, 1993a].

The presence of an ambient current can augment the buoyancy transported in the plume so that the freshwater transport matches the discharge from the river, thereby establishing a steady-state. For any ambient current in the direction of Kelvin wave propagation, the plume will evolve to a steady-state width. The steadystate transport provided by the presence of an ambient current is independent of the strength of the current. The time to reach steady-state is, however, determined by the amplitude of the ambient flow. After reaching a steady-state width, the bulge is swept downstream at a speed approximately equal to the ambient flow strength. Because the local winds often vary over short time scales, plumes in nature are only likely to reach steady-state for ambient currents exceeding $10 \mathrm{~cm} / \mathrm{s}$.

The ambient current has a marked effect on the salinity distribution of the plume. The bulge is distorted by the ambient current and swept downstream after growing to a steady-state width. This behavior is consistent with the hydrography of plumes observed in the field. The plumes observed in nature do not always consist of a distinct bulge and separate narrow coastal current; instead, they often exhibit a roughly uniform width, possibly due to the mean ambient currents [Boicourt, 1981; Geyer et al., 1998].

In Chapter 3, the role that winds and their variability play in the cross-shore motion of a plume is investigated using observations of the western Gulf of Maine plume. The observations suggest that the cross-shore plume structure varies markedly as a function of the fluctuations in wind forcing. The variations in the observed plume width are consistent with Ekman dynamics. Upwelling winds are observed to spread the plume tens of kilometers offshore. Downwelling winds narrow the plume 
to only a few Rossby radii in width. This behavior agrees well with both previous modeling studies and observations of plumes which exhibit the basic tendencies of Ekman dynamics [Chao, 1987; Kourafalou et al., 1996; Münchow and Garvine, 1993b].

In order to provide a quantitative evaluation of the Ekman physics and its relationship to cross-shore plume motions, a simple slab model is used to analyze the observed variability in the Gulf of Maine hydrography. Qualitative agreement is found between the observed variations in plume width and those predicted by Ekman theory for short time scales of integration. Near surface cross-shore currents are significantly correlated with alongshore wind stress, consistent with an Ekman balance of alongshore momentum. Estimates of the terms in the alongshore momentum balance, calculated from moored current meter arrays, also indicate that Ekman dynamics dominate. Although previous studies have shown the macroscopic plume behavior is consistent with Ekman dynamics, the analysis presented in Chapter 3 demonstrates that a simple Ekman balance is a useful way to estimate the cross-shore plume motions induced by alongshore winds.

In Chapter 4, a process-oriented numerical modeling experiment was used to investigate the advective and mixing response of a plume to an upwelling favorable wind. The numerical model demonstrates that the first order response of a plume to an upwelling wind is to be stretched and advected offshore by the surface Ekman currents. For a sustained upwelling wind, the plume evolves to a nearly uniform thickness and continues to move offshore. As the plume stretches, it also thins. As a result, the thinned plume is susceptible to mixing by the shear-induced turbulence generated by the wind. 
For a moderate amplitude upwelling wind, mixing rates are elevated by an order of magnitude in comparison with the unforced plume. Mixing is most intense at the seaward front where the sheared Ekman flow field strains the cross-shore salinity gradient, thereby replenishing the stratification and maintaining vertical mixing. A simple Richardson number criterion is successful at reproducing the observed mean plume thickness in the numerical model for a large range of forcing conditions. Although the mixing processes are largely two-dimensional, the observed rates of mixing are consistent with the one-dimensional mixing observed in the laboratory [Kantha et al., 1977; Kato and Phillips, 1969; Trowbridge, 1992].

While downwelling winds also appear capable of inducing mixing in the plume, the total mixing achieved during downwelling winds is less than that observed during a similar amplitude upwelling event. The greater mixing during upwelling appears to be a reflection of the larger plume surface area over which the wind acts in comparison with downwelling conditions.

The results of this thesis demonstrate that the fate and alongshore transport of a river plume are not generally dominated by the baroclinicity and associated densitydriven currents from the freshwater itself [Chao and Boicourt, 1986; Garvine, 1987]. Instead, the behavior of the plume often reflects the response to external forcing agents. This thesis has shown that ambient currents and wind events can have a pronounced effect on the alongshore transport of fresh water, the cross-shore plume structure, and the mixing of the plume. 


\subsection{Unresolved issues}

While this thesis has addressed a number of important questions regarding the dynamics of river plumes, there are many interesting problems that remain unresolved. In particular, there is a need to understand the detailed dynamics associated with a plume's response to downwelling winds and how the timing and variations of river discharge and wind forcing influence the fate of a plume.

The response of the plume to an upwelling wind is well described by both the field observations of the western Gulf of Maine plume (Chapter 3) and the physical paradigm developed in Chapter 4, but the downwelling response of a plume remains largely unexplored. It is clear that downwelling winds are capable of confining the plume to within a few kilometers from the coast. Furthermore, as was demonstrated in Chapter 4, downwelling winds enhance mixing in the plume, although less so than during upwelling winds. The development of a combined advection and mixing picture of the downwelling response of a plume, similar to the one developed for upwelling in Chapter 4, is a necessary step towards completing the understanding of how plumes respond to wind forcing. It is unclear, however, whether a twodimensional framework can be used to describe the downwelling response, since preliminary model investigations suggest large divergences in alongshore transport.

This thesis has only considered the problem of a steady river discharge. An important issue that remains unresolved is how unsteadiness of river discharge during the spring freshet influences plume behavior. Another question that needs to be studied is how the timing of wind events and the river discharge influence the alongshore transport and ultimate fate of the fresh water. For example, the western Gulf of Maine plume exhibits an overlap in time-scales between the freshwater inflow and 
the wind forcing. The timing of river runoff and wind forcing and the influence of this timing on the fate of a river plume remains unaddressed.

This thesis has found that the plume varies temporally, even with steady forcing. This presents many difficulties in trying to observe the detailed plume dynamics in nature by using traditional hydrographic survey methods. Careful use of surface drifters and airborne salinity mapping [Miller et al., 1998] are two potentially useful ways to resolve the short-time variability of river plumes. 


\section{Appendix: The unsteady Ekman problem}

This appendix contains an outline of the algebraic details for the decay time scale of inertial oscillations for the unsteady Ekman response problem.

In order to determine the approximate decay time scale associated with the Ekman response, the Ekman problem is solved for a slab of fluid of finite vertical extent on which a stress is suddently introduced at $t=0$ at the fluid surface $(z=0)$. The basic idea is that the fluid is stratified so that the influence of the wind is confined to a depth $z=-h$ and $h$ is much smaller than the neutral Ekman depth for a infinite domain, unstratified fluid.

The unsteady 1-D Ekman problem is governed by the following momentum equations

$$
\begin{aligned}
& \frac{\partial u}{\partial t}-f v=K_{M} \frac{\partial^{2} u}{\partial z^{2}} \\
& \frac{\partial v}{\partial t}+f u=K_{M} \frac{\partial^{2} v}{\partial z^{2}}
\end{aligned}
$$

where $u$ and $v$ are the horizontal components of velocity, $z$ is the vertical dimension, $K_{M}$ is the eddy diffusivity of momentum, and $f$ is the Coriolis parameter. 
The boundary and initial conditions of the problem are

$$
\begin{array}{r}
u(z, 0)=v(z, 0)=0 \\
\frac{\partial u(0, t)}{\partial z}=0 \\
\frac{\partial v(0, t)}{\partial z}=\frac{u_{*}{ }^{2}}{K_{M}} \\
\frac{\partial u(-h, t)}{\partial z}=\frac{\partial v(-h, t)}{\partial z}=0
\end{array}
$$

where $z=-h$ is the base of the slab of fluid, $z=0$ is the surface of the fluid, and $u_{*}$ is the shear velocity associated with the wind stress $\tau$

$$
u_{*}^{2}=\frac{\tau}{\rho}
$$

where $\rho$ is the density of the water.

The solution may be obtained by writing the velocities in the complex form, $U=u+i v$. This yields a second order partial differential equation that can be divided into an unsteady and steady problem. The solution for the complex velocity is

$$
\begin{aligned}
& U=\frac{u_{*}^{2} \delta}{K_{M}}\left\{(1+i) \frac{\cosh \left[(1+i) \frac{z+h}{\delta}\right]}{\sinh \left[(1+i) \frac{h}{\delta}\right]}\right. \\
& -2 \sqrt{2} \sum_{n=0}^{\infty}\left(\int_{0}^{\left(\frac{h^{2} f}{K_{M}}\right)^{1 / 2}} U_{s}(z) \cos \left[n \pi \frac{z}{h}\right] d\left(\frac{z}{h}\right)\right) \times \\
& \left.\exp \left(-(n \pi)^{2} \frac{K_{M}}{h^{2}} t\right)[\cos (f t)-i \sin (f t)]\right\}
\end{aligned}
$$

where $\delta=\sqrt{K_{M} / 2 f}$ is the neutral Ekman scale for an infinite domain, unbounded Ekman problem, it has been assumed that $\sqrt{K_{M} / 2 f} \ll h$, and 


$$
U_{s}(z)=\left(\frac{1+i}{\sqrt{2}}\right) \frac{\cosh \left[(1+i) \frac{z+h}{\delta}\right]}{\sinh \left[(1+i) \frac{h}{\delta}\right]}
$$

The transient part of the solution given by (A.3) is damped inertial oscillations with a decay time scale of $h^{2} / K_{M}$. Assuming the eddy diffusivity of momentum is proportional to $u_{*} h$ and $h \propto\left(\frac{\tau}{\rho}\right)^{\frac{2}{3}}$ (from equation (4.5)), and recalling $u_{*}^{2}=\frac{\tau}{\rho}$, it follows that the time scale of decay for the inertial oscillations is

$$
T_{\text {inertial }}=\left(\frac{4 R i_{c} u_{*}}{g^{\prime} f^{2}}\right)^{1 / 3}
$$

For a moderate amplitude wind event $\left(u_{*}=10^{-2} \mathrm{~m} / \mathrm{s}\right), g^{\prime}=10^{-2} \mathrm{~m} / \mathrm{s}^{2}$, and $R i_{c}=1$, $T_{\text {inertial }} \approx 12$ hours. For stronger winds stresses, the time scale is longer. 


\section{Bibliography}

Allen, J. S., P. A. Newberger and J. Federiuk, Upwelling circulation on the Oregon continental shelf, Journal of Physical Oceanography, 25, 1843-1866, 1995.

Atkinson, J. F., Detachment of buoyant surface jets discharged on a slope, Journal of Hydraulic Engineering, 119, 878-894, 1993.

Beardsley, R. C. and W. C. Boicourt, On estuarine and continental-shelf circulation in the Middle Atlantic Bight, in Evolution of Physical Oceanography, edited by B. A. Warren and C. Wunsch, pp. 198-233, MIT Press, 1981.

Beardsley, R. C., J. Hart, The dynamics of oceanic fronts. Part II: shelf water structure due to freshwater discharge, Journal of Physical Oceanography, 11, 1215-1223, 1981.

Beardsley, R. C., R. Limeburner and L. Rosenfield, CODE-2 moored array and largescale data report, Woods Hole Oceanographic Institution, WHOI 85-35, 234 pp, 1985.

Blanton, J., F. Werner, C. Kim, L. Atkinson, T. Lee and D. Savidge, Transport and fate of low-density water in a coastal frontal zone, Continental Shelf Research, 14, 401-427, 1994.

Blanton, J. O. and L. P. Atkinson, Transport and fate of river discharge on the continental shelf of the southeastern united states, Journal of Geophysical Research, 88, 4730-4738, 1983. 
Blumberg, A. F. and G. L. Mellor, A description of a three-dimensional coastal ocean circulation model, in Three-dimensional coastal ocean models, edited by N. Heaps, pp. 1-16, American Geophysical Union, 1987.

Boicourt, W. C., The circulation of water on the continental shelf from Chesapeake Bay to Cape Hatteras, The Johns Hopkins University, Baltimore, MD, PhD Thesis, 1973.

Boicourt, W. C., Circulations in the Chesapeake Bay entrance region: estuary-shelf interaction, in Chesapeake Bay plume study, Superflux, pp. 61-78, NASA CP-2188, 1981.

Brink, K. H., Topographic drag due to barotropic flow over the continental shelf and slope, Journal of Physical Oceanography, 16, 2152-2158, 1986.

Brink, K. H., D. Halpern and R. L. Smith, Circulation in the Peruvian upwelling system near 15 degrees South, Journal of Geophysical Research, 85, 40364048, 1980.

Brown, W. S. and J. D. Irish, The annual evolution of geostrophic flow in the Gulf of Maine: 1986-1987, Journal of Physical Oceanography, 22, 445-473, 1992.

Chao, S. -Y., Wind-driven motion near inner shelf fronts, Journal of Geophysical Research, 92, 3849-3860, 1987.

Chao, S. -Y., River-forced estuarine plumes, Journal of Physical Oceanography, 18, 72-88, 1988a.

Chao, S. -Y., Wind-driven motion of estuarine plumes, Journal of Physical Oceanography, 18, 1144-1166, 1988b.

Chao, S. Y., Tidal modulation of estuarine plumes, Journal of Physical Oceanography, 20, 1115-1123, 1990.

Chao, S. - Y., Hyperpycnal and buoyant plumes from a sediment-laden river, Journal of Geophysical Research, 103, 3067-3081, 1998. 
Chao, S. -Y. and W. C. Boicourt, Onset of estuarine plumes, Journal of Physical Oceanography, 16, 2137-2149, 1986.

Chao, S. -Y. and T. W. Kao, Frontal instabilities of baroclinic ocean currents with applications to the Gulf Stream, Journal of Physical Oceanography, 17, 792807, 1987.

Chapman, D. C. and S. J. Lentz, Trapping of a coastal density front by the bottom boundary layer, Journal of Physical Oceanography, 24, 1464-1479, 1994.

Chapman, D. C. and S. J. Lentz, Adjustment of stratified flow over a sloping bottom, Journal of Physical Oceanography, 27, 340-356, 1997.

Craig, P. D., Velocity profiles and surface roughness under breaking waves, Journal of Geophysical Research, 101, 1265-1277, 1996.

Craig, P. D. and M. L. Banner, Modeling wave-enhanced turbulence in the ocean surface layer, Journal of Physical Oceanography, 24, 2546-2559, 1994.

Csanady, G. T., Intermittent full upwelling in Lake Ontario, Journal of Geophysical Research, 82, 397-419, 1977.

Csanady, G. T., Wind effects on surface to bottom fronts, Journal of Geophysical Research, 83, 4633-4640, 1978.

De Ruiter, W. P. M., A. W. Visser and W. G. Bos, Rhine outflow: a prototypical pulsed discharge plume in a high energy shallow sea, Journal of Marine Systems, 12, 263-276, 1997.

Eriksen, C. C., Measurements and models of fine structure, internal gravity waves, and wave breaking in the deep ocean, Journal of Geophysical Research, 83, 2989-3009, 1978.

Federiuk, J. and J. S. Allen, Model studies of near-inertial waves in flow over the oregon continental shelf, Journal of Physical Oceanography, 26, 2053-2075, 1996. 
Fernando, H. J. S., Turbulent mixing in stratified fluids, Annual Review of Fluid Mechanics, 23, 455-493, 1991.

Fluery, M., M. Mory, E. J. Hopfinger and D. Auchere, Effects of rotation on turbulent mixing across a density interface, Journal of Fluid Mechanics, 223, 165-191, 1991.

Fong, D. A., W. R. Geyer and R. P. Signell, The wind-forced response of a buoyant coastal current: observations of the western Gulf of Maine plume, Journal of Marine Systems, 12, 69-81, 1997.

Franks, P. J. S. and D. M. Anderson, Alongshore transport of a toxic phytoplankton bloom in a buoyancy current: Alexandrium tamerense in the Gulf of Maine, Marine Biology, 112, 153-164, 1992a.

Franks, P. J. S. and D. M. Anderson, Toxic phytoplankton blooms in the Southwestern Gulf of Maine, Marine Biology, 112, 165-174, 1992b.

Garvine, R. W., Physical features of the Conneticut River outflow during high discharge, Journal of Geophysical Research, 79, 831-846, 1974.

Garvine, R. W., Frontal jump conditions from models of shallow buoyant surface layer hydrodynamics, Tellus, 33, 301-312, 1981.

Garvine, R. W., Radial spreading of buoyant surface plumes in coastal waters, Journal of Geophysical Research, 89, 1989-1996, 1984.

Garvine, R. W., Estuarine plumes and fronts in shelf waters: a layer model, Journal of Physical Oceanography, 17, 1877-1896, 1987.

Garvine, R. W., A dynamical system of classifying buoyant coastal discharges, Continental Shelf Research, 15, 1585-1596, 1995.

Garvine, R. W., Bouyant discharge on the inner continental shelf: a frontal model, Journal of Marine Research, 54, 1-33, 1996. 
Garvine, R. W. and J. D. Monk, Frontal structure of a river plume, Journal of Geophysical Research, 79, 2251-2259, 1974.

Geyer, W. R., Tide-induced mixing in the Amazon frontal zone, Journal of Geophysical Research, 100, 2341-2353, 1995.

Geyer, W. R., R. P. Signell, D. A. Fong, J. Wang, D. M. Anderson and B. P. Keafer, The Kennebec River plume and the coastal current in the western Gulf of Maine, Continental Shelf Research, submitted, 1998.

Glenberg, A. M., Learning from data: an introduction to statistical reasoning, Harcourt Brace Jovanovich, Publishers, 535 pp., 1988.

Griffiths, R. W. and E. J. Hopfinger, Gravity currents moving along a lateral boundary in a rotating fluid, Journal of Fluid Mechanics, 134, 357-399, 1983.

Haidvogel, D. B. and K. H. Brink, Mean currents driven by topographic drag over the continental shelf and slope, Journal of Physical Oceanography, 16, 2159$2171,1986$.

Hansen, D. V. and M. Rattray, Gravitational circulation in straits and estuaries, Journal of Marine Research, 23, 104-122, 1965.

Hickey, B. M., L. J. Pietrafesa, D. A. Jay and W. C. Boicourt, The Columbia River plume study: subtidal variability in the velocity and salinity fields, Journal of Geophysical Research, in press, 1998.

Holloway, G., K. Brink and D. Haidvogel, Topograhic stress in coastal circulation dynamics, in Poleward Flows Along Eastern Ocean Boundaries, edited by S. J. Neshyba, C. N. K. Mooers, R. L. Smith and R. T. Barber, pp. 315-330, Springer-Verlag, 1989.

Hurst, J. W. and C. M. Yentsch, Patterns of intoxication of shellfish in the Gulf of Maine coastal waters, Canadian J. Fish Aquatic Sci., 38, 152-156, 1981. 
Kantha, L. H., O. M. Phillips and R. S. Azad, On turbulent entrainment at a stable density interface, Journal of Fluid Mechanics, 79, 753-768, 1977.

Kato, H. and O. M. Phillips, On the penetration of a turbulent layer into stratified fluid, Journal of Fluid Mechanics, 37, 643-655, 1969.

Kourafalou, V. H., T. N. Lee, L-Y. Oey and J. D. Wang, The fate of river discharge on the continental shelf 2 . transport of coastal low-salinity waters under realistic wind and tidal forcing., Journal of Geophysical Research, 101, 3435-3455, 1996 a.

Kourafalou, V. H., L-Y. Oey, J. D. Wang and T. N. Lee, The fate of river discharge on the continental shelf 1 . modeling the river plume and inner shelf coastal current, Journal of Geophysical Research , 101, 3415-3434, 1996b.

Kranenburg, C., Wind-induced entrainment in a stably stratified fluid, Journal of Fluid Mechanics, 145, 253-273, 1984.

Kundu, P. K., A numerical investigation of mixed layer dynamics, Journal of Geophysical Research, 86, 1979-1988, 1981.

Kundu, P. K. and J. S. Allen, Some three-dimensional characteristics of low-frequency current fluctuations near the Oregon coast, Journal of Physical Oceanography, 6, 181-199, 1976 .

Large, W. G. and S. Pond, Open ocean momentum flux measurements in moderate to strong winds, Journal of Physical Oceanography, 11, 324-336, 1981.

Lentz, S. J., The surface boundary layer in coastal upwelling regions, Journal of Physical Oceanography, 22, 1517-1539, 1992.

Lentz, S. J., The Amazon River Plume during AMASSEDS: Subtidal current variability and the importance of wind forcing, Journal of Geophysical Research, 100, 2377-2390, 1995. 
Lentz, S. J. and R. Limeburner, The Amazon River Plume during AMASSEDS: spatial characteristics and salinity variability, Journal of Geophysical Research, 100, 2355-2376, 1995.

Loder, J. W., B. Petrie and G. Gawarkiewicz, The coastal ocean off northeastern North America: a large-scale view, in The Sea, edited by K. Brink and A. Robinson, 11, in press, 1998.

Masse, A. K. and C. R. Murthy, Observations of the Niagara River thermal plume, Journal of Geophysical Research, 95, 851-875, 1990.

Masse, A. K. and C. R. Murthy, Analysis of the Niagara River plume dynamics, Journal of Geophysical Research, 97, 2403-2420, 1992.

McCreary, J. P., S. Zhang and S. R. Shetye, Coastal circulations driven by river outflow in a variable-density 1-1/2-layer model, Journal of Geophysical Research, 102, 15535-15554, 1997.

Mellor, G. L. and T. Yamada, Development of a turbulence closure model for geophysical fluid problems, Review of Geophysical Space Physics, 20, 851-875, 1982.

Miles, J. W., Richardson number criterion for the stability of stratified flow, Physics of Fluids, 29, 3470-3471, 1986.

Miller, J. L., M. A. Goodberlet and J. B. Zaitzeff, Airborne salinity mapper makes debut in coastal zone, EOS, 79(14), 173-177, 1998.

Münchow, A. and R. W. Garvine, Buoyancy and wind forcing of a coastal current, Journal of Marine Research, 51, 293-322, 1993a.

Münchow, A. and R. W. Garvine, Dynamical properties of a buoyancy-driven coastal current, Journal of Geophysical Research, 98, 20063-20077, $1993 \mathrm{~b}$. 
Nittrouer, C. A., D. J. DeMaster, A. G. Figueiredo and J. M. Rine, AMASSEDS: An interdisciplinary investigation of a complex coastal environment, Oceanography, 4, 3-7, 1991.

Nof, D., Eddy-wall interactions, Journal of Marine Research, 46, 527-555, 1988.

Nunez Vaz, R. A. and J. H. Simpson, Turbulence closure modeling of estuarine stratification, Journal of Geophysical Research, 99, 16143-16160, 1994.

O'Donnell, J., The formation and fate of a river plume: a numerical model, Journal of Physical Oceanography, 20, 551-569, 1990.

Oey, L. -Y. and G. L. Mellor, Subtidal variability of estuarine outflow, plume, and coastal current: a model study, Journal of Physical Oceanography, 23, 164$171,1993$.

Orlanski, I., A simple boundary condition for unbounded hyperbolic flows, Journal of Computational Physics, 21, 251-269, 1976.

Pacanowski, R. C. and S. C. H. Philander, Parameterization of vertical mixing in numerical models of tropical seas, Journal of Physical Oceanography, 11, 1443-1451, 1981.

Pollard, R. T., P. B. Rhines and R. O. R. Y. Thompson, The deepening of the wind-mixed layer, Geophysical Fluid Dynamics, 3, 381-404, 1973.

Price, J. F., On the scaling of stress-driven entrainment experiments, Journal of Fluid Mechanics, 90, 509-529, 1979.

Price, J. F., C. N. K. Mooers and J. C. V. Leer, Observation and simulation of storm-induced mixed-layer deepening, Journal of Physical Oceanography, 8 , 582-599, 1978.

Price, J. F., R. A. Weller and R. Pinkel, Diurnal cycling: observations and models of the upper ocean response to diurnal heating, cooling, and wind mixing, Journal of Geophysical Research, 91, 8411-8427, 1986. 
Shi, C. and D. Nof, The splitting of eddies along boundaries, Journal of Marine Research, 51, 771-795, 1993.

Shumway, S., S. Sherman-Caswell and J. W. Hurst, Paralytic shellfish poisoning in Maine: monitoring a monster, J. Shellfish Research, 7, 643-52, 1988.

Simpson, J. H., The shelf-sea fronts: implications of their existence and behavior, Trans. R. Soc. London, 302, 531-546, 1981.

Simpson, J. H. and D. Bowers, Models of stratification and frontal movement in shelf seas, Deep Sea Research, 28A, 727-738, 1980.

Simpson, J. H., J. Brown, J. Matthews and G. Allen, Tidal straining, density currents, and stirring in the control of estuarine stratification, Estuaries, 13, 125-132, 1990.

Smolarkiewicz, P. K. and W. W. Grabowski, the multidimensional positive definite advection transport algorithm, Journal of Computational Physics, 86, 355$375,1990$.

Souza, A. J. and J. H. Simpson, Controls on stratification in the Rhine ROFI system, Journal of Marine Systems, 12, 311-323, 1997.

Stern, M. E., J. A. Whitehead and B. L. Hau, The intrusion of a density current along the coast of a rotating fluid, Journal of Fluid Mechanics, 123, 237-265, 1982.

Tennekes, H. and J. L. Lumley, A First Course in Turbulence, MIT Press, 1972.

Thorpe, S. A., Experiments on the instability of stratified shear flows: miscible fluids, Journal of Fluid Mechanics, 46, 299-319, 1971.

Trowbridge, J. H., A simple description of the deepening and structure of a stably stratified flow driven by a surface stress, Journal of Geophysical Research, $97,15529-15543,1992$. 
Valle-Levinsion, A., J. M. Klinck and G. H. Wheless, Inflows/outflows at the transition between a coastal plain estuary and the coastal ocean, Continental Shelf Research, 16, 1819-1847, 1996.

Whitehead, J. A. and D. C. Chapman, Laboratory observations of a gravity current on a sloping bottom: the generation of shelf waves, Journal of Fluid Mechanics, 172, 373-399, 1986.

Wu, J., Wind-induced entrainment across a stable density interface, Journal of Fluid Mechanics, 86, 293-311, 1973.

Yankovsky, A. E. and D. C. Chapman, A simple theory for the fate of buoyant coastal discharges, Journal of Physical Oceanography, 27, 1386-1401, 1997.

Zhang, Q. H., G. S. Janowitz and L. J. Pietrafesa, The interaction of estuarine and shelf waters: a model and applications, Journal of Physical Oceanography, 17, 455-469, 1987. 